\title{
العنف الأسري والعدوان وتوكيد الذات لدى الأبناء
}

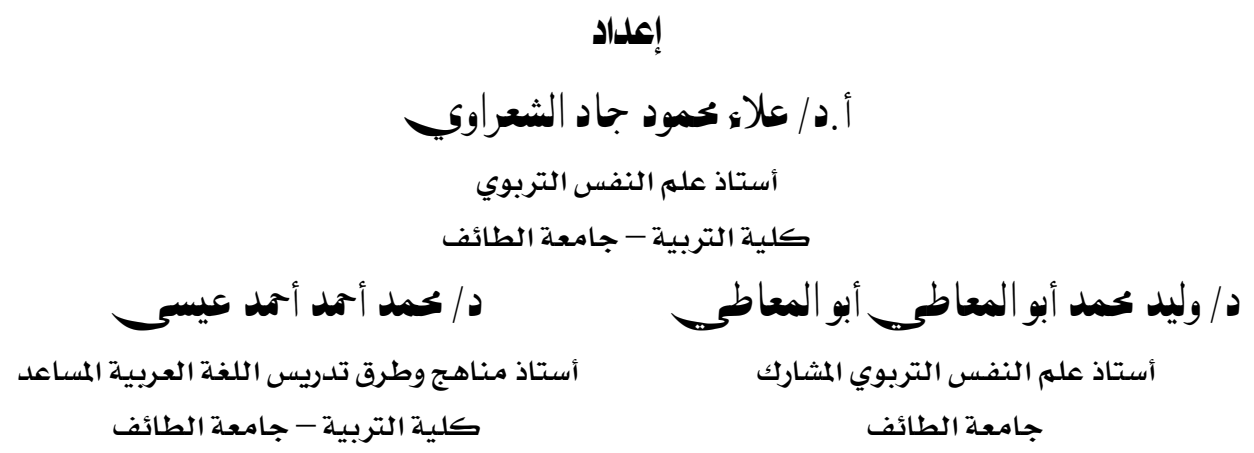

مجلة بحوث التربية النوعية ـ جامعة المنصورة

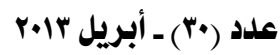




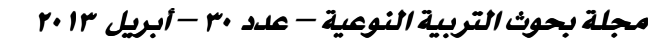

\title{
العنف الأسري والعدوان وتوكيد الذات لدى الأبناء
}

\author{
إعداد \\ أ.د/علاء محمود جاد الشعراوي* \\ د/محمد أحمد أحمد عيسهــ**

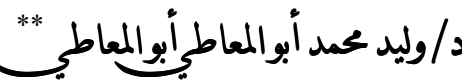

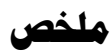

يعتبر العنف الأسري من أكثر الظواهر والقضايا الاجتماعيـة التي دعت البـاحثين لإجـراء

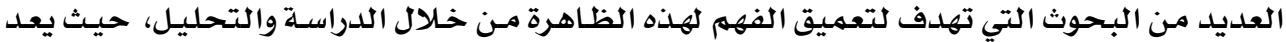

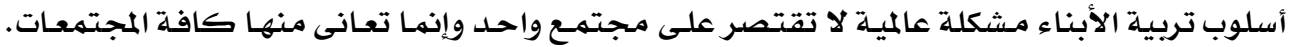

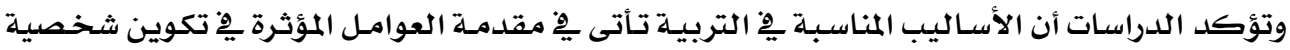

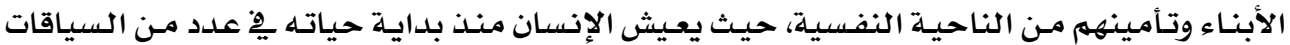

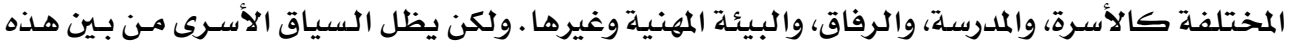
السياقات سياقا بالغ التفرد والخصوصية.

وتحاول الدراسة الحالية التحقق من تأثير ممارسـة العنف من قبل أحد الوالدين أو كليهما

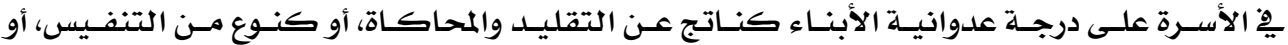

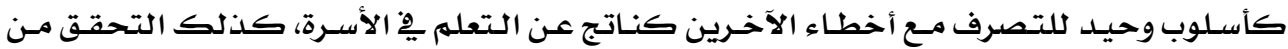

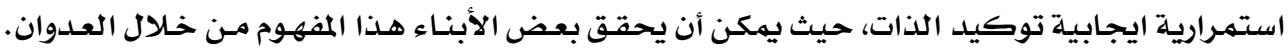

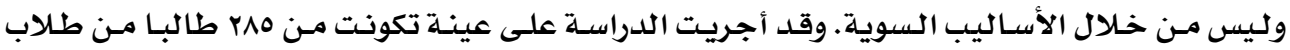

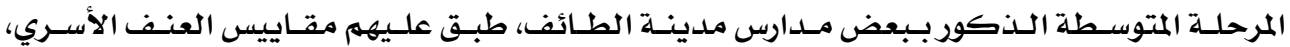

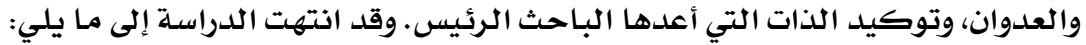

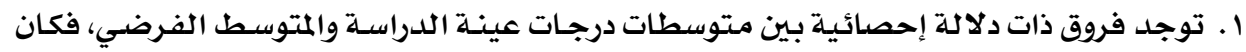

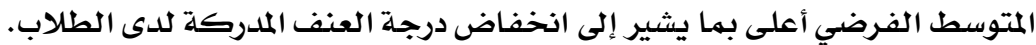
r. لا توجد علاقات دالة إحصائيا بين درجات أبعاد مقياسي العنف والعدوان. r. لا توجد علاقات دالة إحصائيا بين درجات أبعاد مقياسي العنف والعدوان. ع. لا يوجد عامل مشترك بين أبعاد مقياسي العدوان وتوكيد الذات بما يشير إلى استقلاليتهما. 
العنف الأسرييوالعدوانوتوكيد الذات للىىالأبناء

\section{Family Violence, Aggression and Self-Affirmation for Sons}

\section{Abstract:}

Family violence is one of the social phenomena and issues which receives the attention of most researchers who try to deeply analyze and understand its dimensions. This attention lies with a wider context of the global challenge of child education with all its various aspects related to- for example - family, school, peer, professional environment, etc., But the family aspect remains a very exclusivity and privacy, it is the first and most powerful influential figure in the Son personality, both in the short term or long term and may result in either normal or delinquent son.

The present study attempts to verify the impact of parents violence on the level of children aggression. It also attempts reasoning the aggressive behavior in terms of tradition, simulation, or catharsis; or just accidental mistake; or a form of self- affirmation. The sample of the study included 285 middle schoolboys with some schools a- at Taif who responded to a checklist of domestic for violence, aggression, and selfaffirmation prepared by the principal investigator.

\section{The obtained results showed that:}

1. There are significant differences between the means of scores of the study sample and those of the highest normal average, indicating low degree of violence perception among the study sample.

2. There are no statistically significant relationships between the degrees of the dimensions of violence and aggression.

3. There is no statistically significant relationships between the degrees of the dimensions of violence and aggression.

4. There is no common factor between the dimensions of aggression and self - affirmation indicating their independence. 


\section{العنف الأسري والعدوان وتوكيد الذات لدى الأبناء}

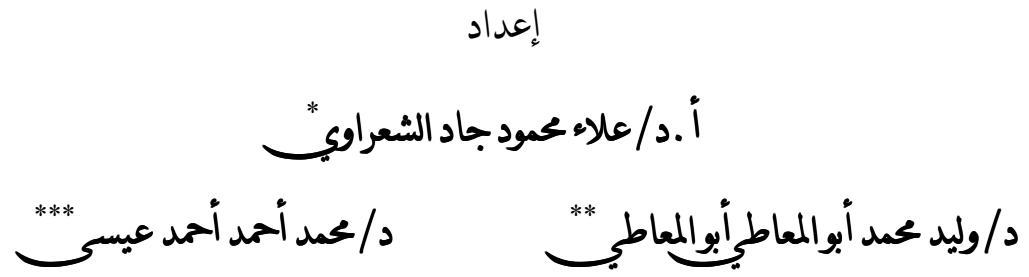

هقدمهة:

تعد الأسرة المؤسسة النفسية والاجتماعيـة الأولى للأبنـاء، ففيها تتشكل شخصياتهم، كهـا

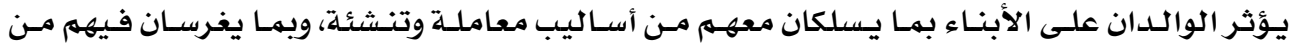

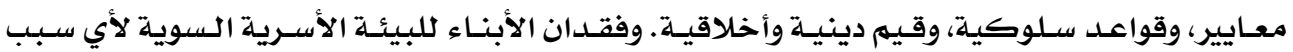

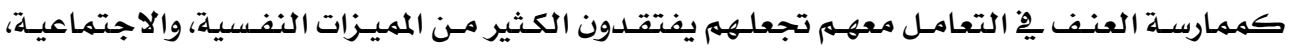

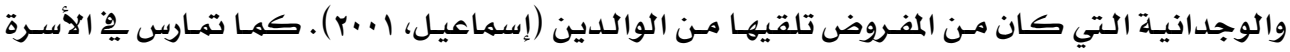

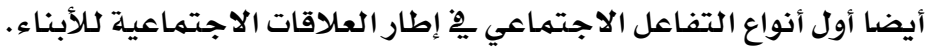

وفى هذا الصدد أكدت الدراسات أهمية الدور الوالدي يِّ تشكيل السلامـة النفسية، أو المرض

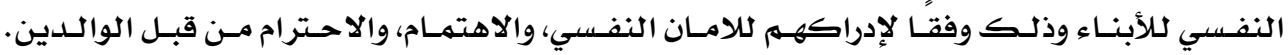

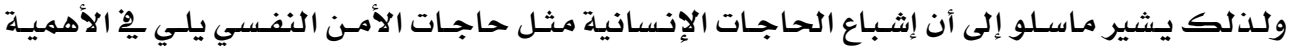

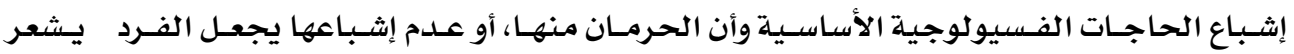
بالتهديد، والخوف، وعدم القدرة على تحقيق ذاته .

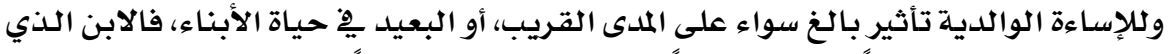

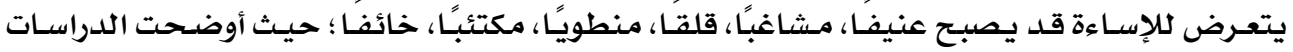

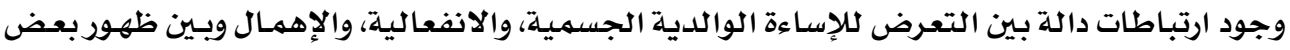

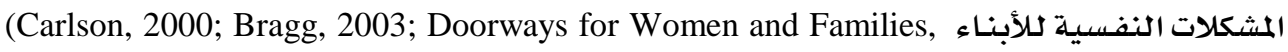
2004; Child Welfare Information Gateway, 2009).

وتعد مشكلة الإساءة الوالدية، وعلدم تلبية حاجات الأبناء الأساسية، وإهما لهم مـن المشكلات

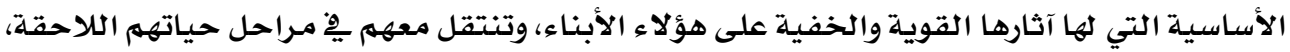

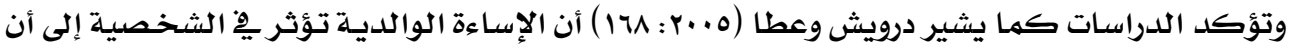

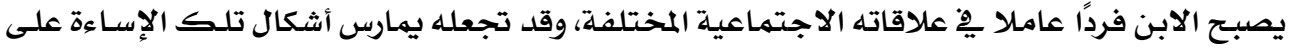

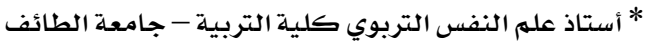

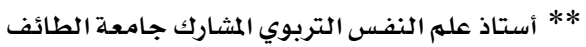

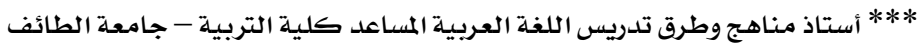


أطفالكه مستقبلا. ويشير والتون (Walton, 2005) إلى أن الخطر الأساسي على الأبناء، وخاصسة

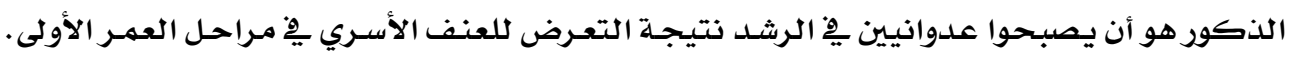

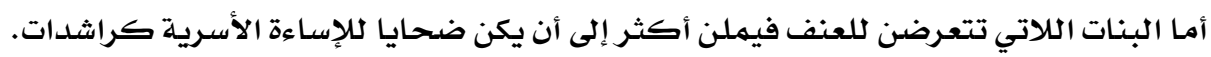

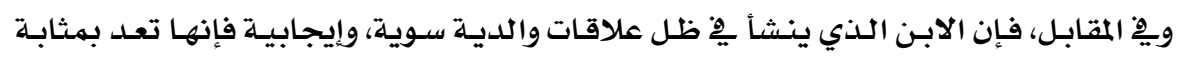

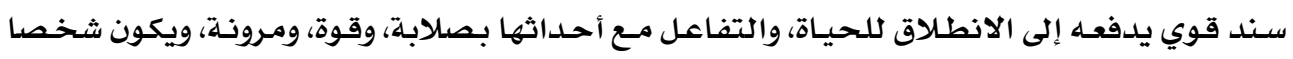

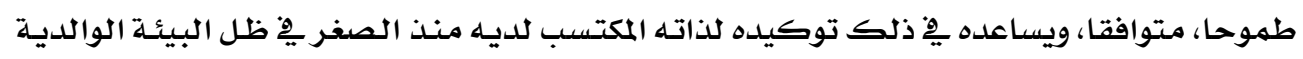

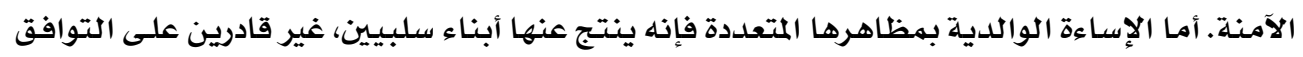

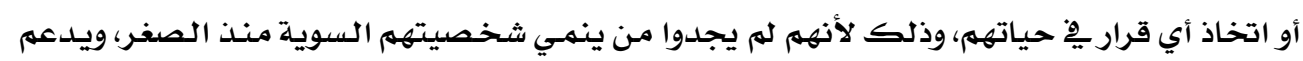

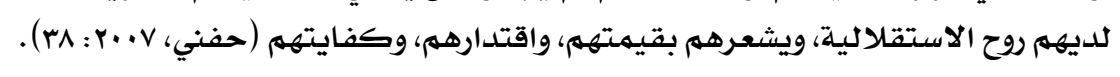

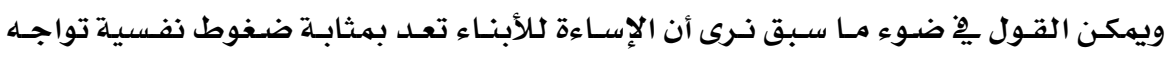

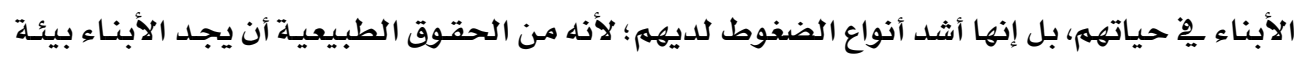

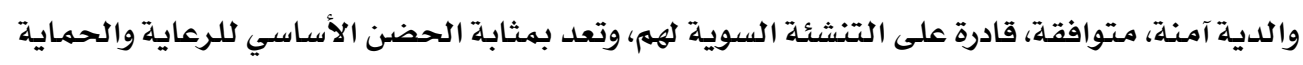

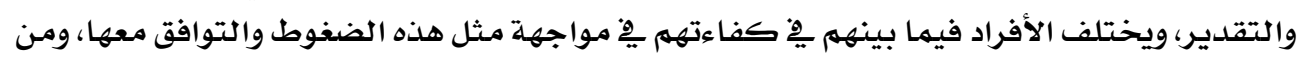

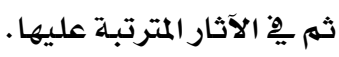

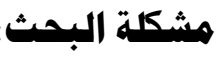

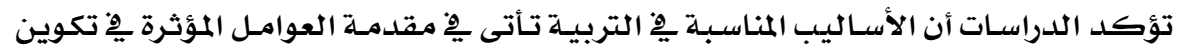

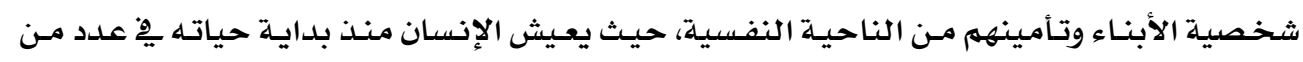

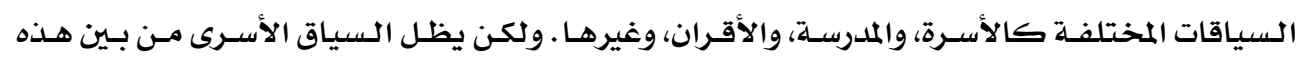

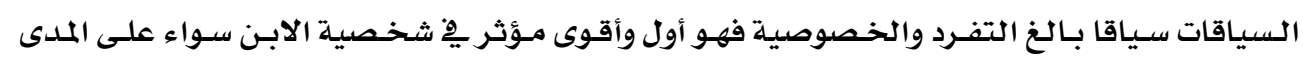

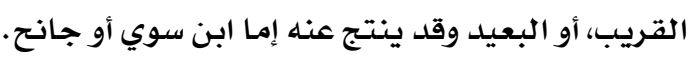

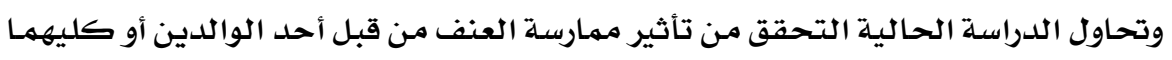

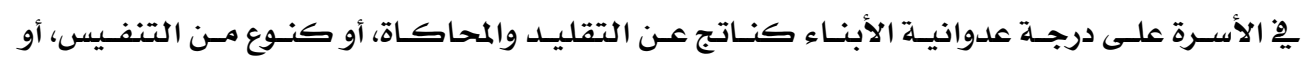

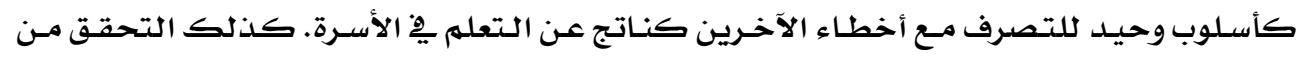

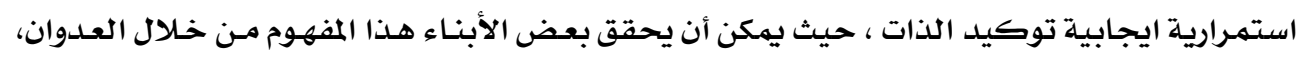

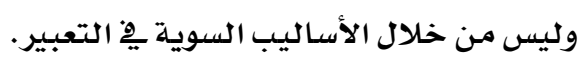

وتتلخص مشكلة الدراسة الحالية ِِّ محاولة الإجابة على التساؤلات التالية:

1. ما مستوى إدراك طلاب العينة لمستوى العنف الأسري الذي يعايشونه هِّ المنزل

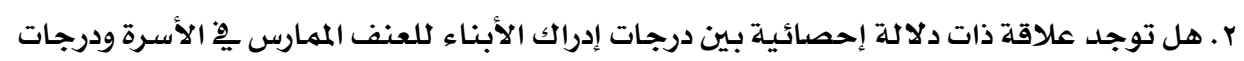

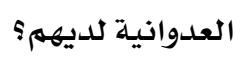

r. هل توجد علاقة ذات دلالة إحصائية بين درجات إدراك الأبناء للعنف الممارس يِّ الأسرة ودرجات

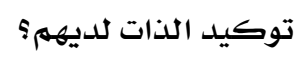

ع . هل يوجد عامل مشترك عام بين درجات الطلاب على مقياسي العدوان وتوكيد الذات؟ 


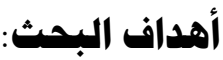 \\ يهدف البحث الحالي إلي:}

1- التعرف على مستتوى إدراك الأبناء للعنف الممارس يجّ الأسرة. r- تحلديد علاقة العنف المدرك من الأسـرة بلدرجة علدوانية الأبناء. r- تحديد علاقة العنف المدرك مـن الأسـرة بلدرجة توكيد الذات لدى الأبناء. ع- تحديد التكوين العاملي لتوكيد الذات للتحقق مـن اسـتمـرار ايجابيتـه أو تحولـه يِّ الاتجـاه

$$
\text { السلببي. }
$$

أهمهيسة البحمث:

تنقسهم أهميـة البـحث إلي:

أـ الأهمية النظرية:

ا. أهميـة الموضوع وهو العنف الأسـري لما لهذا الموضوع من آثار خطيرة على شخصيـة الأبناء.

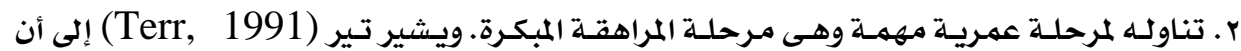
طلاب المرحلة المتوسطة من التعليهم أكثر قدرة على التعبير عن السلوكيات السلبيـة بـورة لفظية. r. فتح المجال لبـحوث أخرى تتــاول إعـداد بـرامـج لخفض المشاكل السلوكية الناتجـة عن المرور بخبر ات عنف يْ المنزل لدى الأبناء.

\section{بـ الأهمية التطبيقبة:}

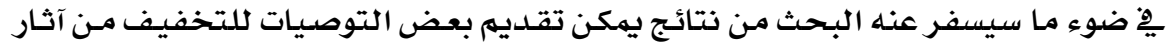

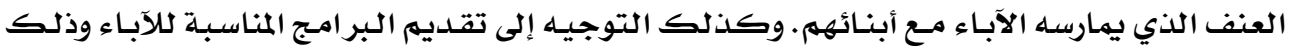

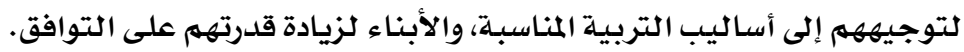

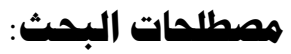

ا- العنف الأسـري: أي سـلوك أو عمـل متعمهد ومـتكرر يصدر مـن قبـل أحسد الوالدين أو كليهما

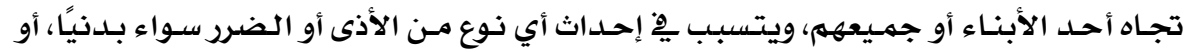
نفسيًا، أو حتى إهماله .ويتضهن الأبعاد التتادية: أ- الإسـاءة الجسميـة: كل ضرر جسـي مبـاشـر موجه نحو الأبنـاء مـن قبل أحسد الوالدين أو

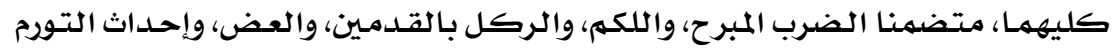
والكدمات.

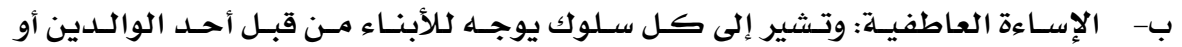

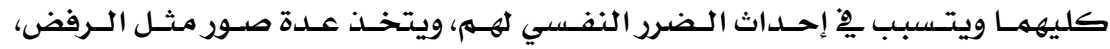

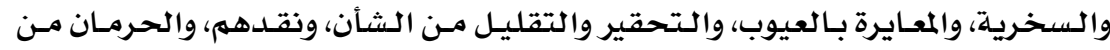
العاطفة والمودة، والتسلط الزائد، والتمييز بين الأبناء. 


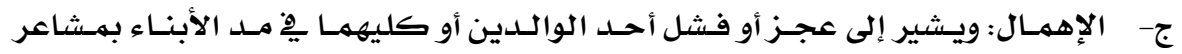

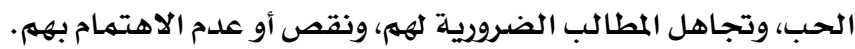

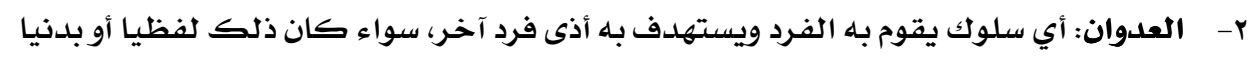

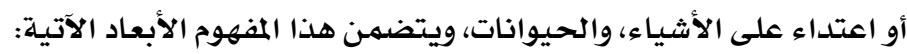

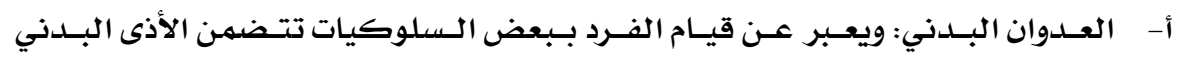

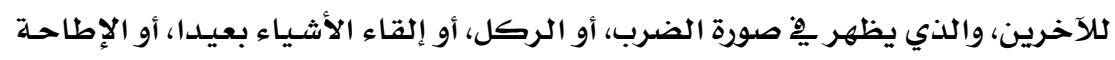
بها بهدف التدمير.

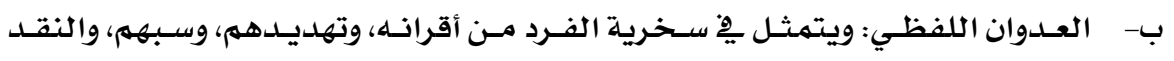
القاسي لهم، والتحقير من شأنهم.

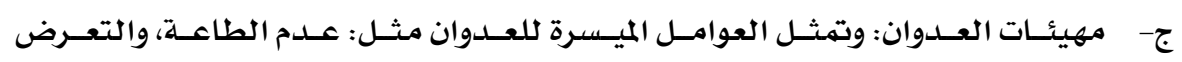

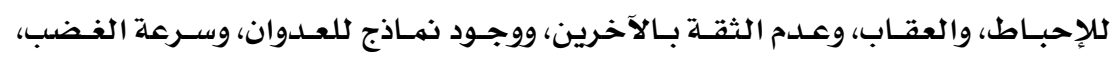

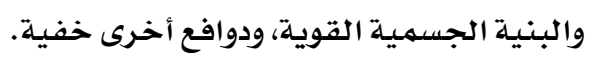

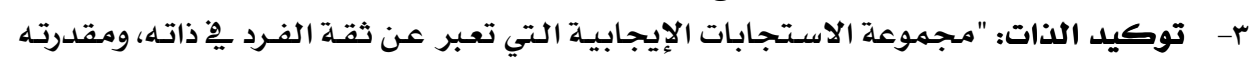

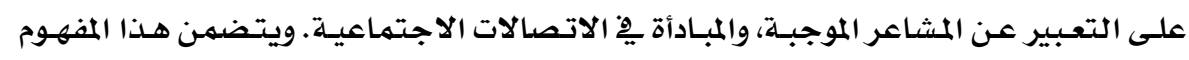

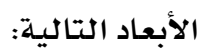

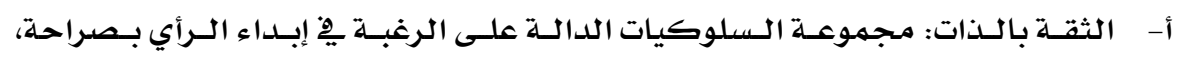

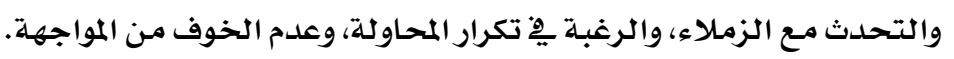

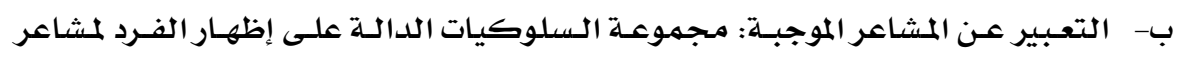

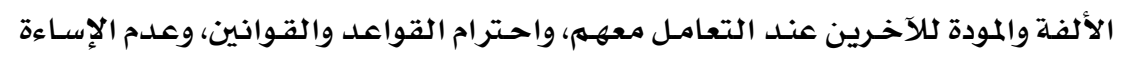
لمثاعر الآخرين، والمقدرة على الانتقال من الأدوار القيادية للأدوار المساندة.

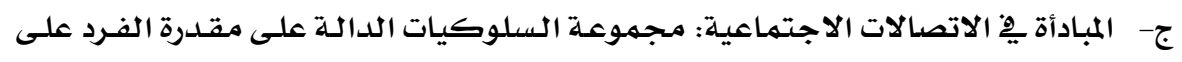

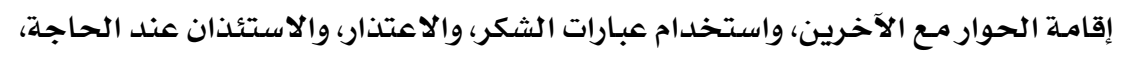
ومساعدة الآخرين. أولا: العنف الأسري الإن البني

حظي موضوع الإسـاءة الوالديـة للأبنـاء باهتهـام كبير منـذ سبعينات القـرن الماضـي لكونها

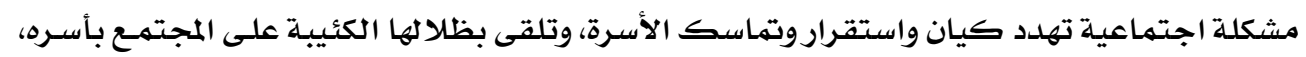

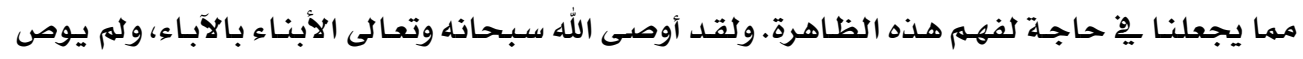

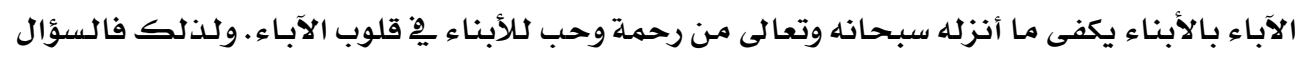

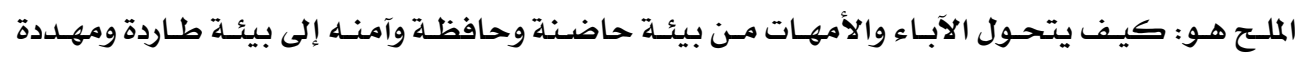

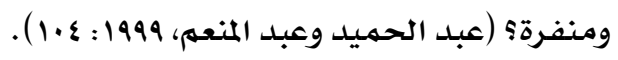




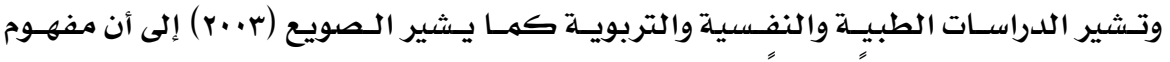

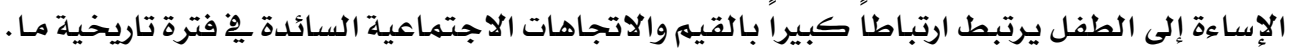

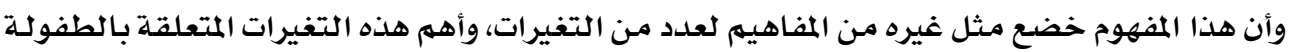

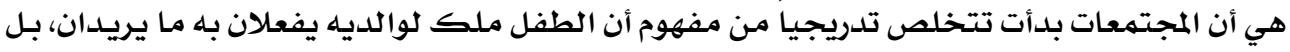

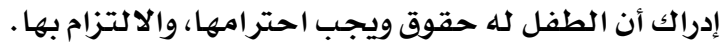

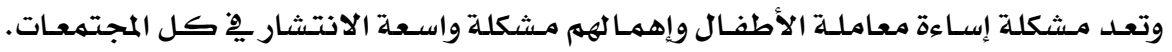

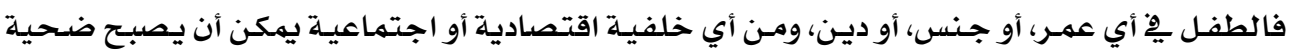

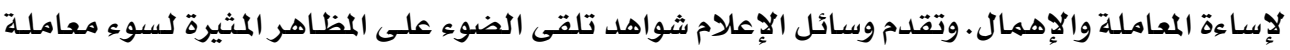

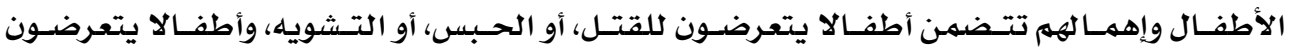

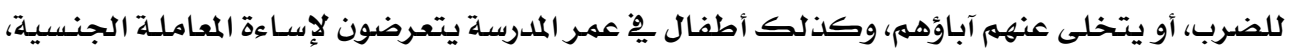

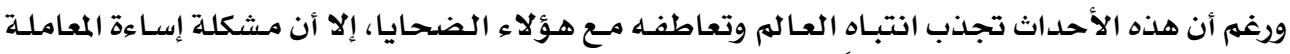

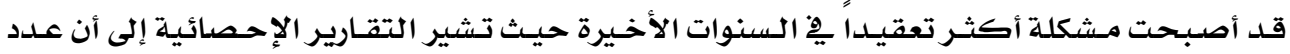

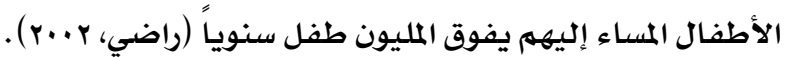

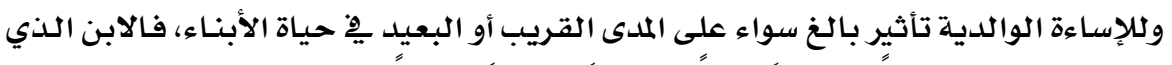

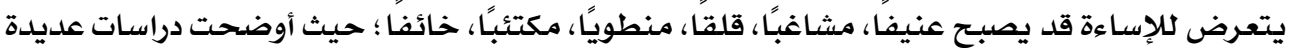

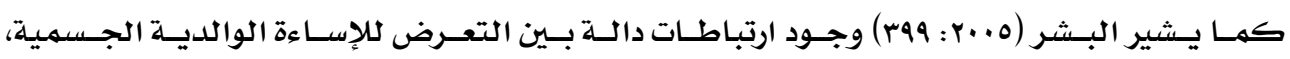
والانفعالية، وبين ظهور بعض المشكلات النفسية لكلأبناء.

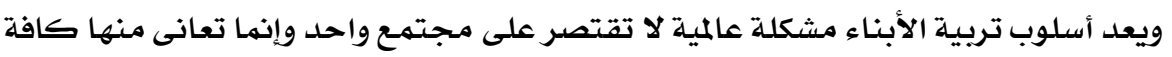

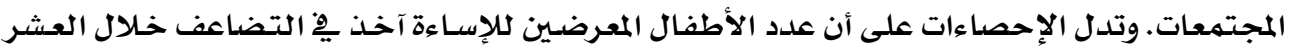

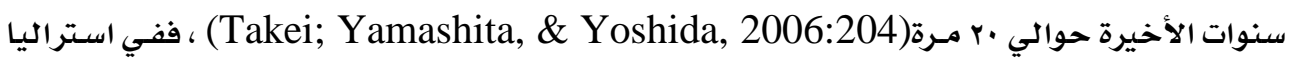

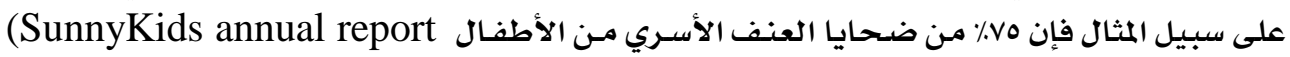
2010).

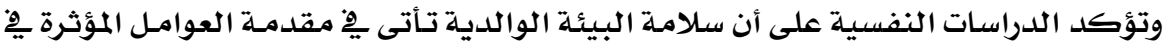

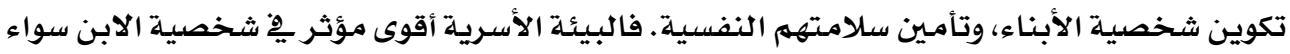

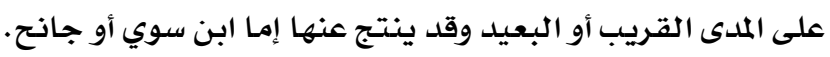

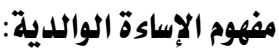

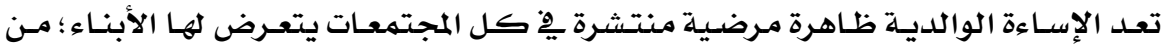

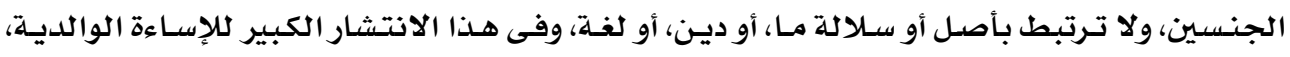

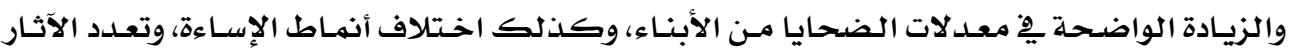

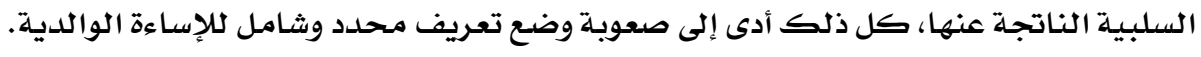

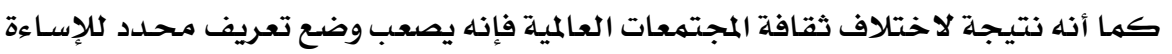

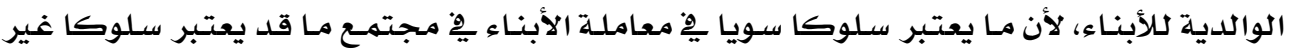




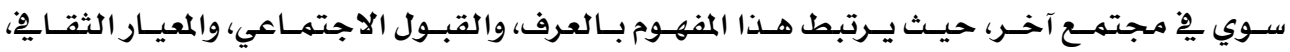

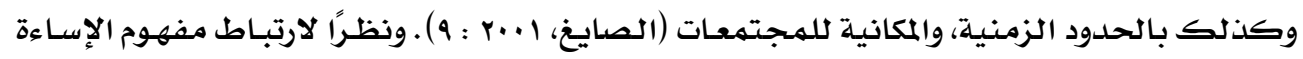

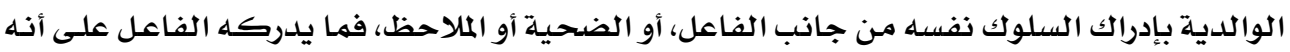

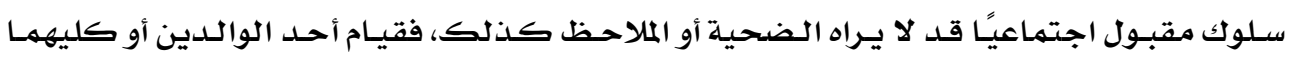

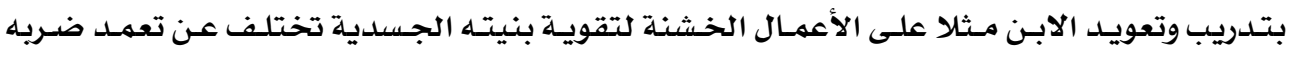

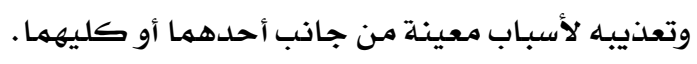

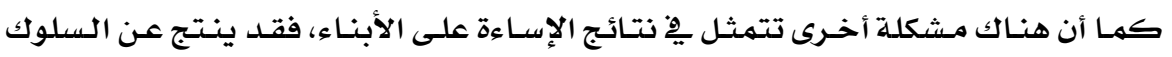

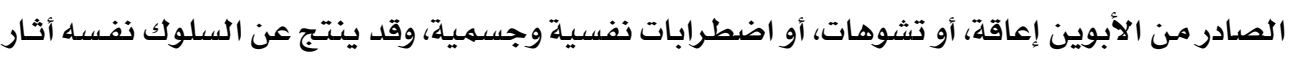

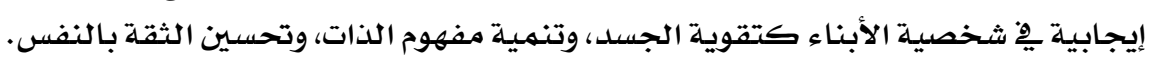

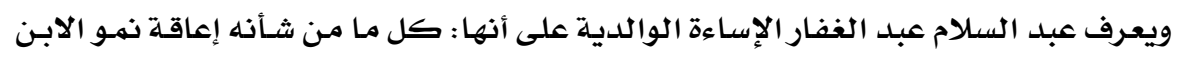

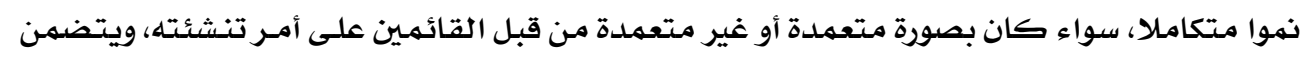

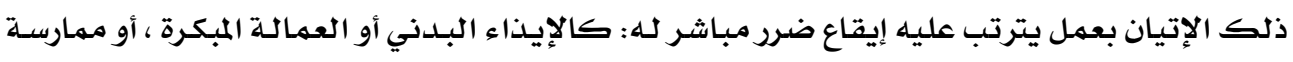

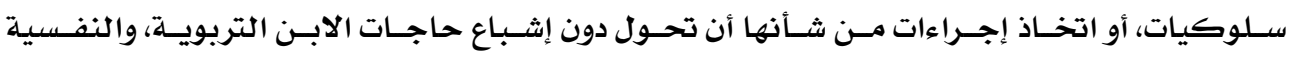

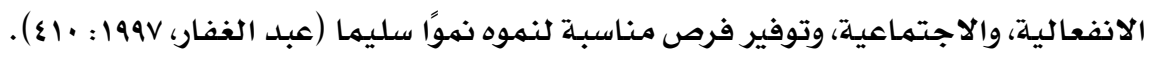

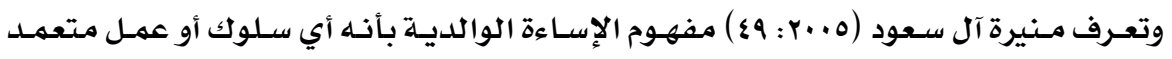

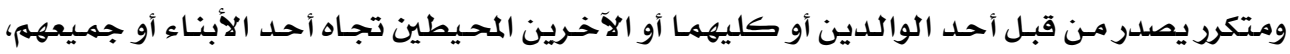

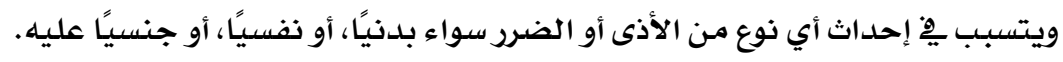

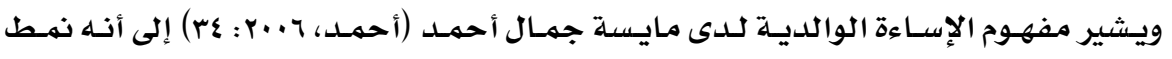

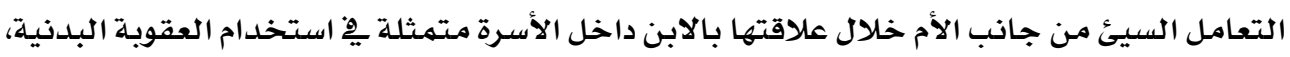

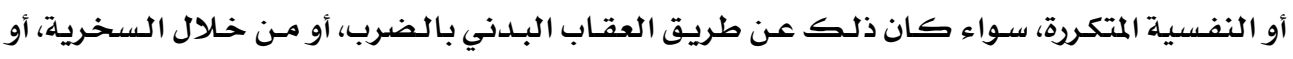

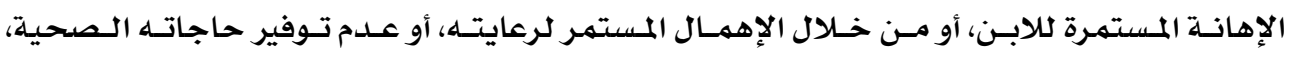

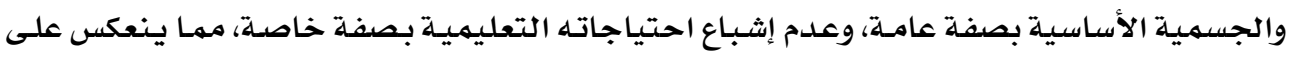

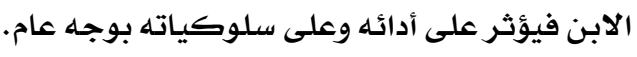

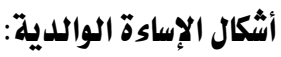

للعنـف الأسـري ِِّ اللغـة الانجليزيـة العديـد مـن المترادفـات تشمل كمها يشير مـاركوفيتز

family violence, Domestic violence, domestic (Markowitz, 2000: 297-303) abuse, spousal abuse, and intimate partner violence (IPV) سلوكية سيئة من قبل أحد الوالدين أو كليهما، ولهـا فعندما نعـرف العنف الأسـري نهتم بأشـكاله

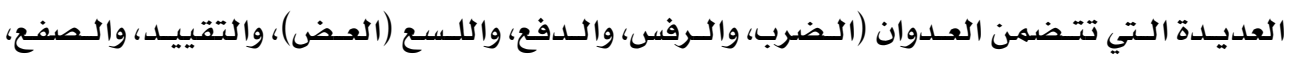

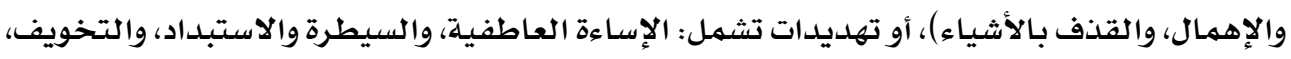

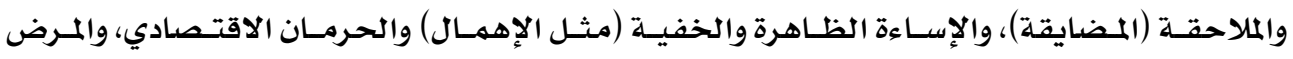


ويشير تير (Terr, 1991) إلى أن العنف المنزلسي يتضمن الإسـاءة: الجسسمية، والنفسية،

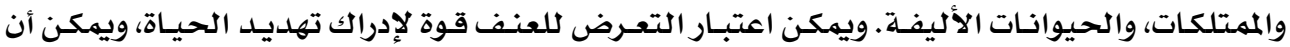

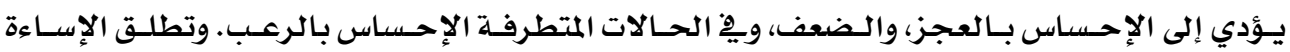

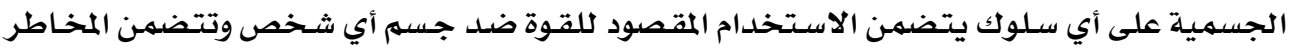

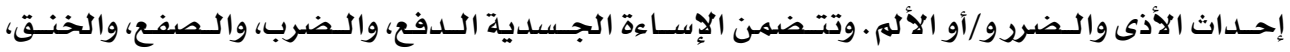

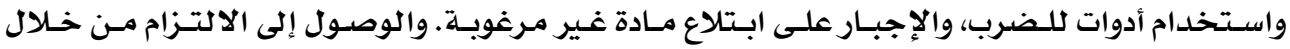

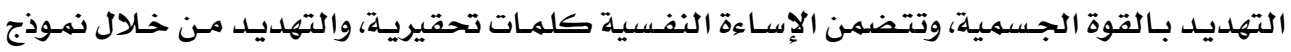
يمثل ضحية للفرد من قبل، وكذلك تتضمن العزلية، والتهديد الاقتصادي، والإساءة العاطفية.

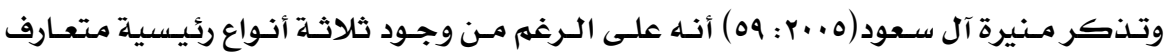

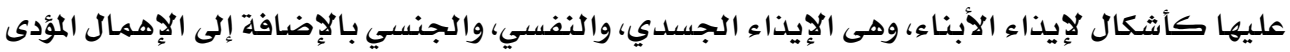

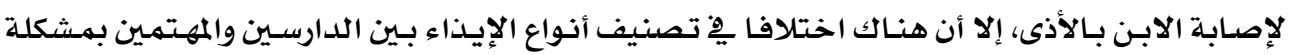

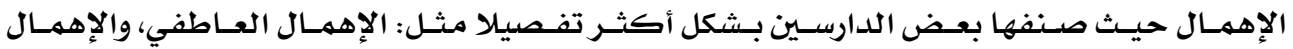

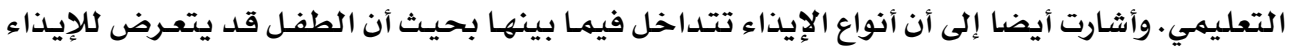

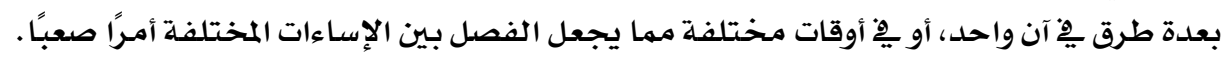

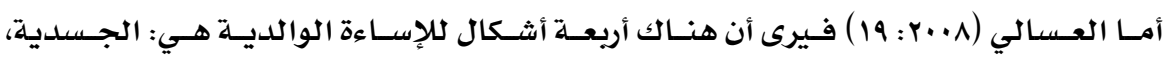

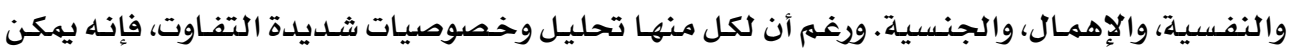

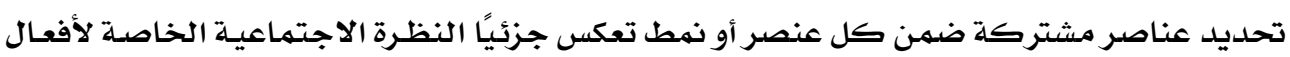

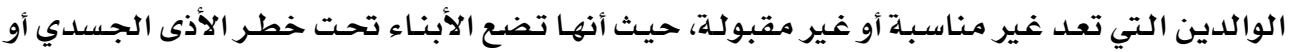
العاطفي. مما سبق يهكن تحديد مظاهر أنواع الإسـاءة المختلفـة كمـا يلسي للاستفادة منها ِِّ صياغة مفردات مقياس العنف.

Physical abuse أولا : الإساءة الجسدياتسية

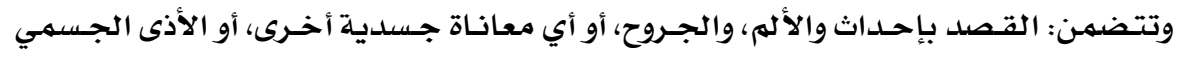

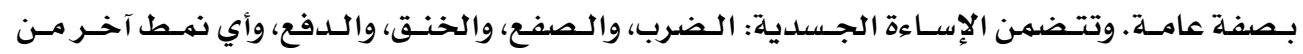

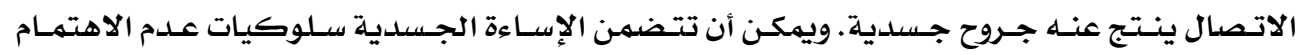

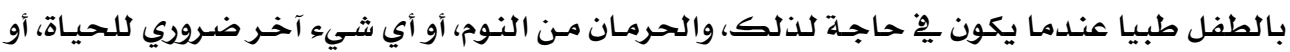

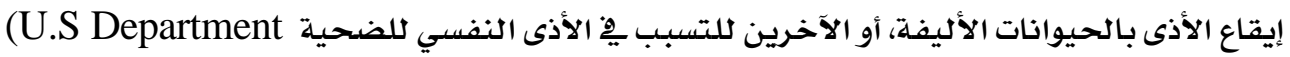
.of Justice, 2007)

بالحيوانات إساءة انفعالية وليست جسدية.

\section{ثانيا : الإساءة العاطفية Emotional abuse}

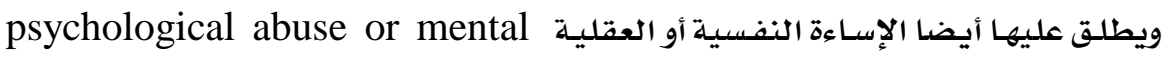

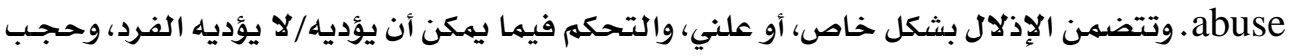


المعلومـات عنه، وتعمد فعل أشياء تجعل الابن يشعر بـالحرج، أو النقص، وعزلـه عن أصـدقائه، وابتزازه

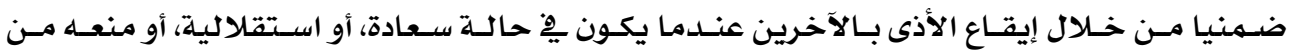
الحصول على المال، أو المصادروالحاجـات الأسـاسية الأخـرى (Follingstad \& DeHart, 2000).

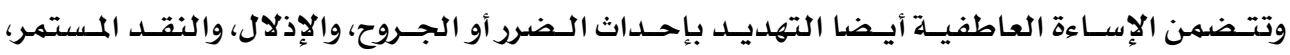

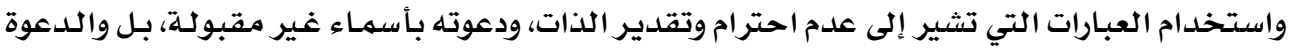

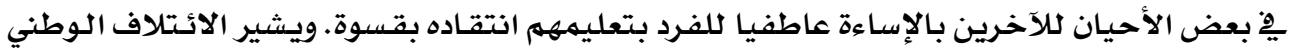

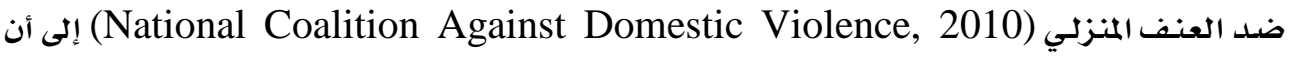

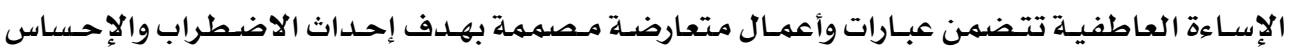

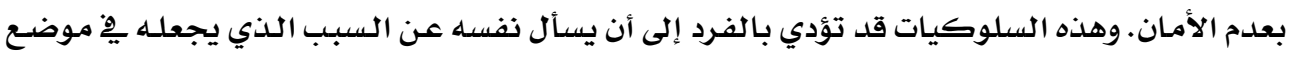
المساء إليه.

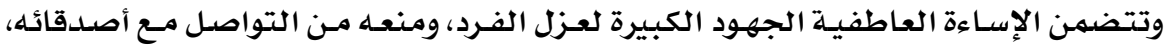

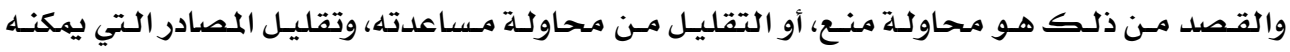

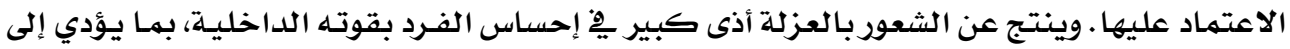

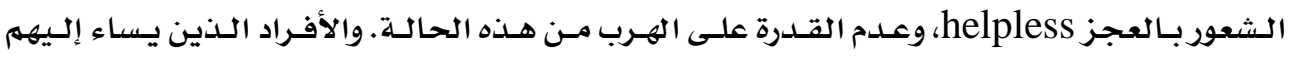

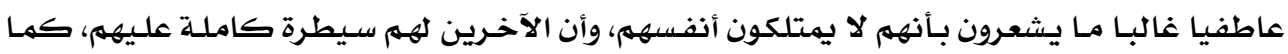

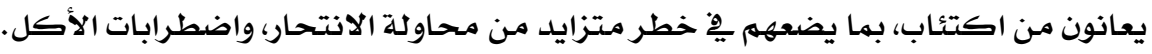

\section{ثالثا: الإهمال}

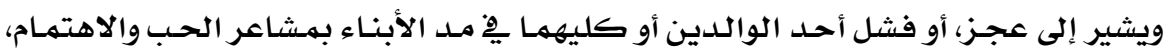

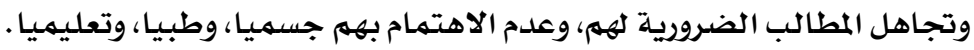

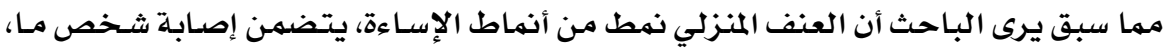

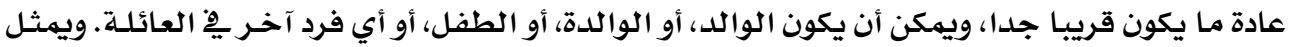

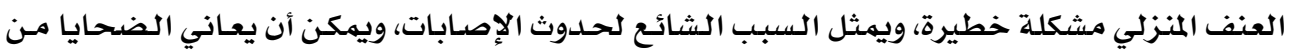

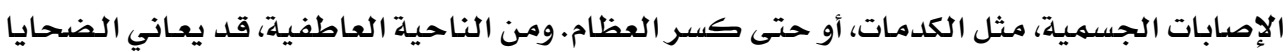

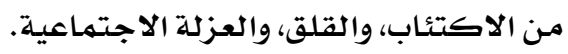
أسباب العنف الأسري:

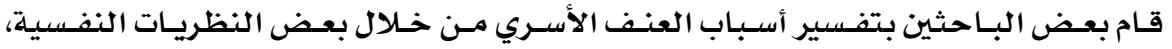

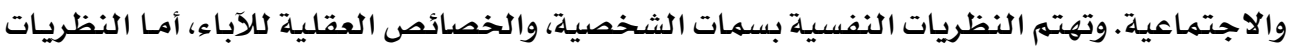

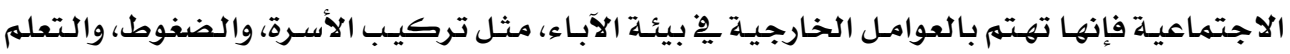

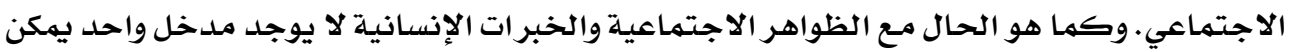

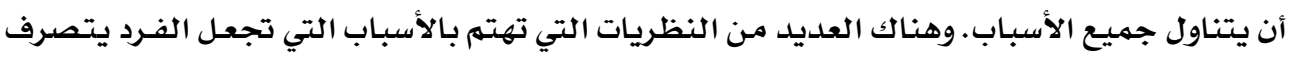
بقسوة تجاه أفراد عائلته. 
تركز النظريـات النفسية على سمات الشخصية، والخصائص العقليـة للمسيءء.وتتضمن

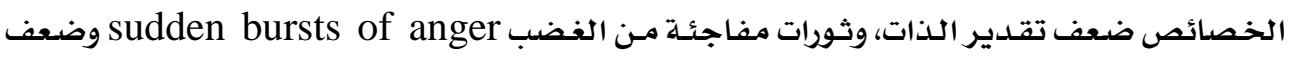

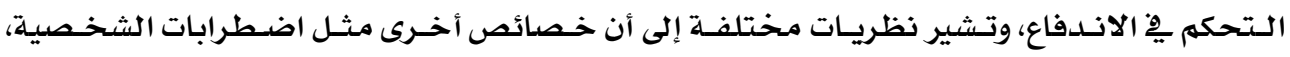

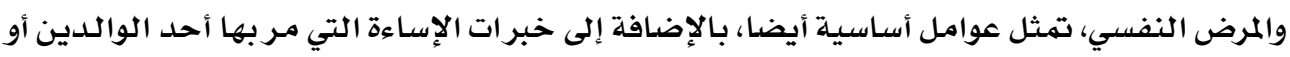

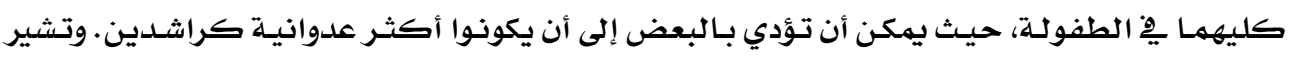
كثير من الدراسات إلى انتشار المرض النفسي بين المسيئين. Hamberger \& Hastings, 1986) 1991; Hart; Dutton \& Newloves, 1993 )

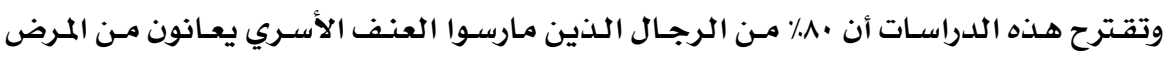

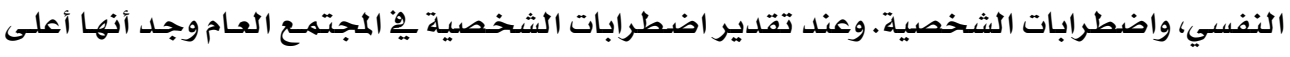

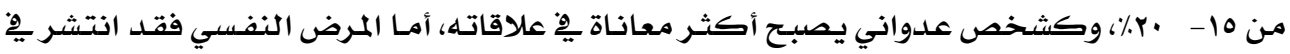

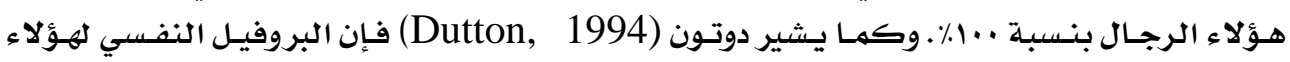

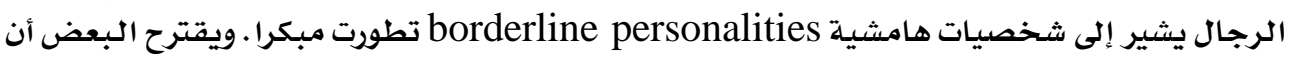

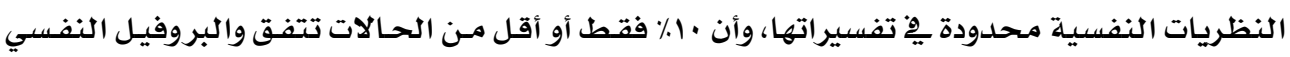

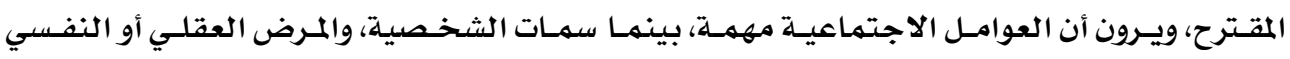
عوامل محدودة lesser factors إِّ تفسيراتها.

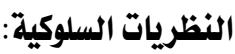

تقوم هذه النظريات على تحليل السلوك، ولتطبيق تحليل السلوك تستخدم المبادئ الأساسية

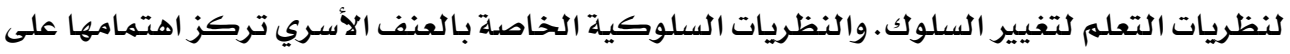

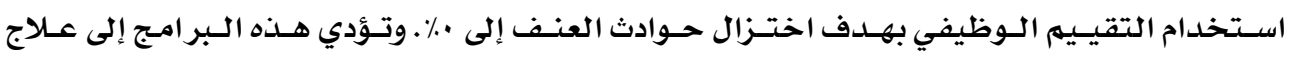

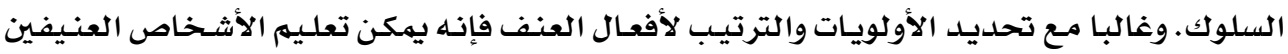

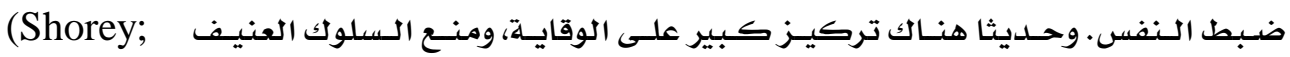
Cornelius \& Bell, 2008; Bonem; Stanely- Kime \& Corbin, 2008).

نظرية الثروة (المورد): Resource theory واقترح هذه النظرية وليام جود (Goode, 1971) وفيها يشير إلى أن النساء المعتمدات على النى

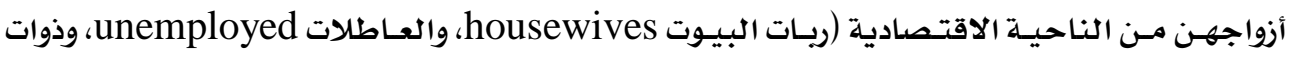

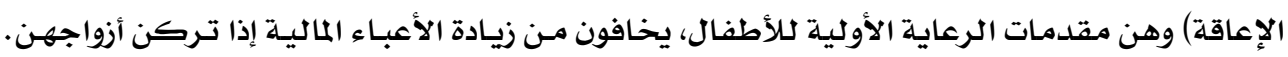

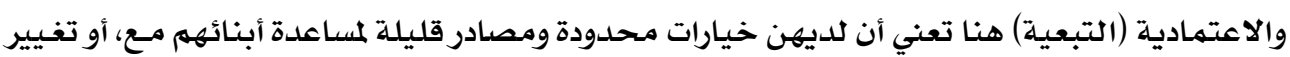
سلوك أزواجهم.

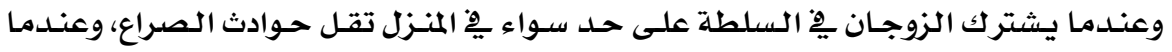

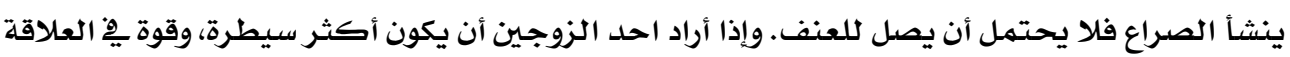

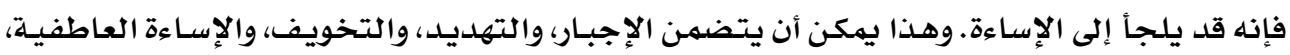




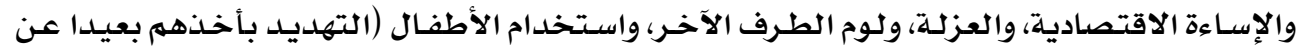

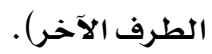

الضفوط الاجتماعية: (Aneshensel, 1992)

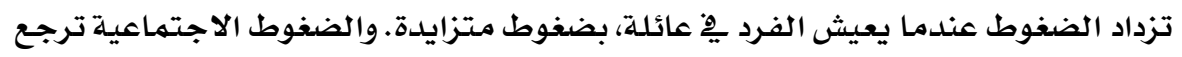

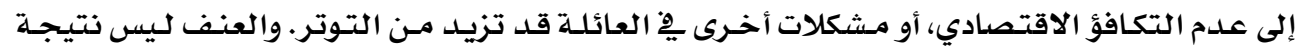

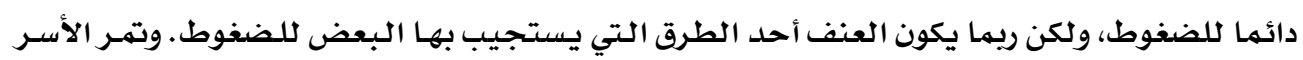

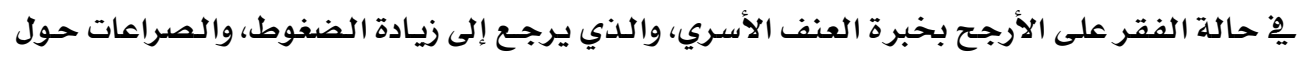

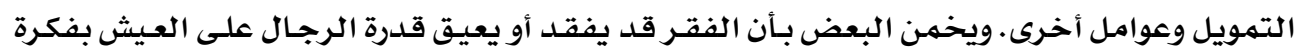

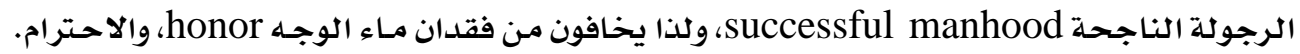

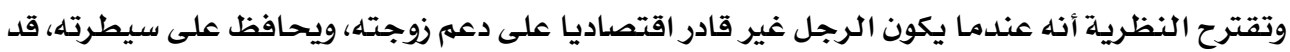

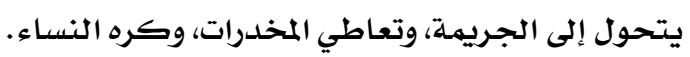
نظرية التعلم الاجتماعي: Social learning theory

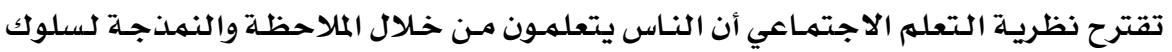

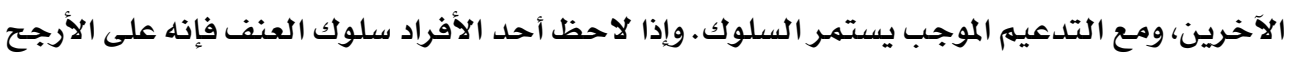

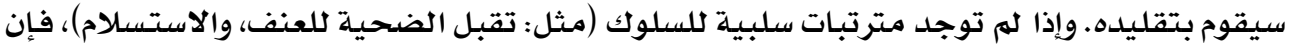

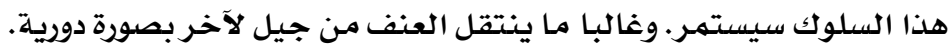

القوة والسيطرة: Tower and control Pohey, 2009)

ينشأ العنف ِِّ بعض العلاقـات الاجتماعيـة عن الحاجـة لإدراك القـوة أو السيطرة، كشكل

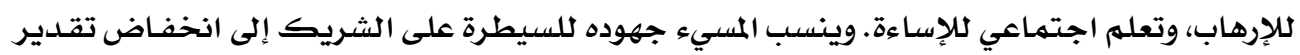

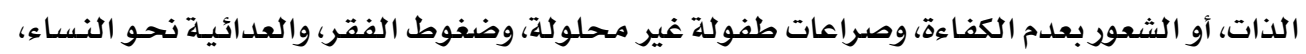

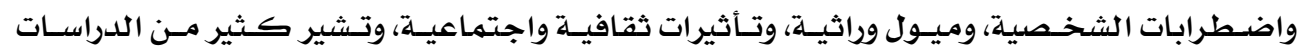

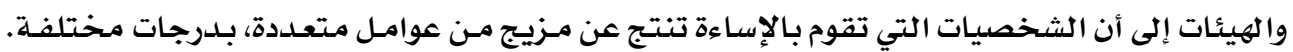

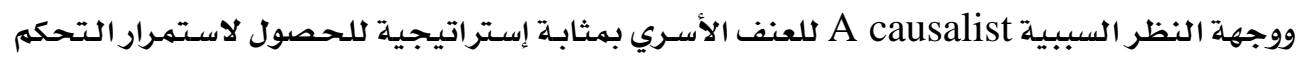

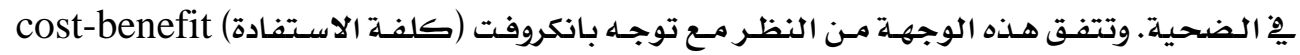

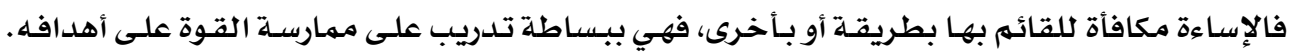

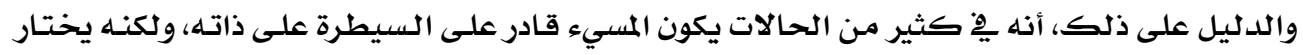

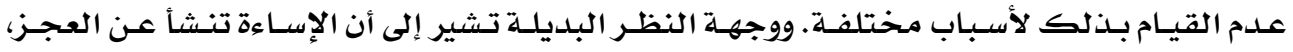

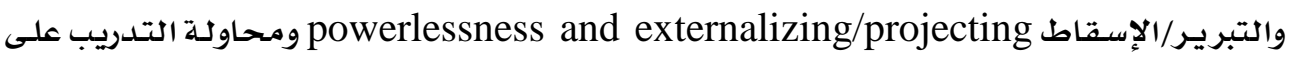
التحكم ِِّ الضحية، فالعنف محاولة للحصول على القوة والسيطرة على الضحية، ولكنه حتى عندما

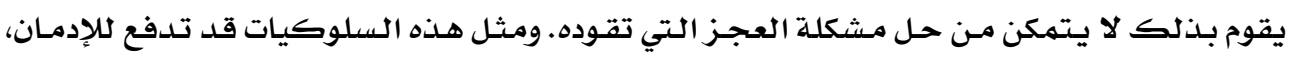

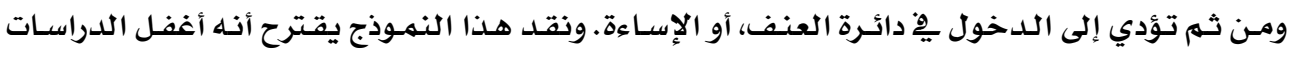

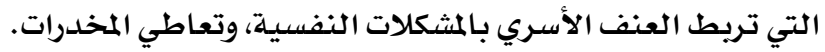


مجلة بحوث التربية النوعية - علد •r - أبريل rا•r ب

يتضح مما سبق أن أسباب العنف متعددة، ومن الصعب حصرها يِّ أسبـاب محسدة، لاختلاف

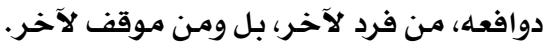

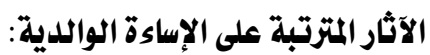

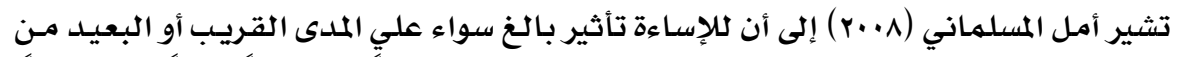

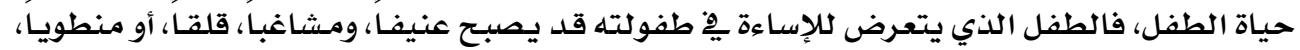

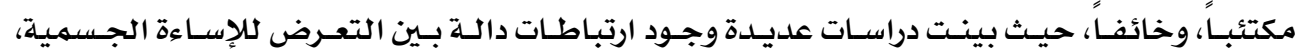

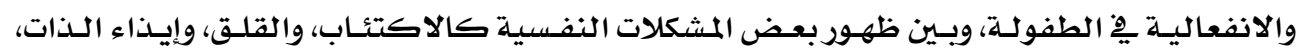

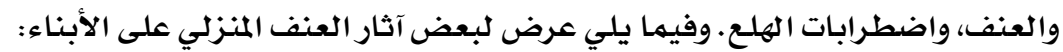

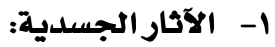

يشير جـونزوهوران (Jones \& Horan, 1997) إلى أن مـن الآثار الجسدية للعنف الدني

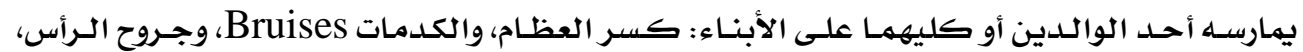

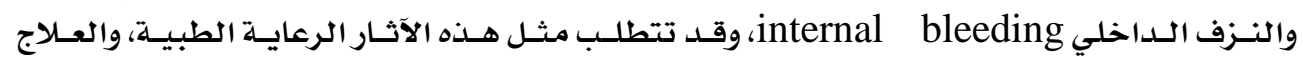

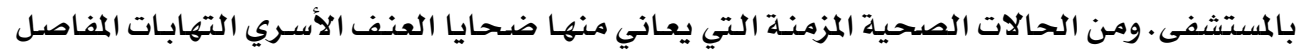
arthritis

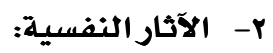

يعـاني الأفراد الذين يتعرضـون للعنف الأسـري مـن درجـات مـرتفعـة مـن الضغوط، والخـوف،

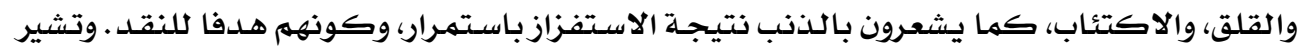

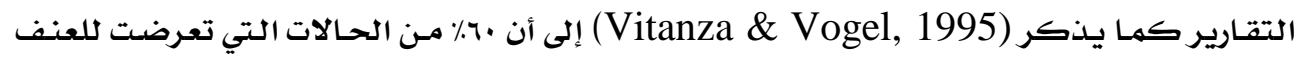

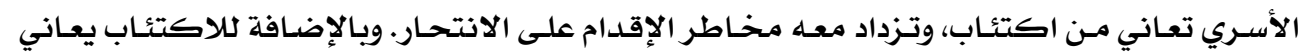

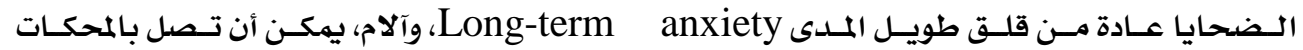

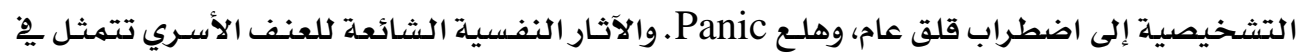

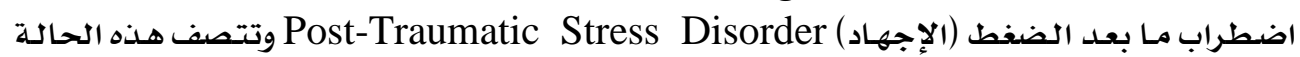

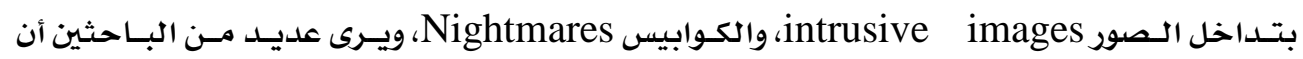
اضطرابات ما بعد الضغط أو الإجهاد هي أفضل تشخيص للمعاناة من الآثار النفسية للعنف المنزلي.

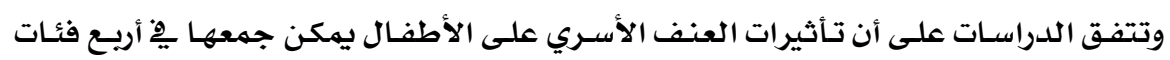

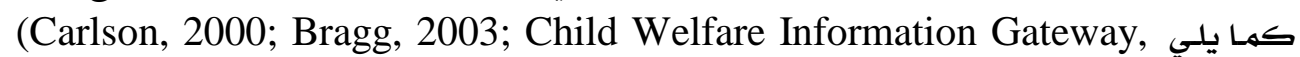
2009):

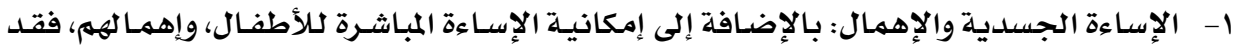

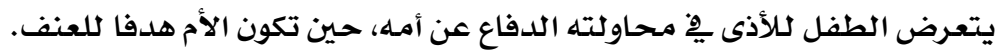


Y- الأمراض الجسمية: يمكن أن يعـاني الأطفـال مـن الضغوط المرتبطة بـالمرض الجسـي، مثل :

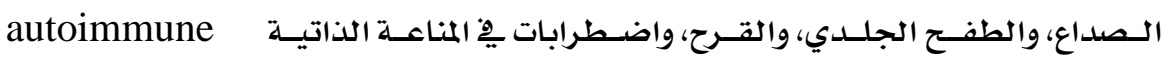
.disorders r- العدوان وصعوبات التفاعل مـع الأقران: يمكن أن يقلد بعض الأطفـال العـدوان والعنف الدني

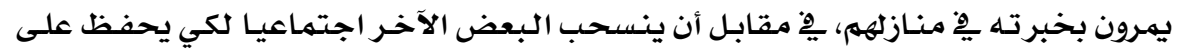
نفسـه الأمن. ع- سـلوكيات عامـة: يمكسن أن يعـاني الأطفـال مـن فقـدان الشهية، والكـوابيس، والقلقق، ونوبـات

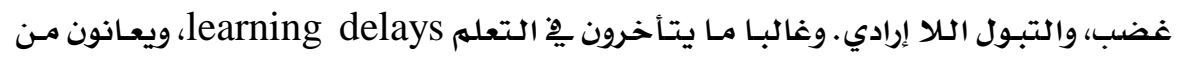

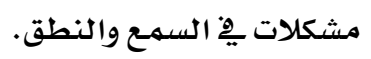

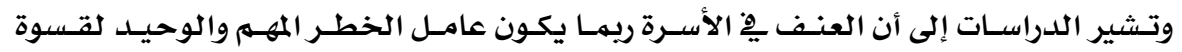

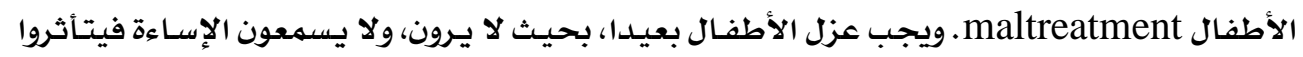

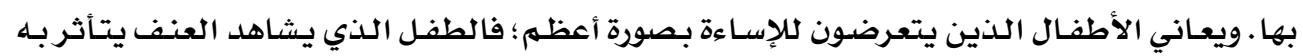

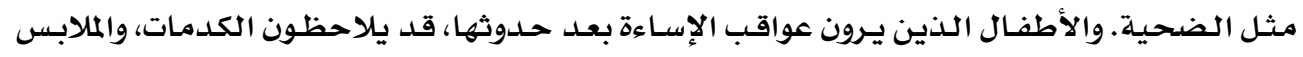

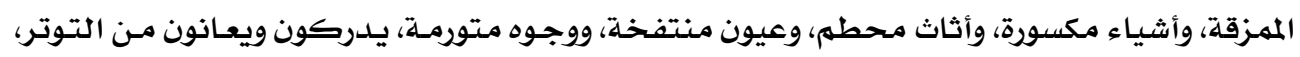

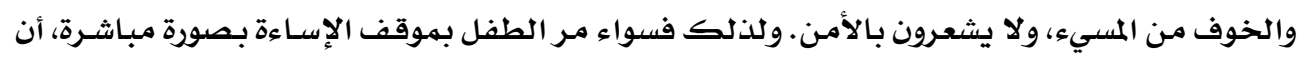

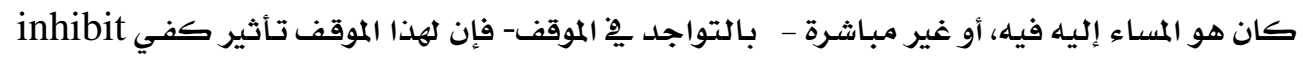

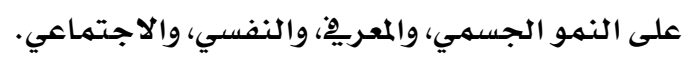
وتشير بوابات المرأة والعائلة (Doorways for Women and Families, 2004) إلى واعلى

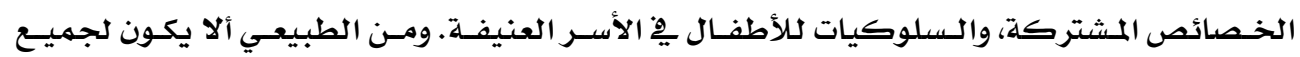

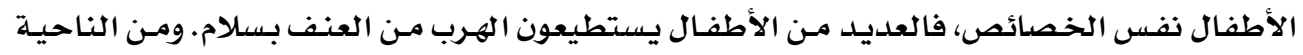

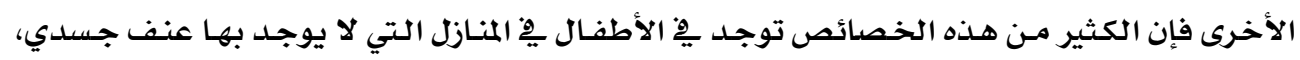

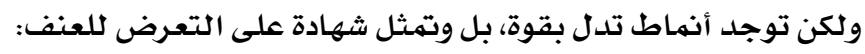

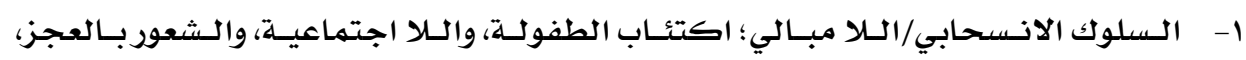

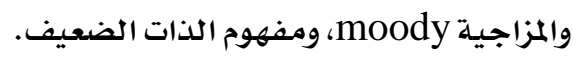

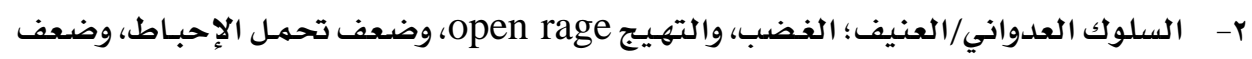

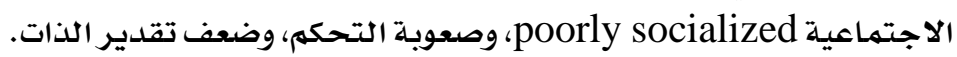

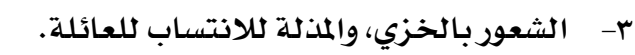

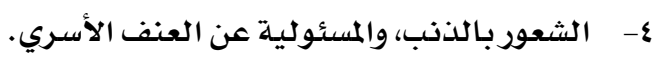

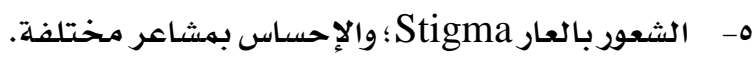

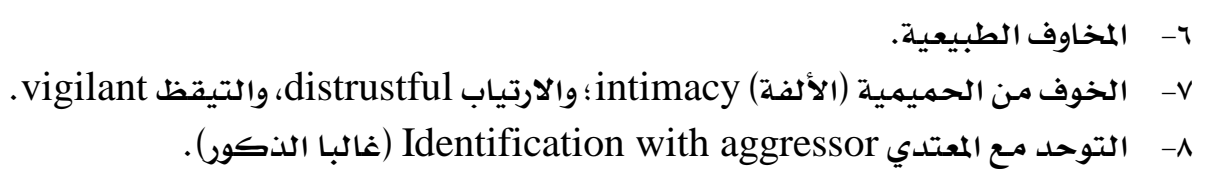


$+2$

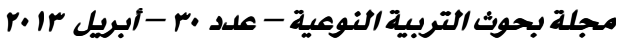

9- القـيم المضطرية Confused values فينظـرون إلى القـوة الجسمية على أنها الوسـيلة

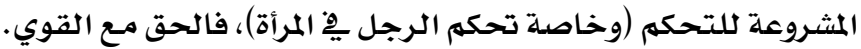

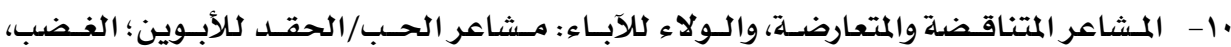

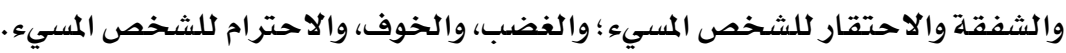

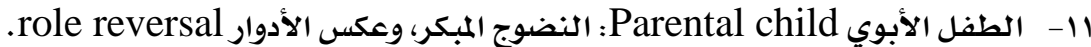

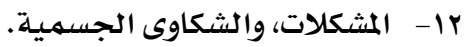

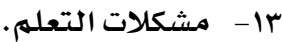

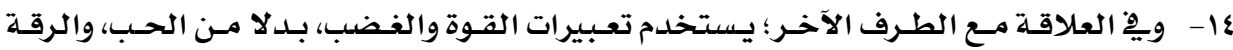
.tenderness

ويرى الباحث أن تأثير العنف على الفـرد وشخصيته قد تتوسطه بعض العوامل، بمعنى أن

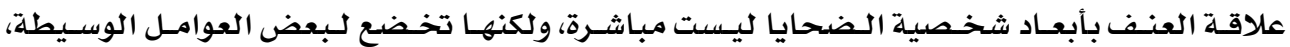

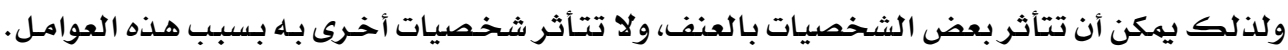

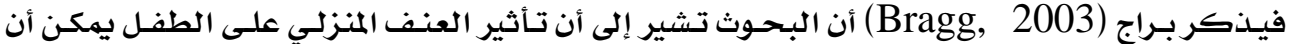
تتوسطه عوامل تشمل:

ا. طبيعة العنف: فالطفل الذي يشاهد العـدوان بـصورة متكررة، وحـادة يـدرك أن العنف نوع مـن

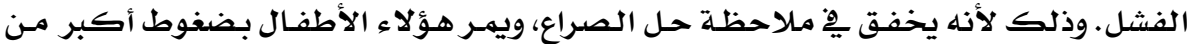
أقرانههم الذين يشاهدون أحداث عنف محدودة. r. اسـتراتيجيات ومهارات التعامـل Coping strategies and skills : فالأطفـال مـع مهارات

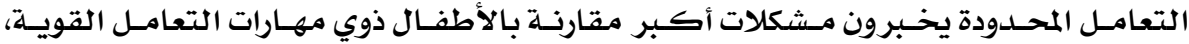

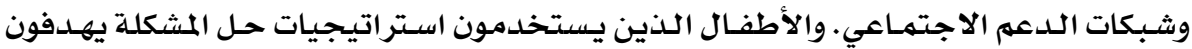

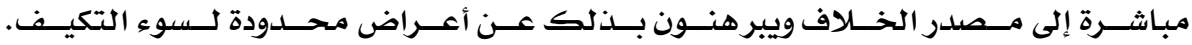

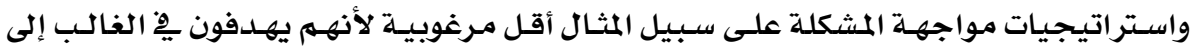

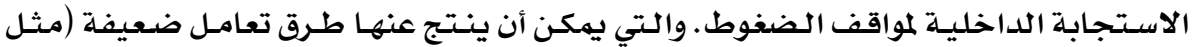
القول بأن الوالد على حقى).

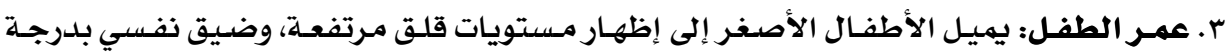

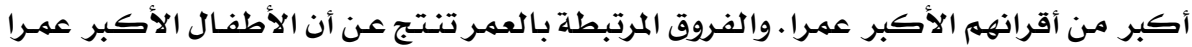

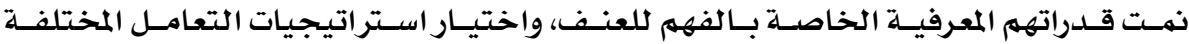
للتخفيف من آثاره العاطفية المزعجة.

وبالإضافة للعوامل الثلاثة السابقة يضيف كارلسون وبوابة معلومات رفاهية الطفل إليها مـا يلي (Carlson, 2000; Child Welfare Information Gateway, 2009): 


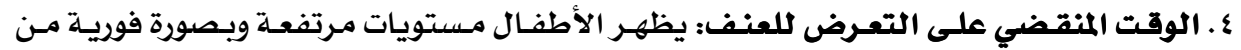

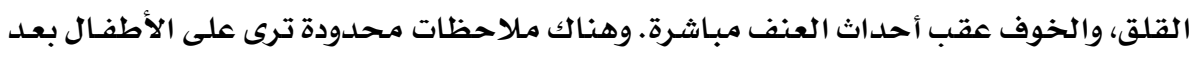
مـرور فترة أطول على حادث العنف.

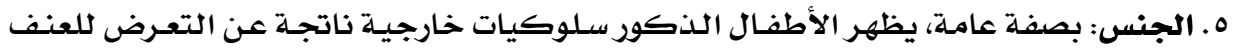
مثل العدوان، بينما تظهر الإناث سلوكيات داخلية بصورة أكبر مثل الاكتئاب أو الانسحاب.

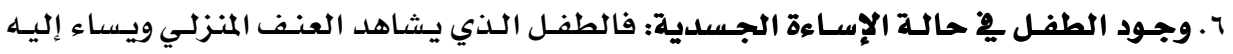

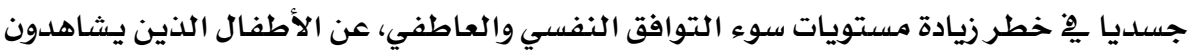
العنف ولا يساء إليهم. ثانيا: العدوان

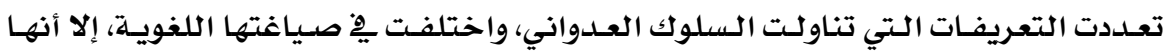

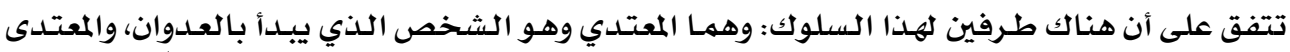

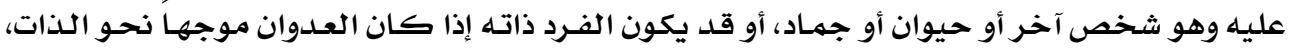
ومن هذه التعريفات:

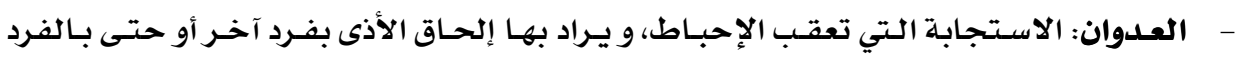

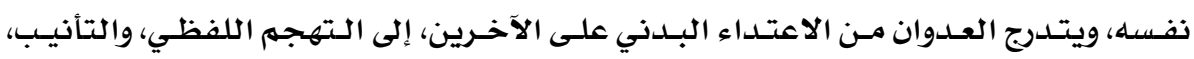

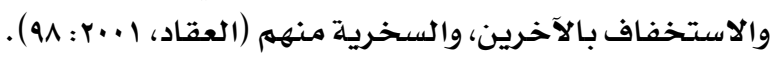

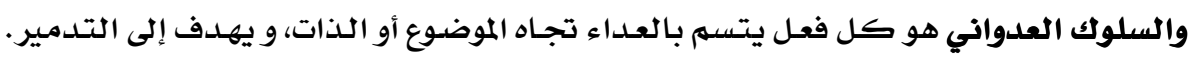

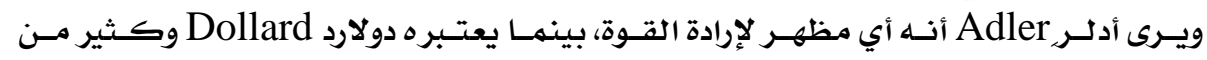

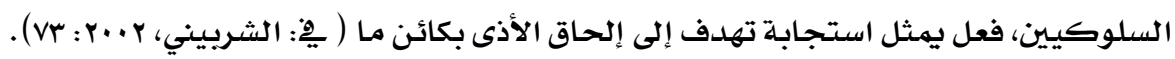

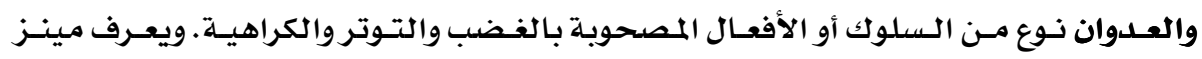

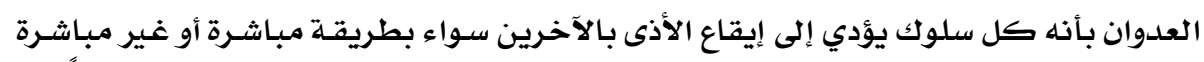

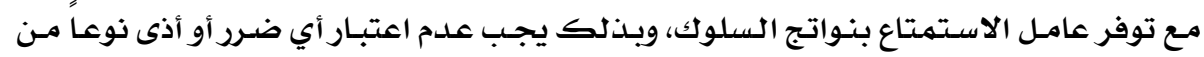

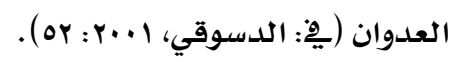

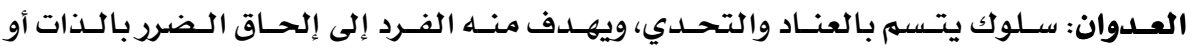

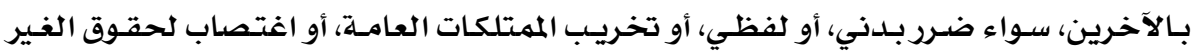

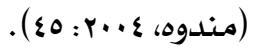

أشـارت بعض التعريفات السـابقة إلى أنواع السلوك العدواني، مثل العـدوان البـدني، أو اللفظي، وإيذاء الذات، أو عدوان على المرافق أو الأشياء.

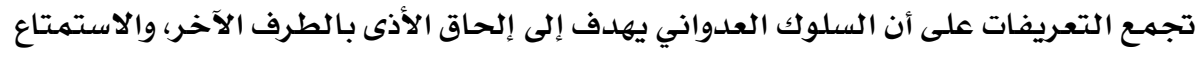
بذلك. أشـارت بعض التعريفات إلى مصاحبة الغضب، والإحباط، والتوتر للعدوان. 
بعض النظريات المفسرة للعدوان:

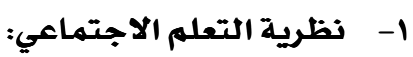

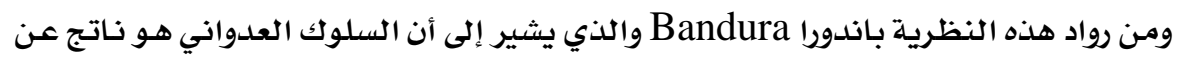

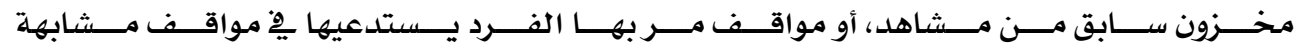

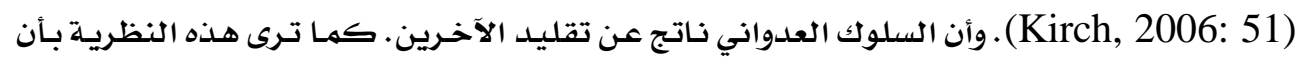

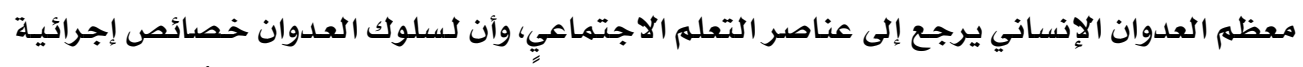

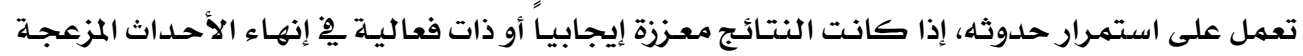

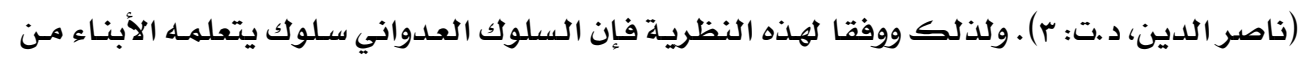

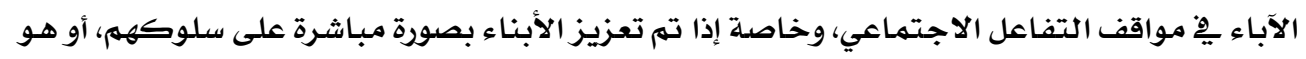

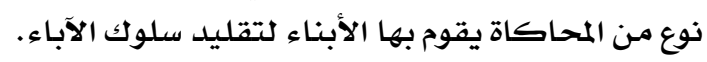

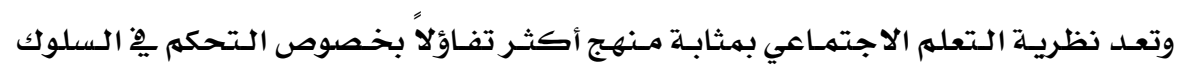

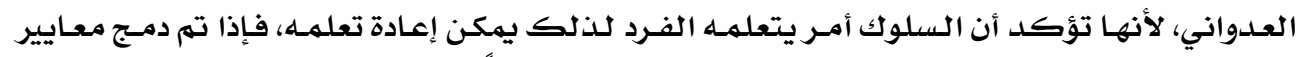

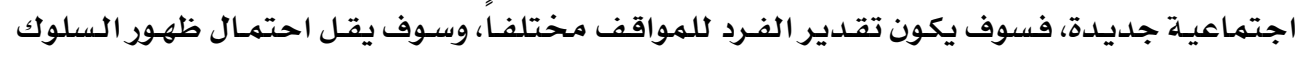

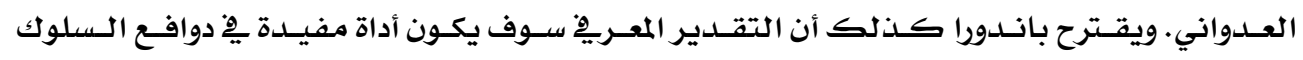

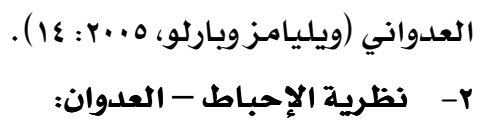

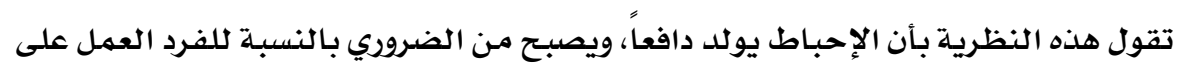

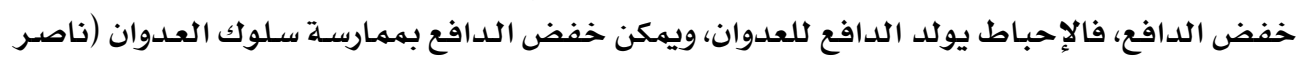

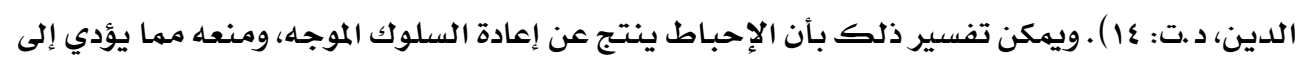

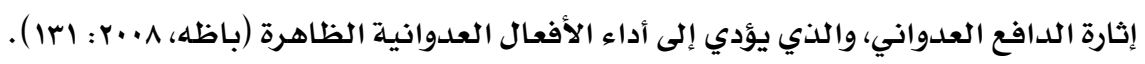

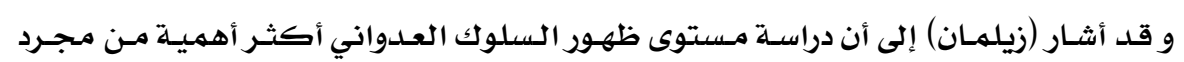

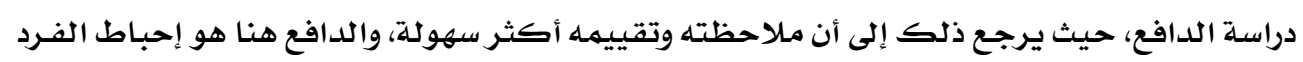

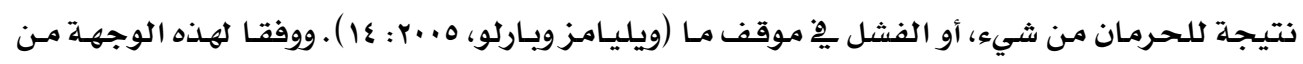

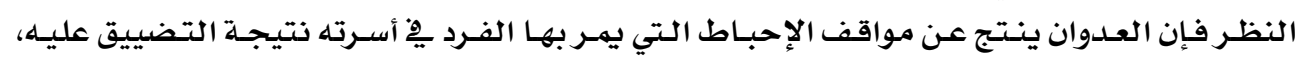

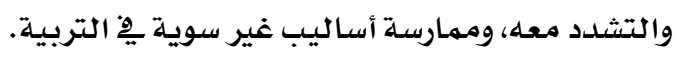

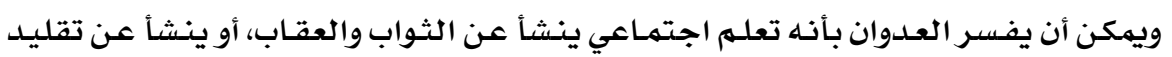

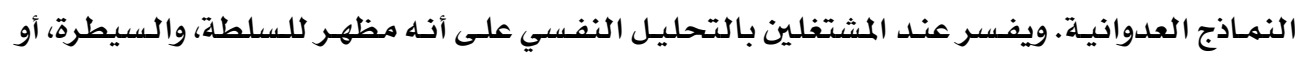

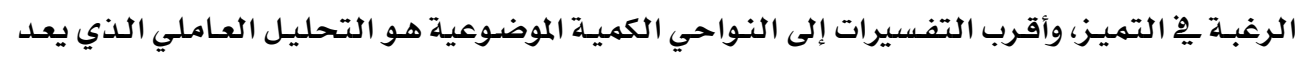

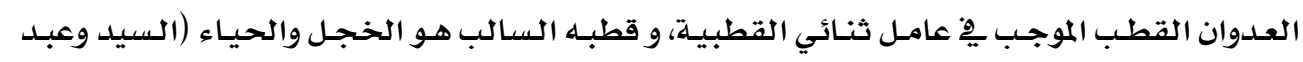

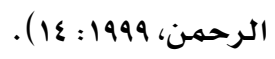




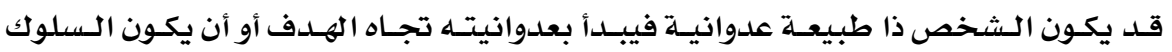

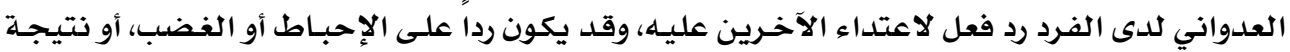

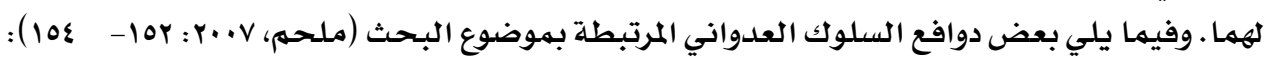

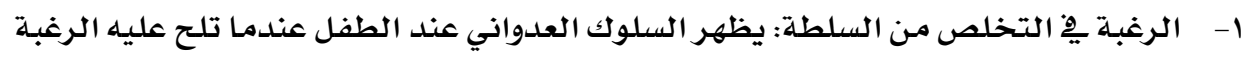

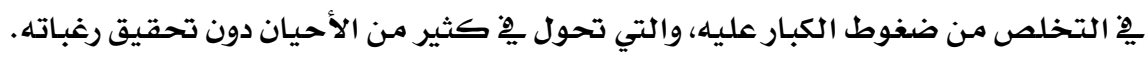

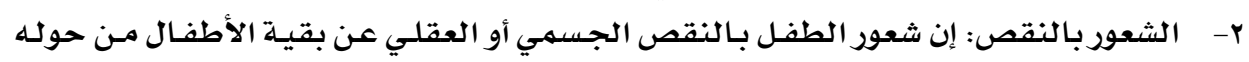

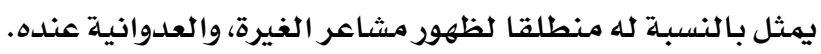

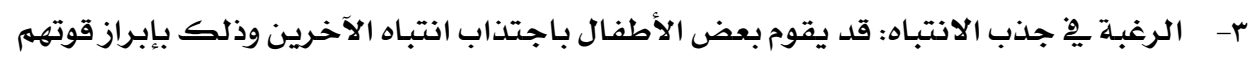

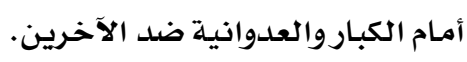

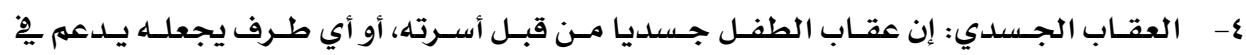

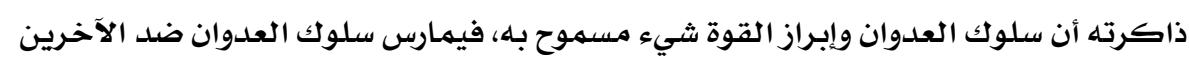

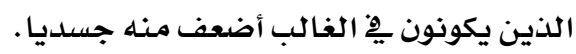

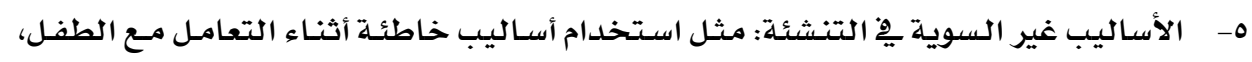

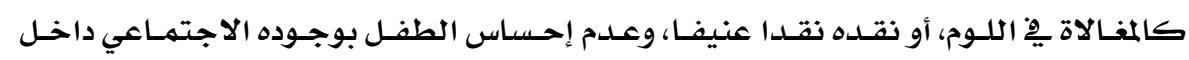

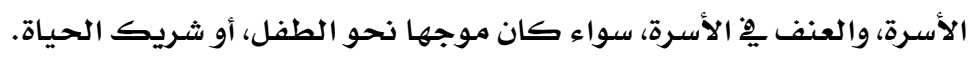

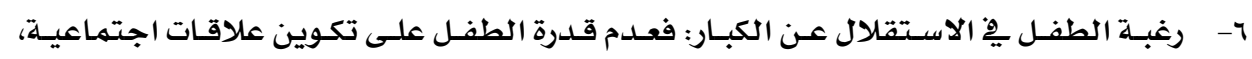

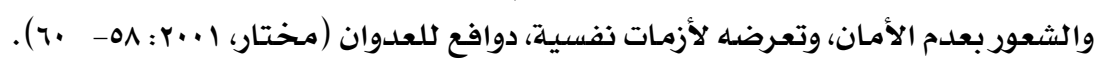

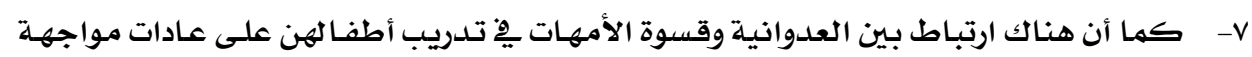

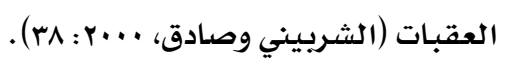

ثالثا: توكيد الذات

تعـددت تعريفـات مفهوم توكيــ الـذات بـين البـاحثين، فهنـاك مـن ينظـر إلى توكيــ الـذات باعتباره حرية التعبير عن المشاعر، مثل:

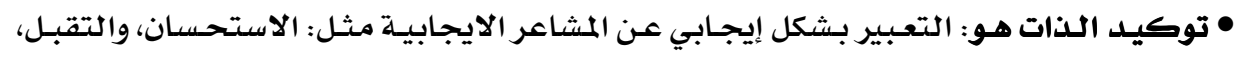

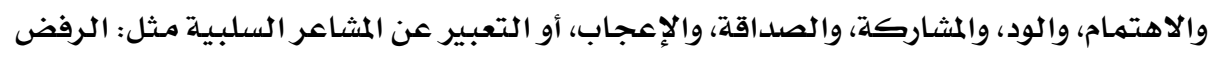

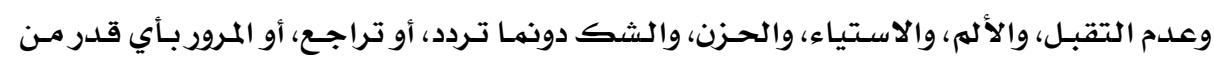

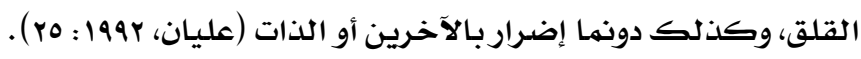

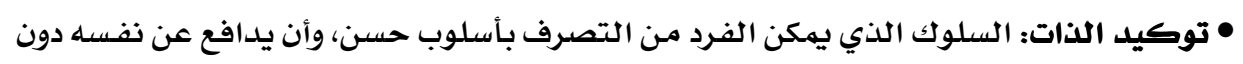

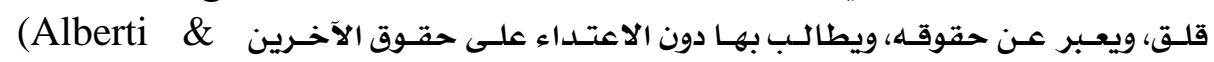
Emmons, 2001).

وهناك من يعرف توكيد الذات على أنه مهارة، مثل: 
• توكيـد الـذات: مهارة سـلوكية لفظيـة، وغـير لفظيـة، موقفيـة، متعلمـة، وذات فاعليـة نسبية،

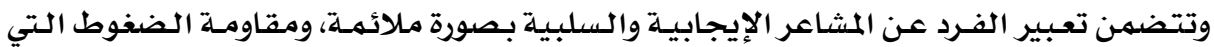

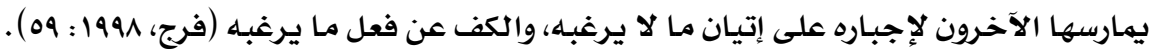

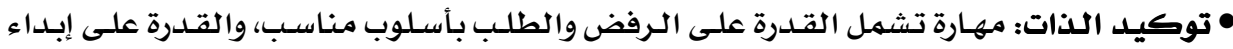

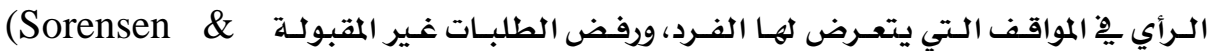

Commedore, 1998).

$$
\text { وهناك من ينظر إلى توكيد الذات باعتباره قدرة، مثل: }
$$

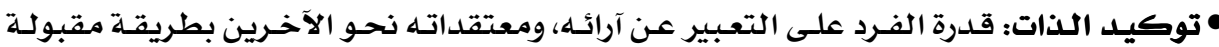

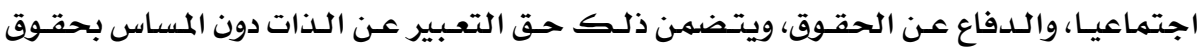

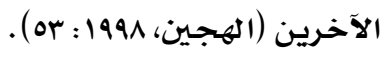

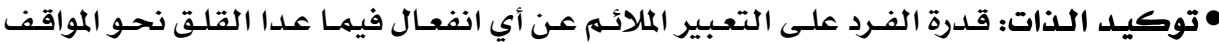

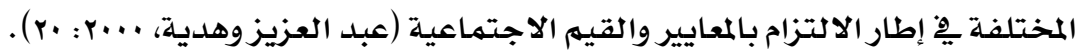

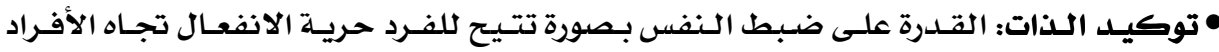

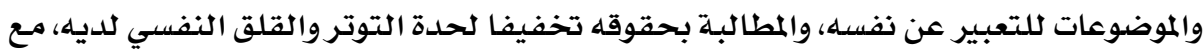

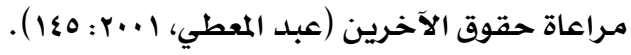

ويرى الباحث أنه بالرغم مـن الاختلاف الظاهر بين التعريفات إلا أنها تتضمن مبـادأة الفرد، وحسن التصرف، والتعبير عن حقوقه مـع مـراعاة حقوق الآخرين.

أساليب تنمية توكيد الذات:

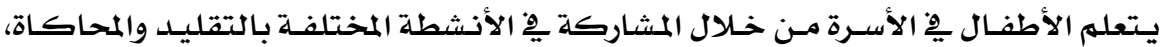
وملاحظة الآخرين. ويٌْ ضوء ذلك يمكن تنمية توكيد الذات يِّات الأسرة من خلال ما يلي:

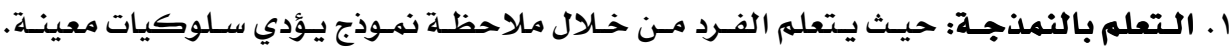

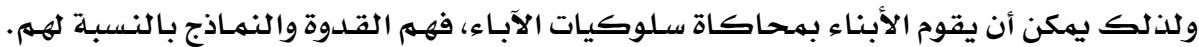

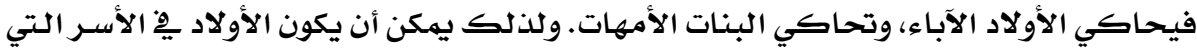

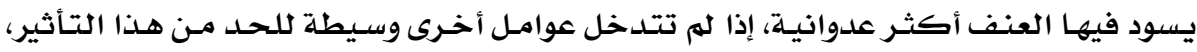

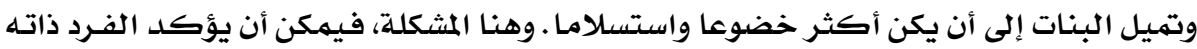

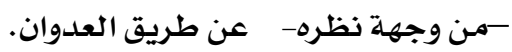

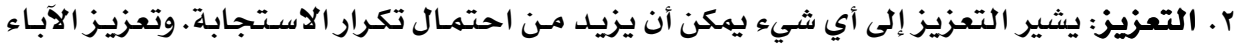

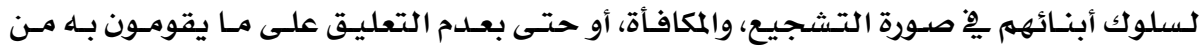

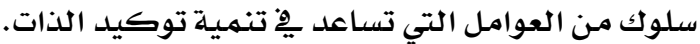

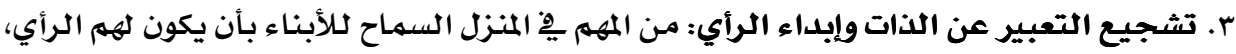

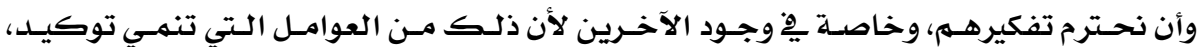




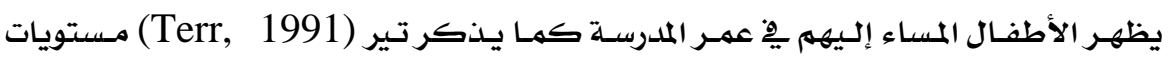

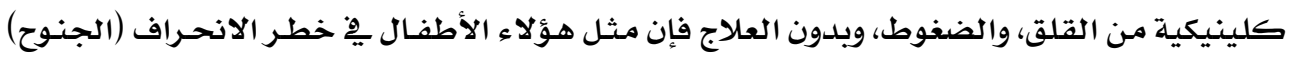

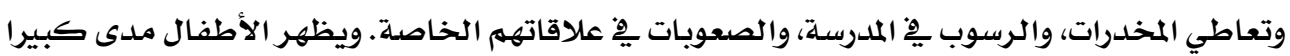

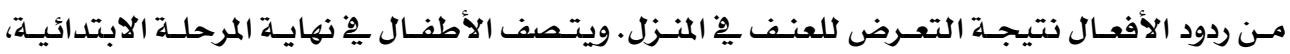

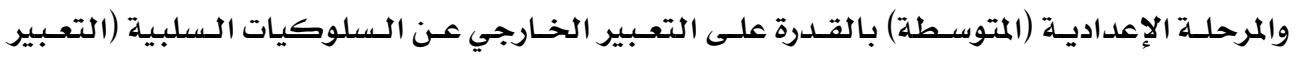

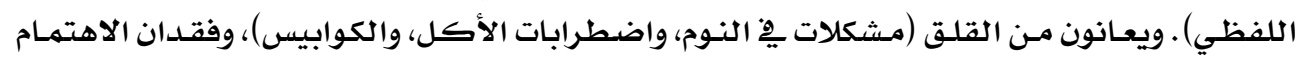

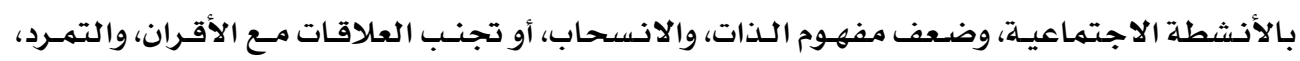
والسلوك المعارض يِّ المدرسـة.

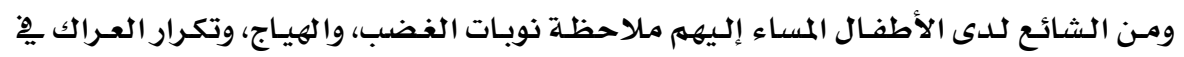

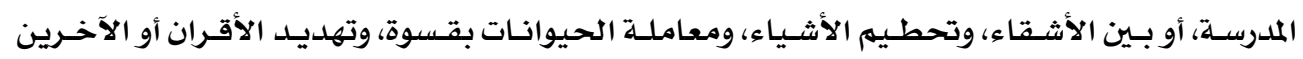

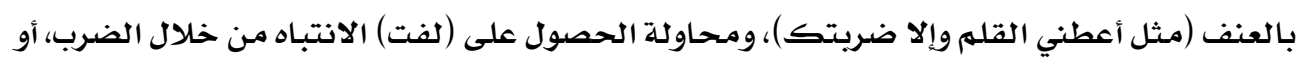

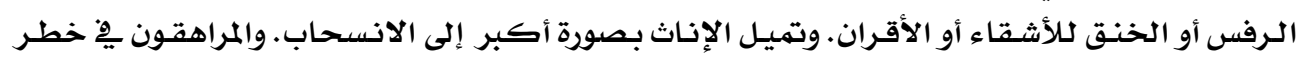

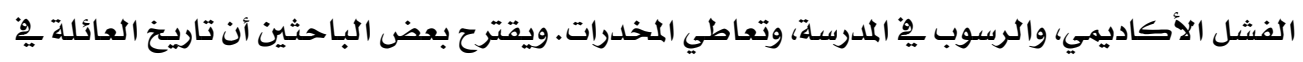
العنف عامل مهم يميز بوضوح بين الشاب الجانح وغير الجانح (SASS, 1996).

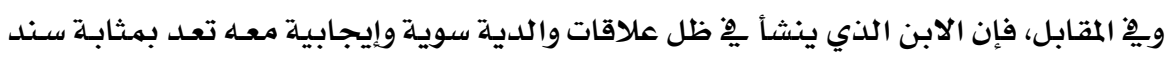

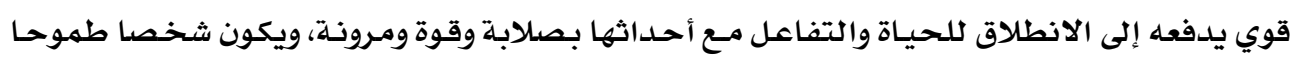

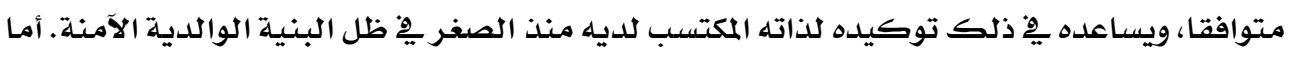

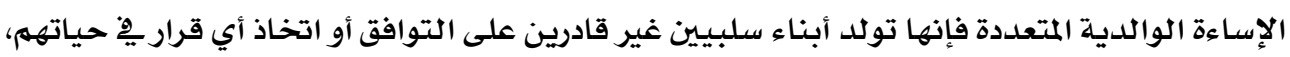

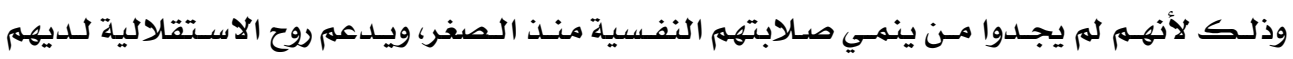

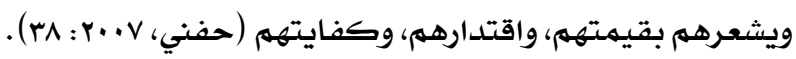

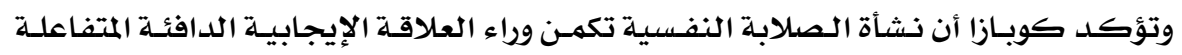

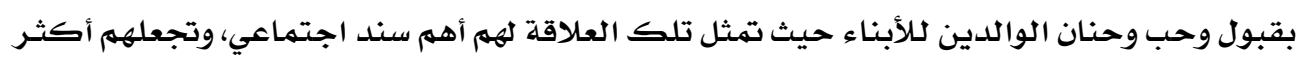

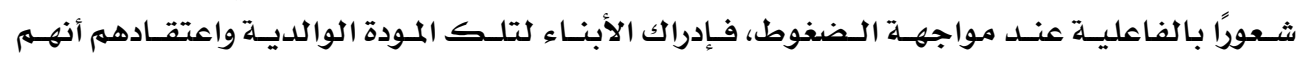

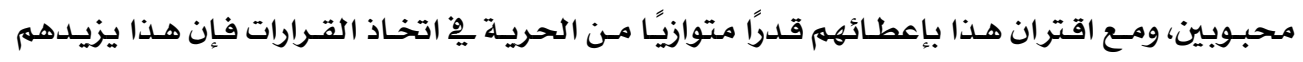

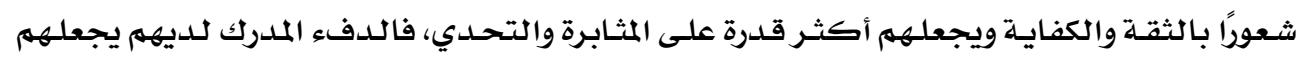

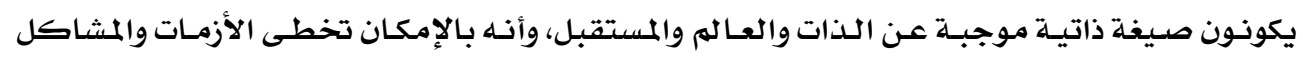

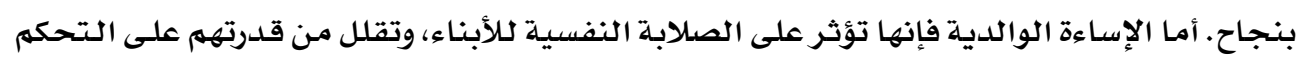

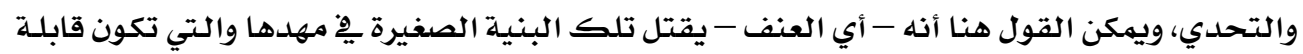

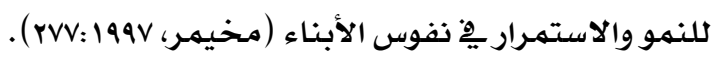




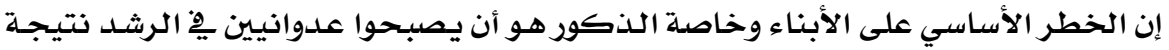

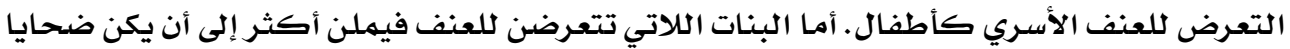

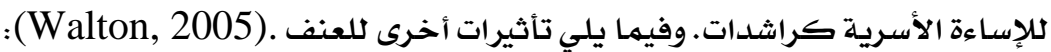

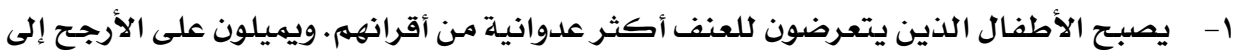

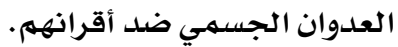

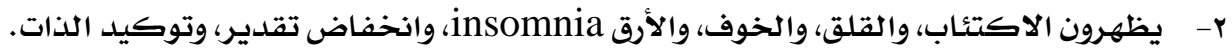

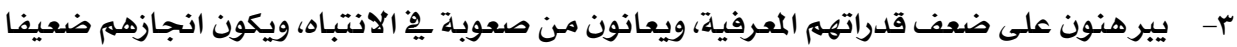

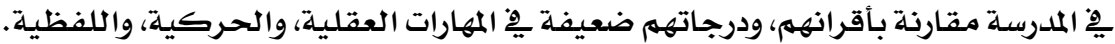

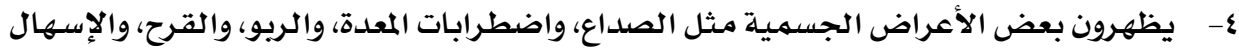

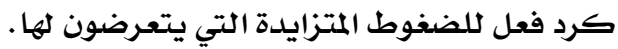

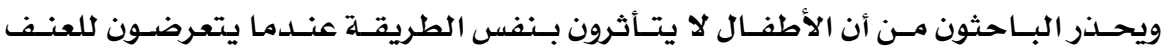

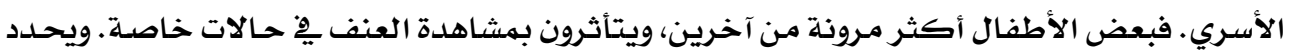
الخبر اء عوامل مختلفة للحماية أو الوقاية تقلل من التأثيرات المحتملة آحلة على الأطفال، تشمل:

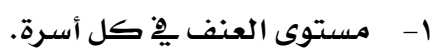
ب- ب الدرجة التي يتعرض بها الطفل للعدوان.

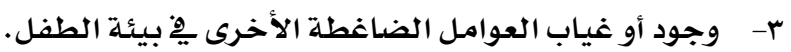

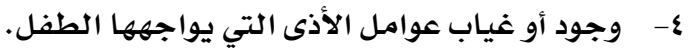

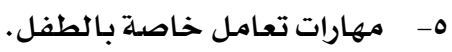

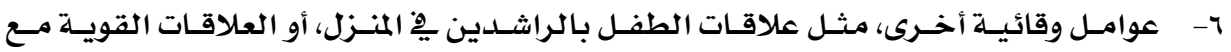
الراشدين الآخرين مثل الأقارب، أو المعلمـين.

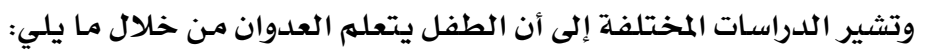
1- مشاهدة أحد الوالدين أوكليهما مِِ مواقف العنف. r- r - تشجيع الآباء لأبنائهم.

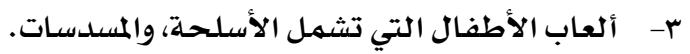

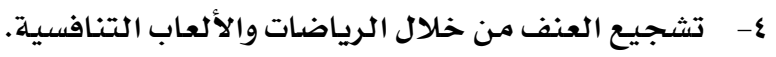

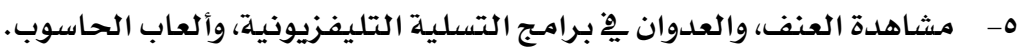
وهِِ المقابل فبإن العوامـل التاليـة تحـد مـن درجـة العدوانيـة، وتحسن مـن درجـة توكيد الدات

1- التعرض لنماذج سلوكية موجبة بلدرجة أكبر من النماذج السلبيـة. r- ب - التقدير المرتفع للذات.

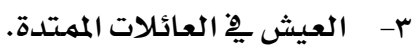

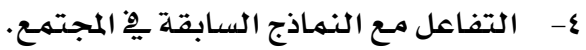




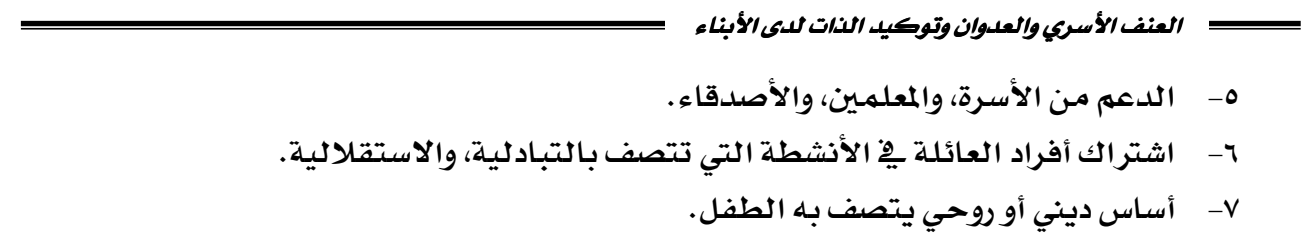

دراسات سابقة:

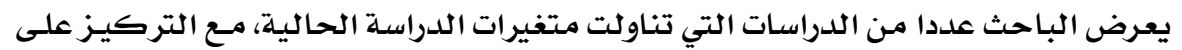

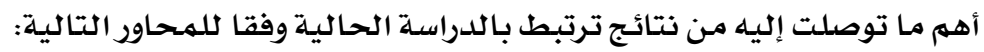

أولا : دراسات تناولت علاقة العنف الأسري والعدوان.

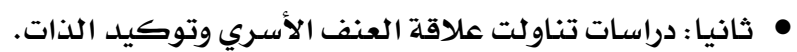

ويتبع ذلك تعقيب على هذه الدراسات، وأخيرا فروض البحث.

أولا: دراسات تناولت علاقة العنف الأسري والعدوان.

يعرض الباحث ِِّ هذا المحور الدراسـات التي تناولت أسـاليب التربية الأسرية، والعنف الأسري

من ناحية وعلاقتها بالعدوان.

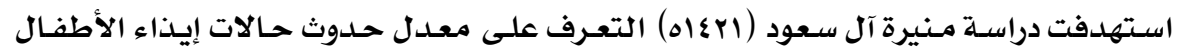

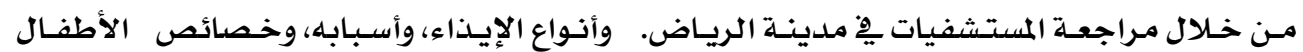

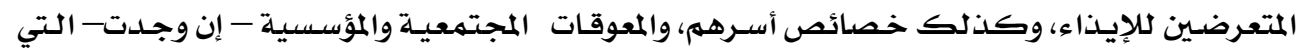

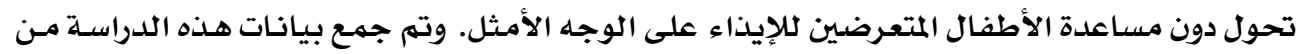

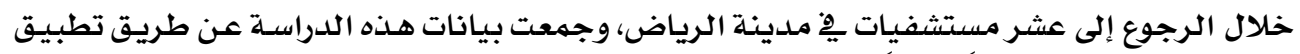

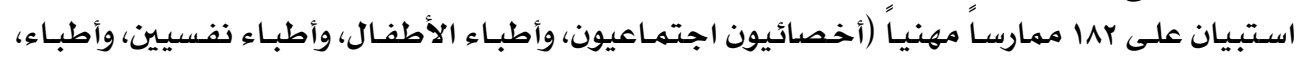

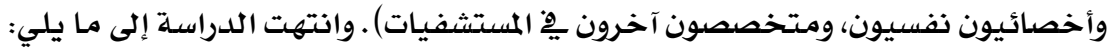

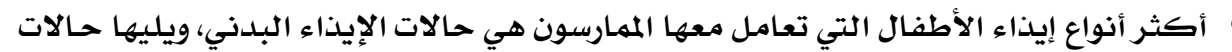

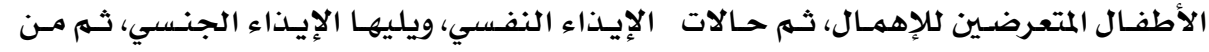

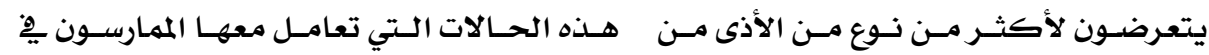

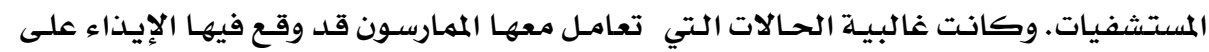

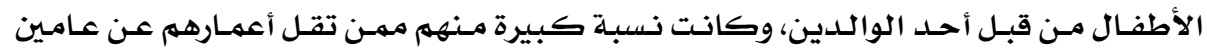

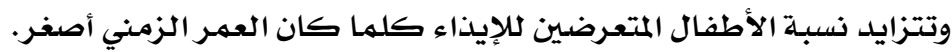

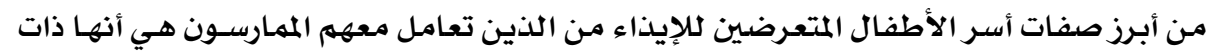

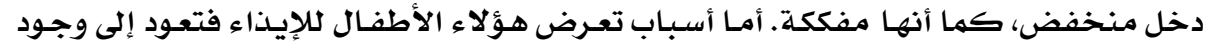

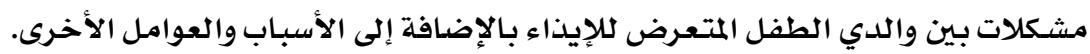

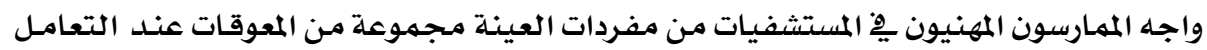

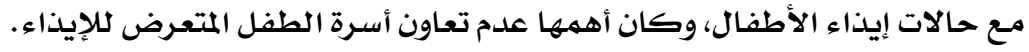




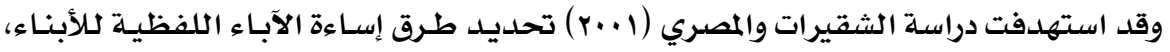

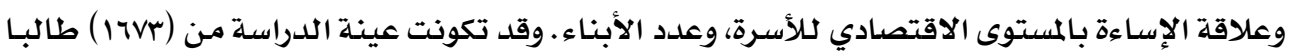

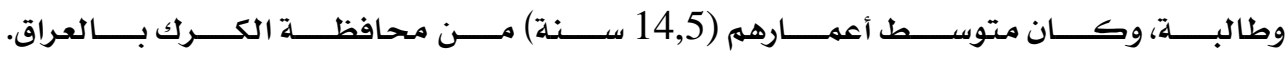

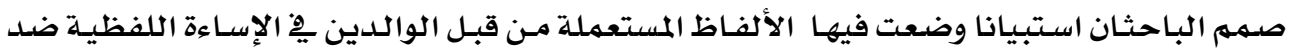

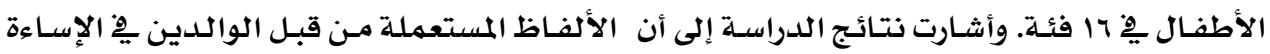

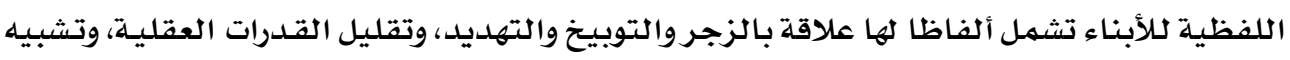

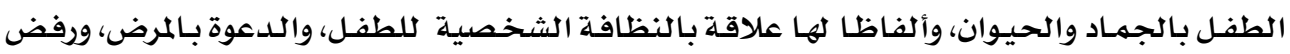

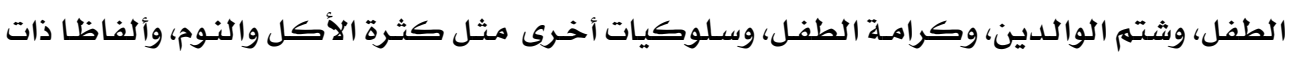

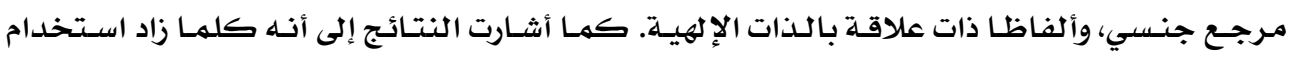

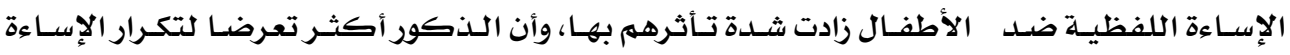

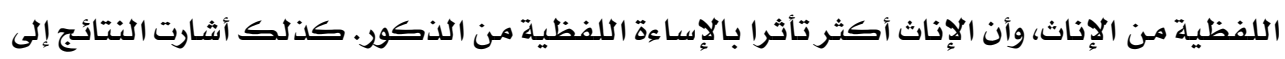

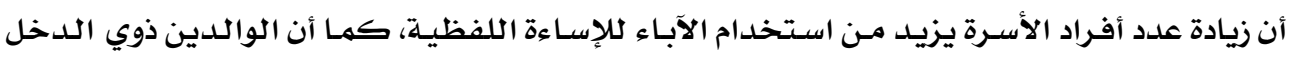
المتدني أكثر استخداما لأساليب الإساءة.

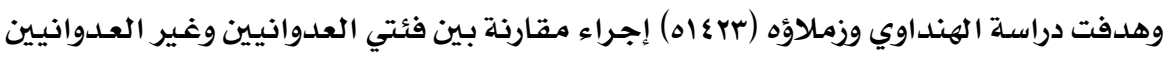

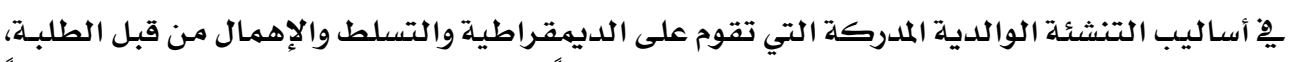

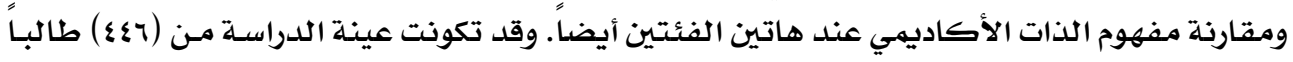

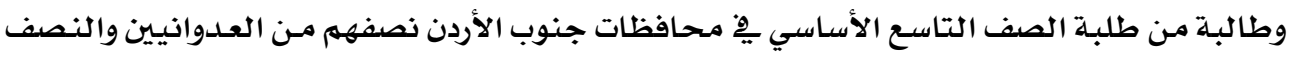

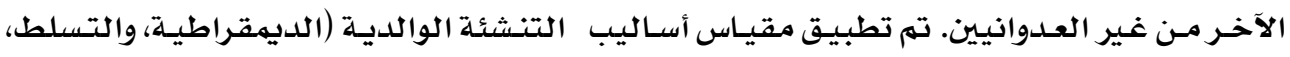

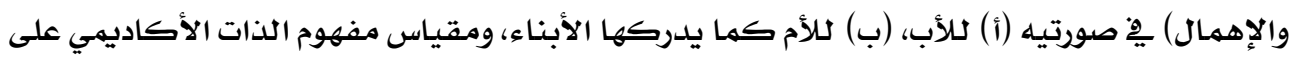

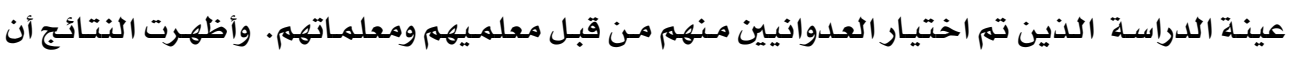

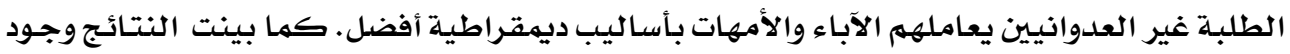

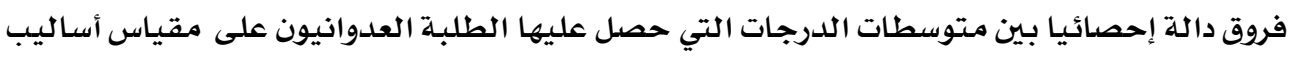

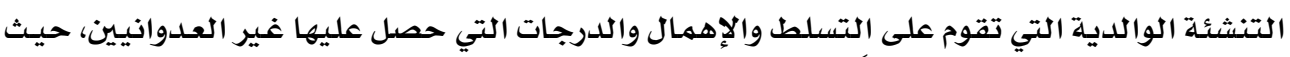

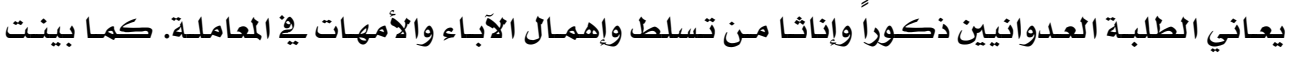

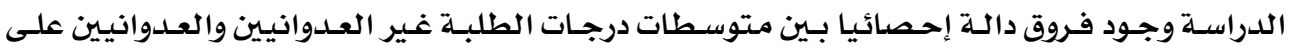

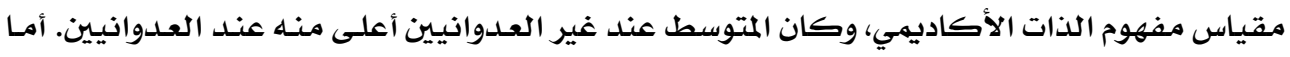

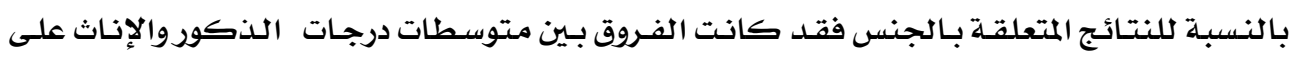

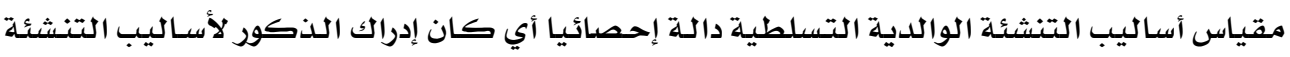

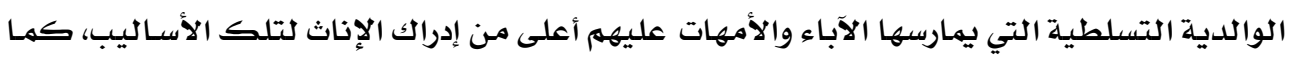

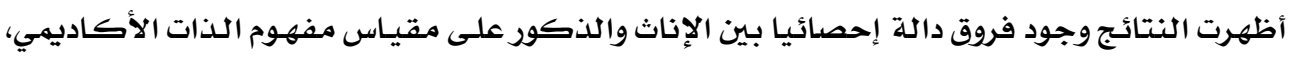

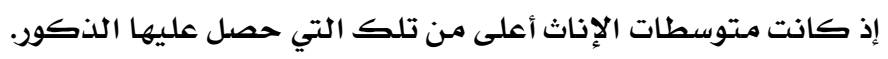

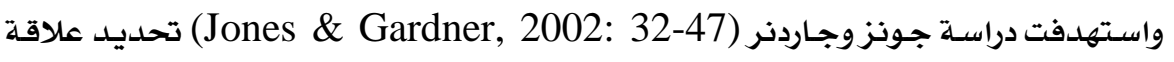
بعض المتغيرات بالاتجـاه نحـو العنفف الأسـري، واستـخدام التفكير، والعـدوان اللفظي، ووسـائل الصراع 


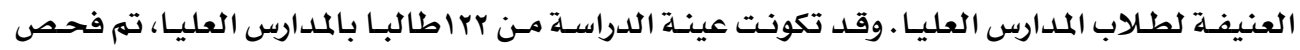

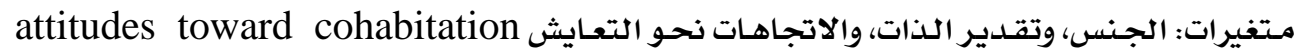

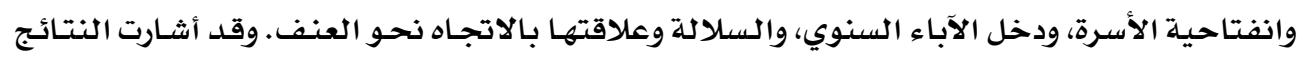

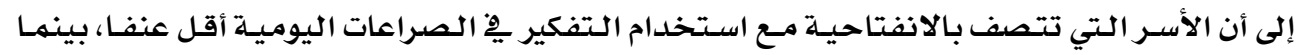

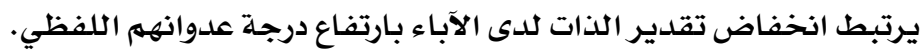

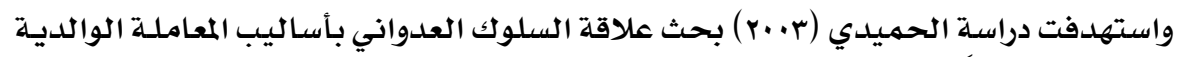

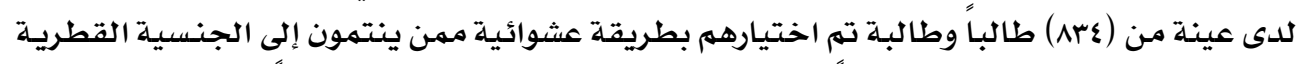

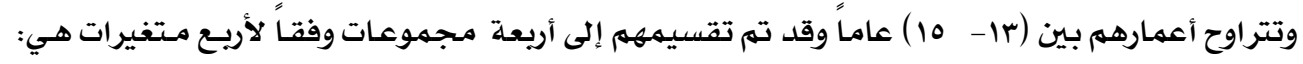

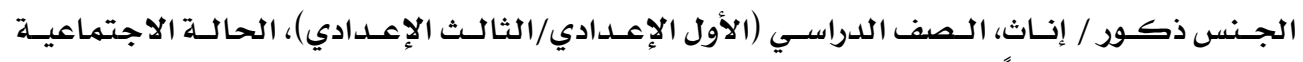

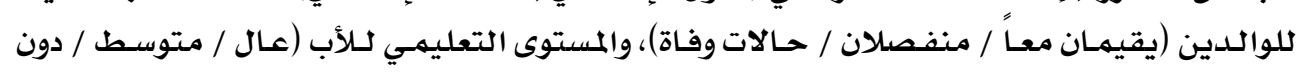
المتوسط) ـ طبق عليهم مقياس السلوك العدواني ومقياس أسـاليب المعاملـة الوالديـة (إعلداد الباحثـة).

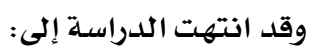

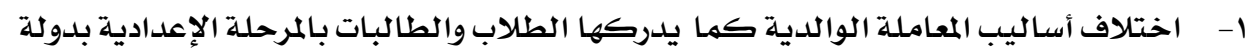

قطر باختلاف متغيرات (الجنس، الصف الدراسي، الحالة الاجتماعية، مستوى تعليم الأب).

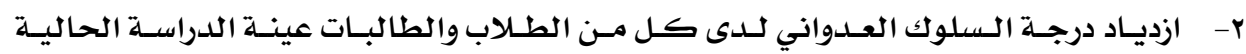

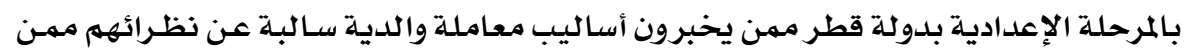

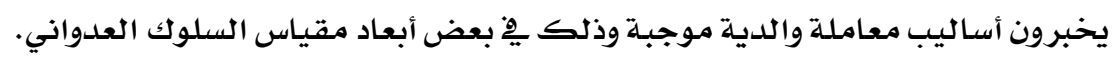

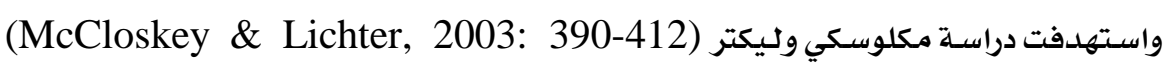

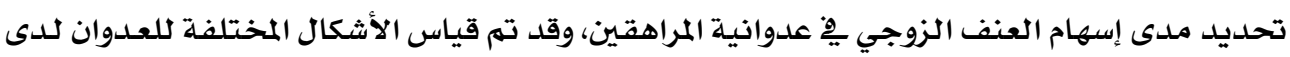

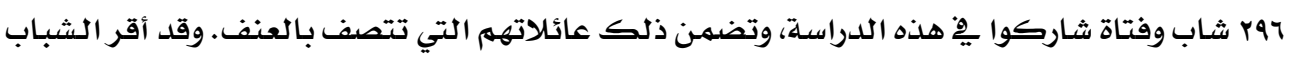

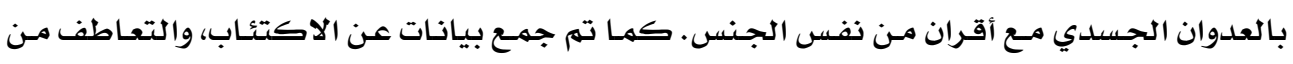

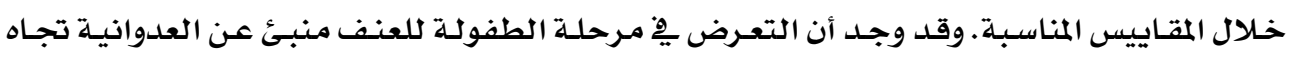

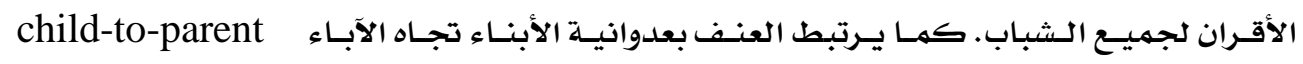

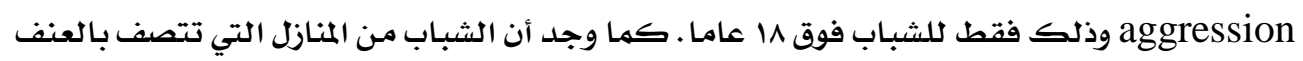

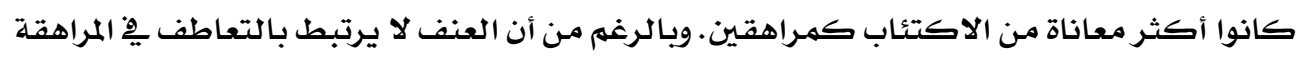

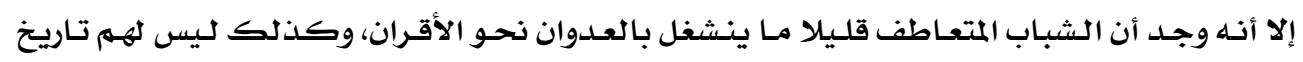

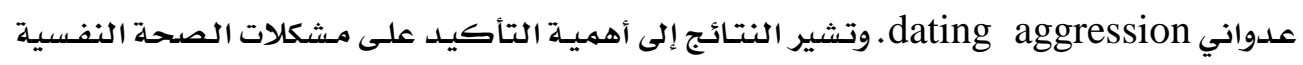
وبناء التعاطف يِّ الشباب الذين يتعرضون للعنف.

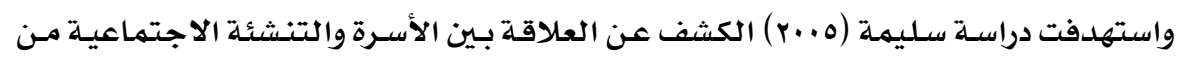

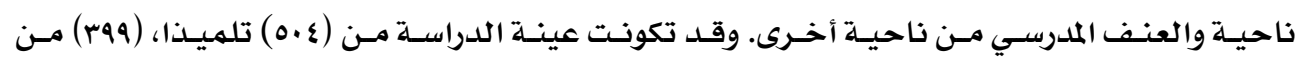

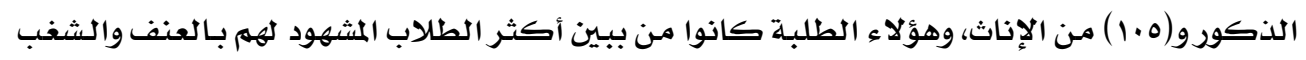


مجلة بحوث التربية النوعية - علد •r - أبريل rا •r ب ب

وعدم الانضباط داخل المدرسـة. ومـن خـالال المقـابلات، واسـتبيان أسـاليب التـشئية الأسـريـة، تم التوصل

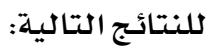

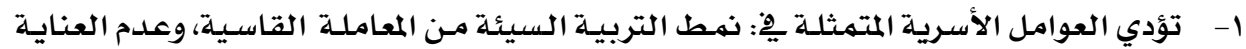

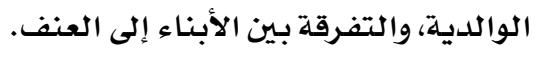

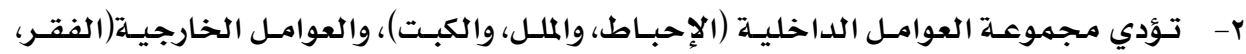

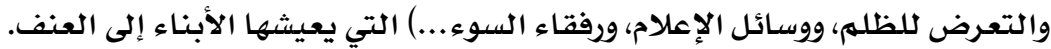

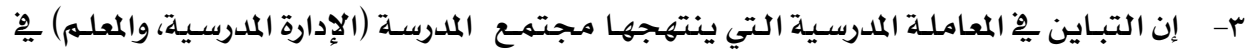

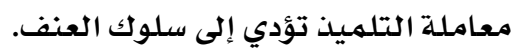

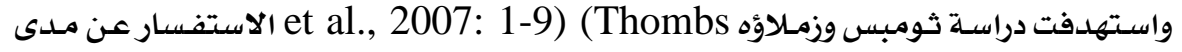

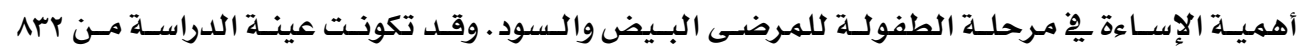

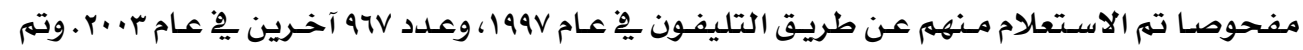

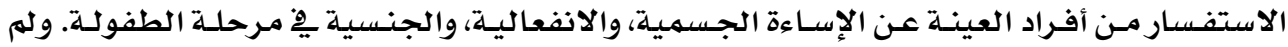

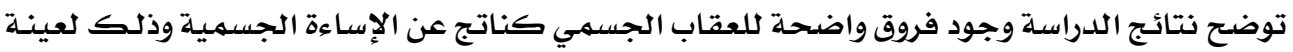

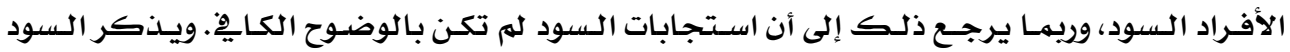

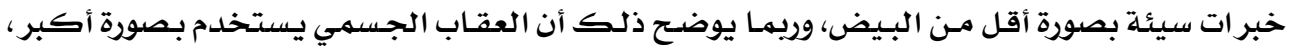

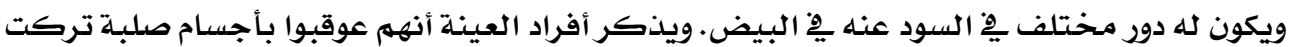
علامات بأجسامهم، أو لاحظها أشخاص دور آخرون.

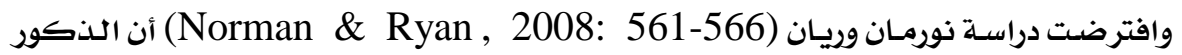

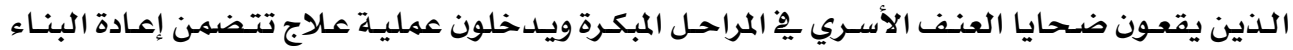

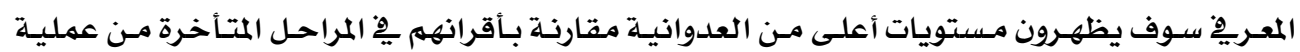

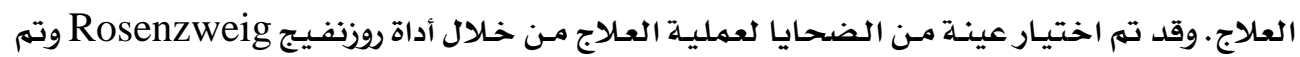

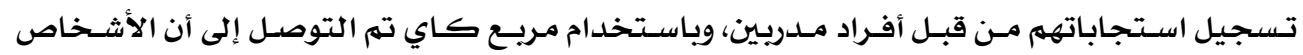

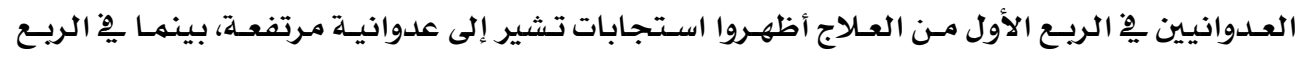

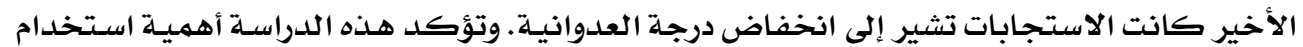

أداة روزنفيج كمؤشر على التقدم فِّ العلاج.

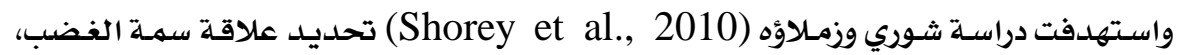

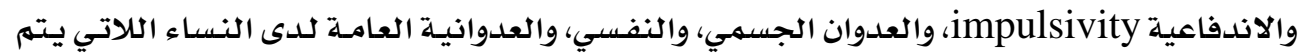

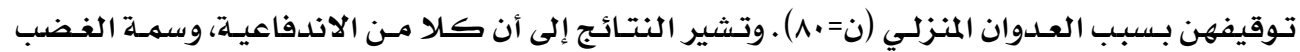

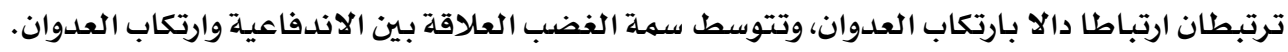

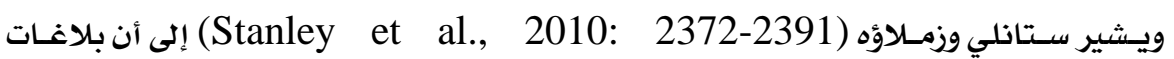
وملاحظات الشرطة عن حوادث العنف المنزلي لتوفير حماية للأطفال هي اعتراف بـالأنى الذي يسبيبه

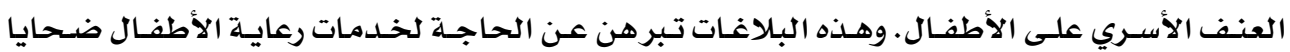


العنف الأسري. وتمثل هذه الدراسـة أول بحث ِِّ المملكة المتحلدة يهتم ببلاغات العنف الأسـري بتعمق،

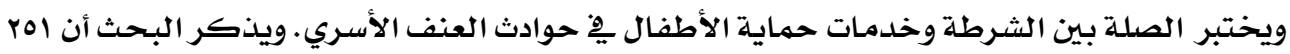

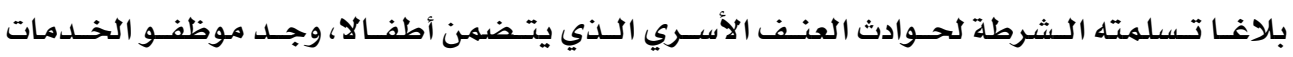

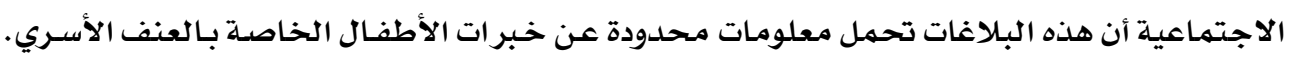

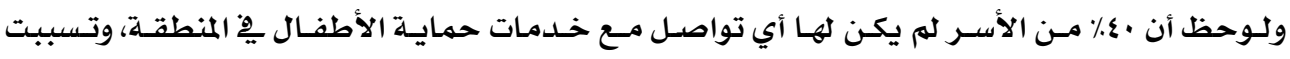

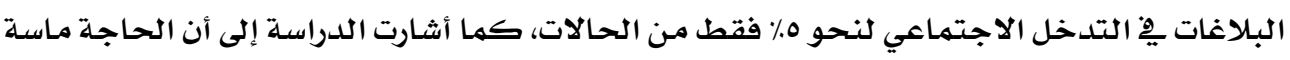

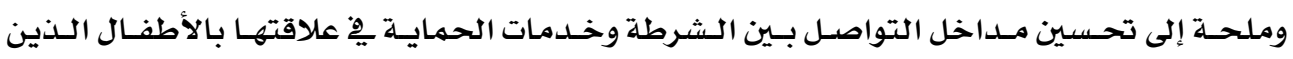
يتعرضون للعنف الأسري. وهدفت دراسة الصبان (11 -r: 1- به ) إلى الكثف عن خبر ات العنف الأسـري والمدرسي للدى

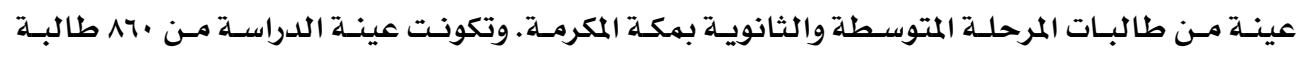

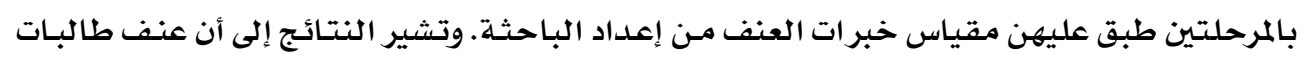

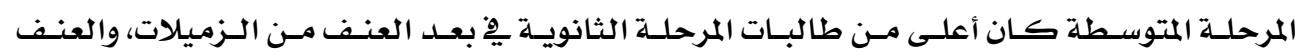

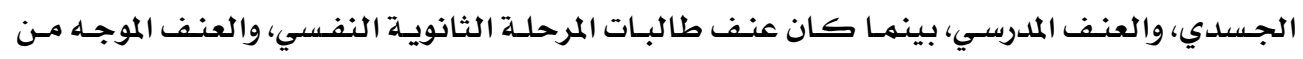

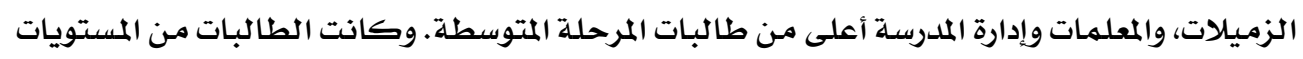
التعليمية الضعيفة أكثر تعرضا للعنف.

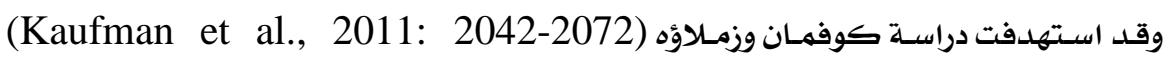

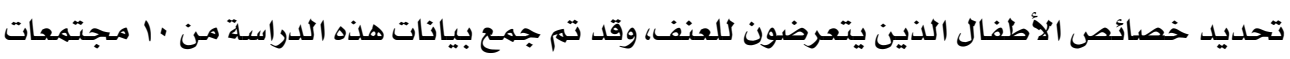

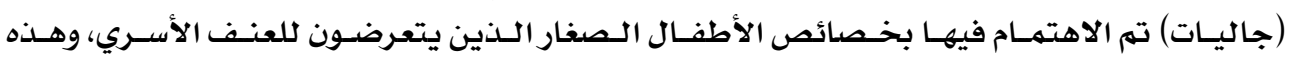

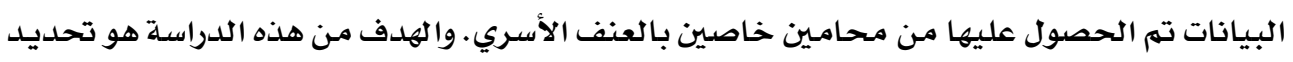

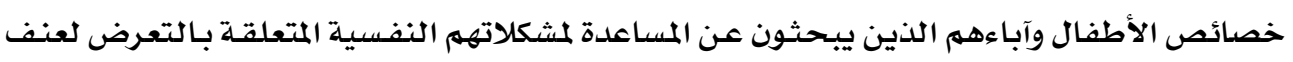

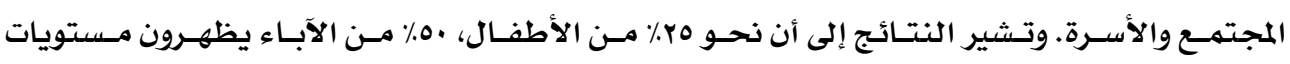

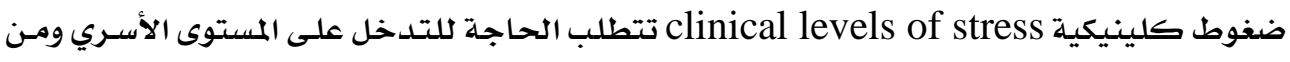

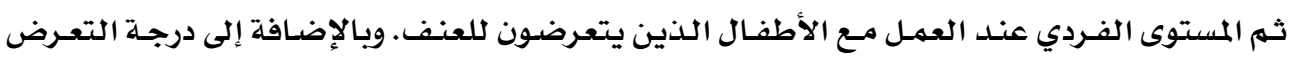

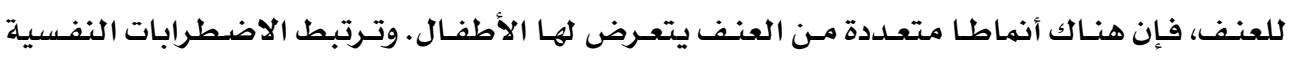

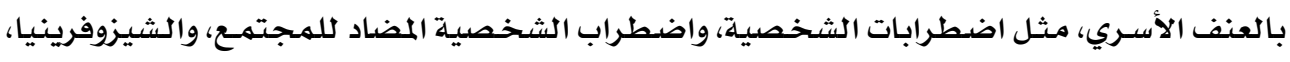

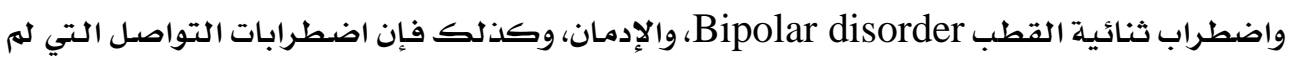

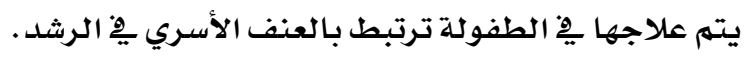
ثانيا: دراسات تناولت علاقة العنف الأسري وتوكيد الذات. يعرض الباحث ِِّ هذا المحور الدراسـات التي تناولت أساليب التربية الأسرية، والعنف الأسري من ناحية وعلاقتها بتوكيد الذات. تشير دراسة جارفينين وكينونين Järvinen \& Keinonen) (1988, إلى أن التفاعل بـين

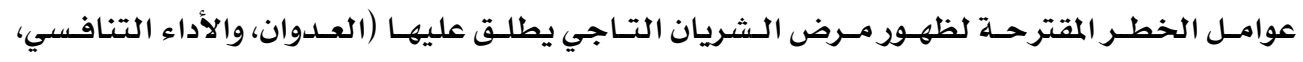


وتفـاعلات وعائيسة قلبيـة) .وتم دراسـة جس مراهقـا مـن الذكور، وقيـاس العلامـات المختلفـة للعـدوان مـن

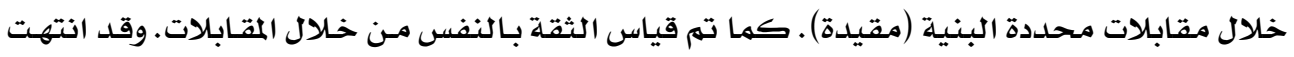

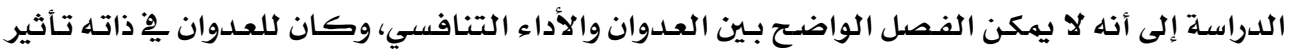

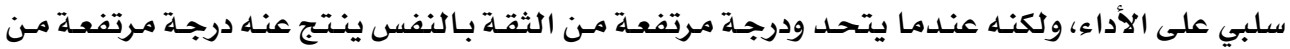

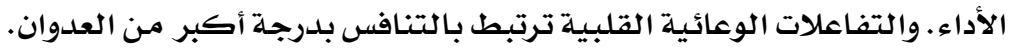

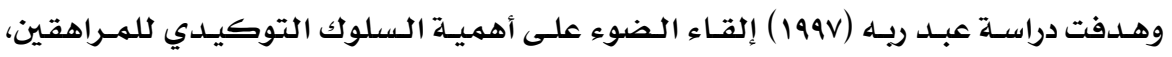

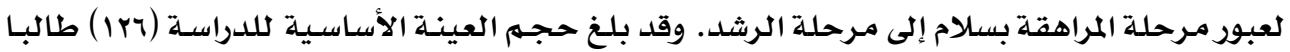

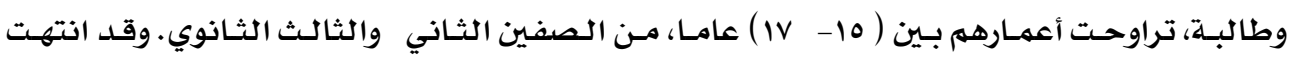

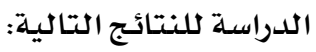

يوجد ارتباط سالب دال إحصائيا بين السلوك التوكيدي والمناخ الأسـرى المتمثل ِِّ القسوة،

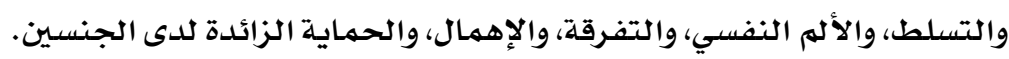

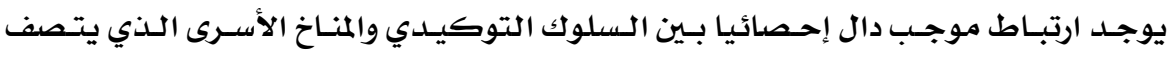
بالسواء لدى الجنسين.

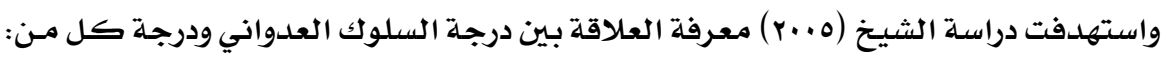

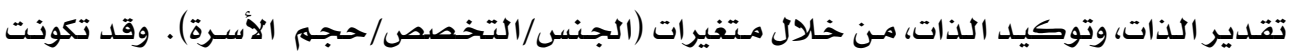

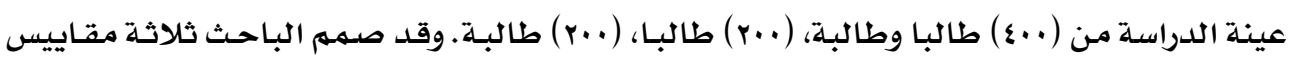

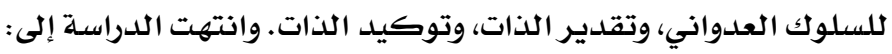

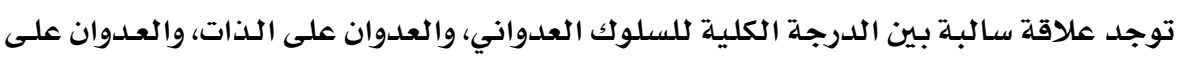
الآخرين ودرجة كل من تقدير الذات، وتوكيد الذاتل

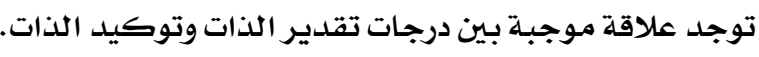

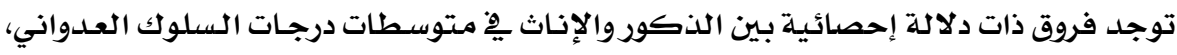

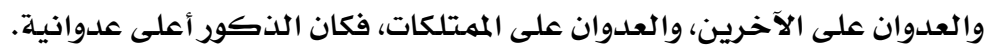

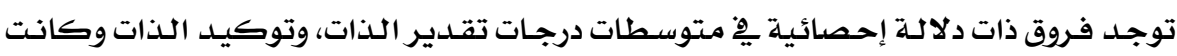
هذه الفروق لصالح الذكور.

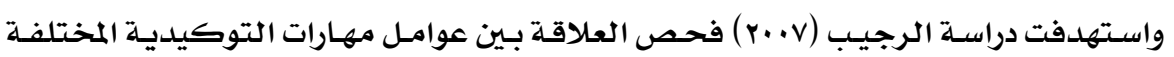

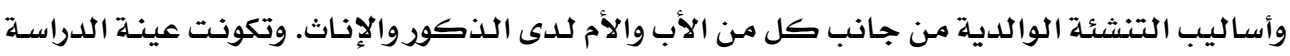

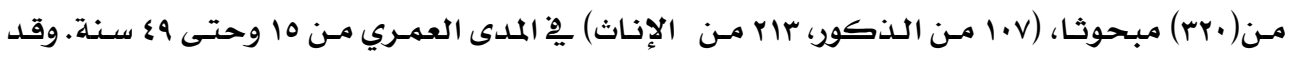

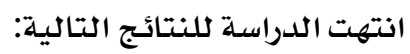

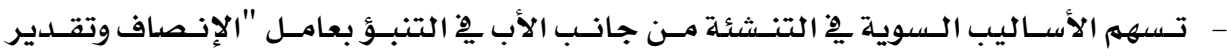
الآخرين" لدى الذكور. 


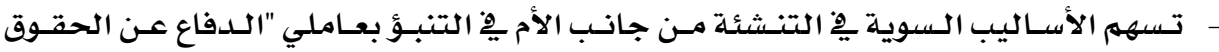

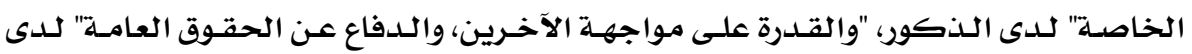
الإناث.

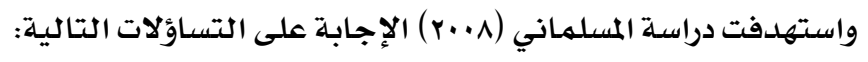

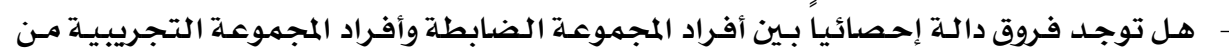

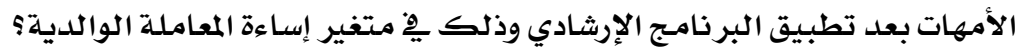

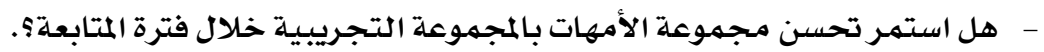

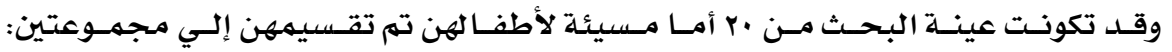

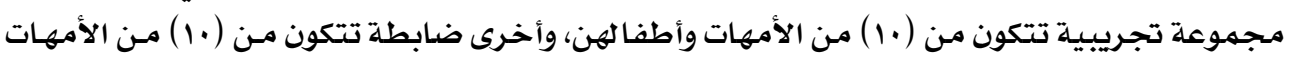

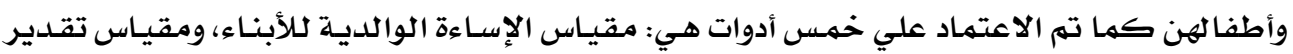

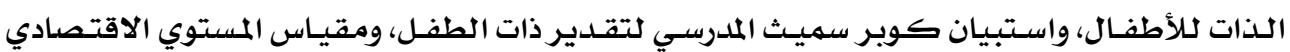

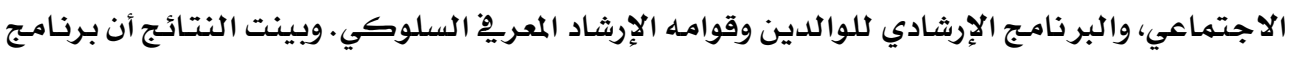

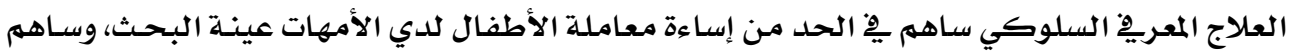

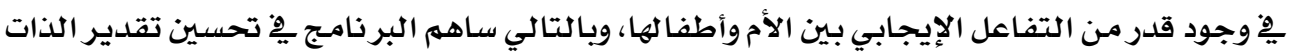

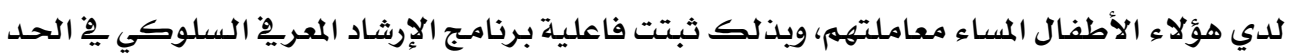
من الإساءة وتحسين تقدير الذات لدي الأطفال.

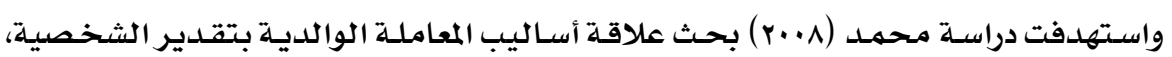

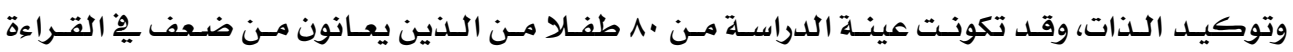

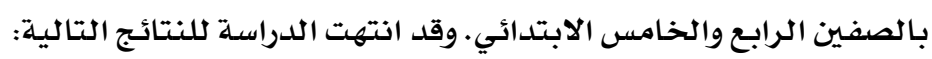

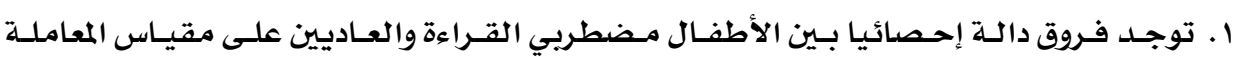

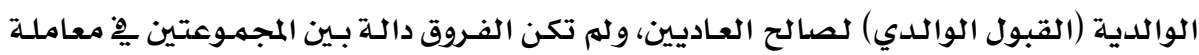

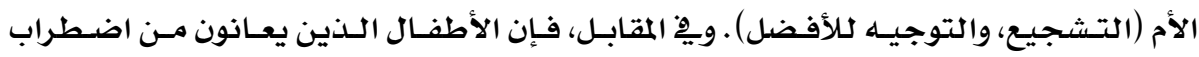

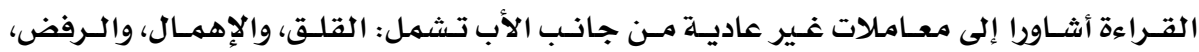

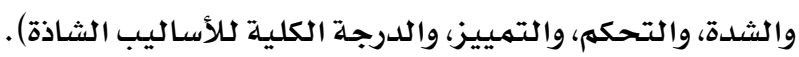

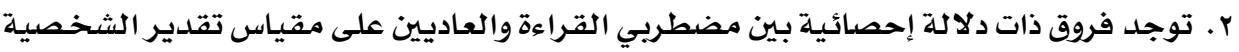

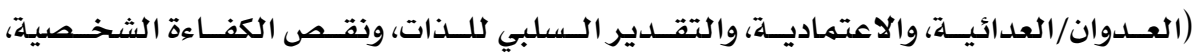

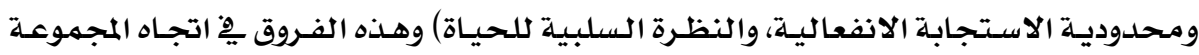

$$
\text { التي تعاني من اضطراب الانتباه. }
$$

r. توجد علاقة موجبة بين الإهمال، والرفض، والشدة من ناحية والتقدير السانداه الب للشخصية مـن

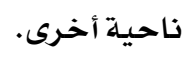

ع. توجد علاقـة موجبـة بـين الحمايـة الزائدة والاعتماديـة، ونقص تقدئدير الـذات، والقلق، والشعور

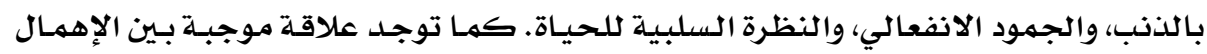




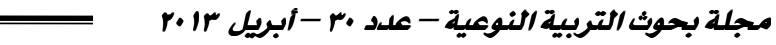

والـرفض وكـل مـن: محدوديـة الاستجابة الانفعاليـة، والنظـرة السالبـة للحيـاة. كمها توجـــ علاقة موجبة بين التحكم ونقص تقدير مندودير الذات.

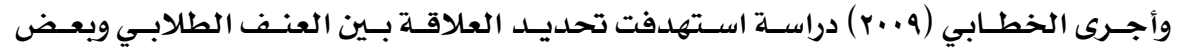

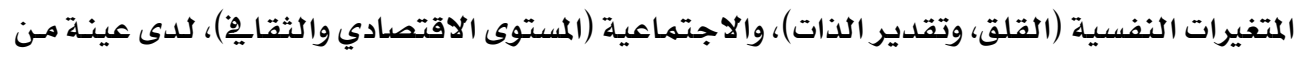

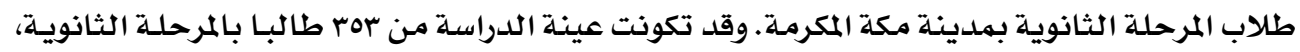

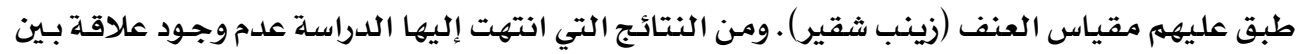

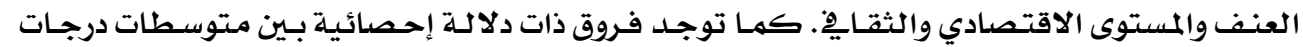
مرتفعي ومنخفض العنف وكل من القلق، وتقدير الذات.

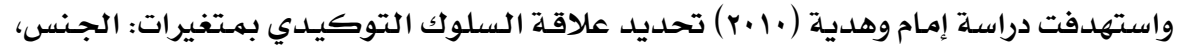

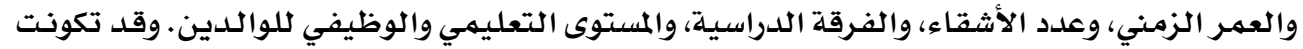

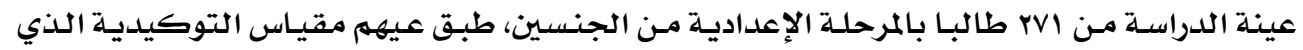

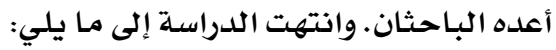

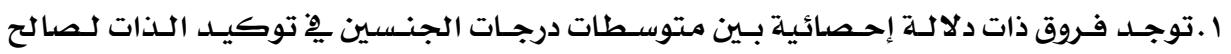

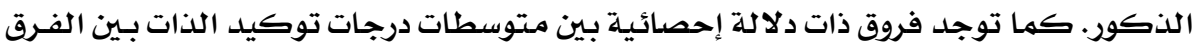

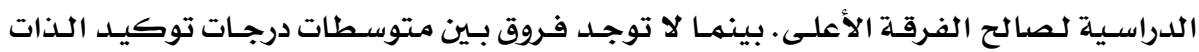

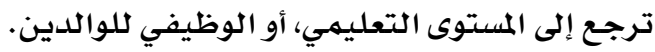

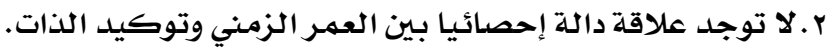

\section{يتضح من العرض السـابق ما يلي:}

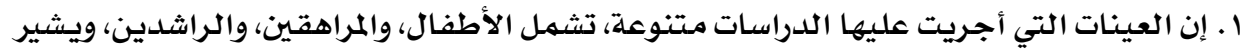
ذلك إلى أن العنف وإن كان يهارس ضد الأطفال والمراهقين إلا أن آثاره يمكن أن تمتـد لمرحلـة

$$
\text { الرشد. }
$$

r. يوجد ارتباط موجب دال إحصائيا بين توكيد الذات وأساليب التربية الأسرية السوية، وارتباط

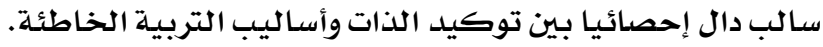

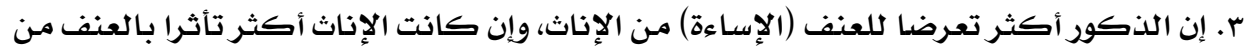

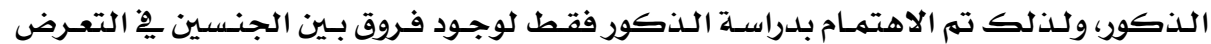
للعنف.

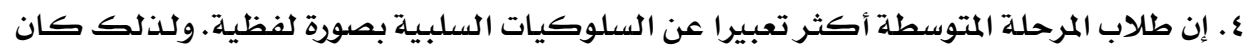
اختيار عينة الدراسة الحالية من هلذه المرحلة.

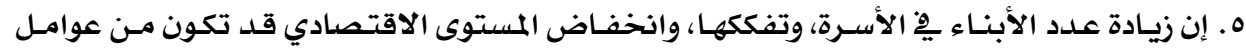

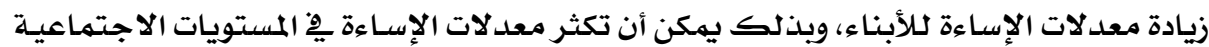


ا ـ لا توجد اختافات بين متوسطات درجـات العنف المدرك للدى الطلاب عينـة الدراسـة والمتوسط

$$
\text { الفرضي. }
$$

r ب يوجد ارتباط موجب دال إحصائيا بين العنف الأسري المدرك ودرجة العدوانية.

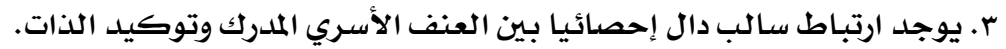

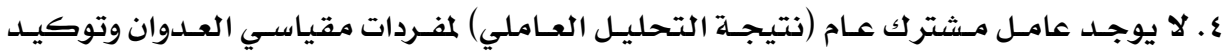

\section{إبراءات البحث: أبحات \\ أولاً: هنهج البحث: البحث:}

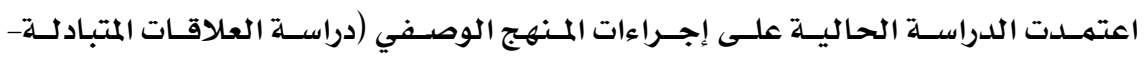

الدراسات الارتباطية).

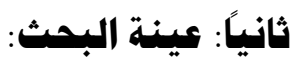

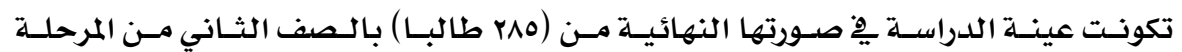

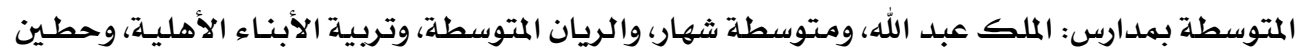

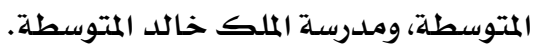

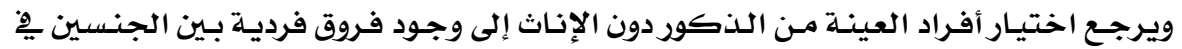

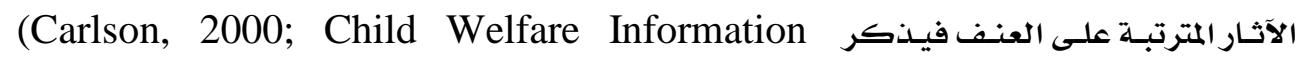

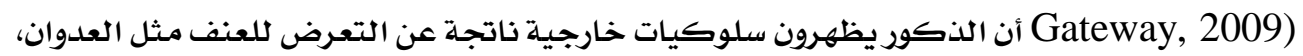
بينما تظهر الإناث سلوكيات داخلية بصورة أكبر مثل الاكتئاب أو الانسحاب.

وقد طبق البـاحثون على أفراد العينـة مقـاييس: العنـف الأسـري، والعـدوان، وتوكيد العيد الدذات.

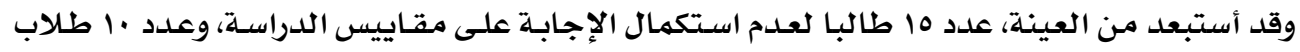

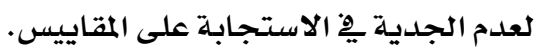

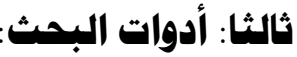

أولا: مقياس العنف الأسري:

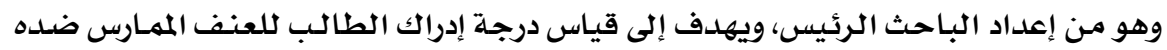

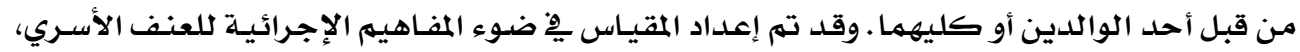

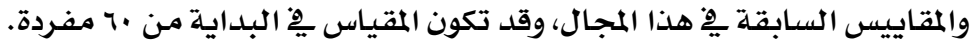

صدق المقياس:

تحقق الباحث من صدق المقياس بالطرق التالية:

IV. 


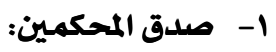

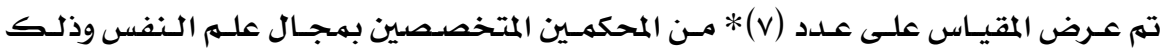

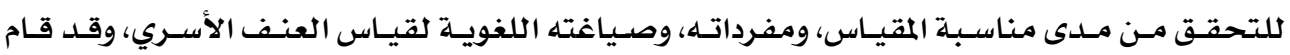

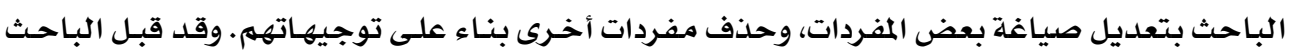

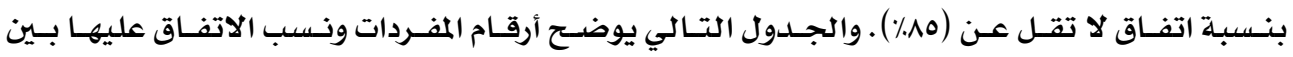

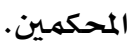

جدول (1)

نسب الاتفاق بين المحكمـين على مفردات مقياس العنف الأسـري

\begin{tabular}{|c|c|c|c|c|c|c|c|c|c|}
\hline نسبة الاتفاق & المفردة & نسبة الاتفاق & المفردة & نسبة الاتفاق & المفردة & نسبة الاتفاق & المفردة & |نسبة الاتفاق & المفردة \\
\hline$\% \wedge 7$ & 0 & $\% 1 \cdots$ & $\xi$ & $\%$ & $r$ & $\% 1 \cdots$ & $r$ & $\%$ & 1 \\
\hline$\% 1$. & 1. & $\% 1 \cdot \cdot$ & 9 & $\% \wedge 7$ & $\wedge$ & $\% 1 \cdots$ & $\checkmark$ & $\%$ & 7 \\
\hline$\% 1 .$. & 10 & $\%$ & $1 \xi$ & $\% \wedge 7$ & ir & $\% 1 .$. & ir & $\%$ & 11 \\
\hline$\% 1 \cdots$ & r. & $\%$ & 19 & $\%$ & 11 & $\%$ \% & iv & $\% 197$ & 17 \\
\hline$\%$ & ro & $\%$ & rq & $\% m$ & rr & $\% 1 \cdots$ & rr & $\%$ & ri \\
\hline$\%$ \% & r. & $\% 1 \cdots$ & $r q$ & $\%$ & $r A$ & $\% \wedge 7$ & rv & $\%$ & rq \\
\hline$\% 1 \cdots$ & ro & $\% \wedge 7$ & rq & $\%(M$ & rr & $\% 1 \cdots$ & rr & $\% 1 \cdots$ & ri \\
\hline$\%$.Ar & $\xi$ & $\% \wedge 9$ & rq & $\% 1 \cdots$ & rA & $\% 1 \cdots$ & $r v$ & $\% \cdots$ & rq \\
\hline$\%$ & \$0 & $\% \wedge 4$ & $\{\xi$ & $\% \wedge 7$ & st & $\%$ & $\varepsilon r$ & $\%$ & $\$ 1$ \\
\hline$\% 1 .$. & 0. & $\% \wedge 7$ & $\varepsilon 9$ & $\%$ & $\leqslant \wedge$ & $\% 1 .$. & sv & $\%$ & $\leqslant 7$ \\
\hline$\%$ & 00 & $\%$ & $0\}$ & $\%$ & or & $\% \wedge 7$ & or & $\%$ & 01 \\
\hline$\%$ \% & 7. & $\%$ & $\Delta 9$ & $\% \wedge 4$ & $\Delta \Lambda$ & $\% 1 \cdots$ & or & $\%$ & 07 \\
\hline
\end{tabular}

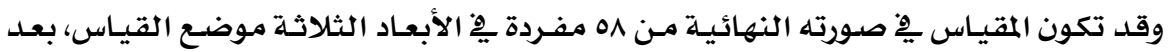

حذف المفردتين التي تحمل أرقام: بr، سب والتي لم تحصل على نسبـة الاتفاق المحددة. يعطى الطالب يڤ

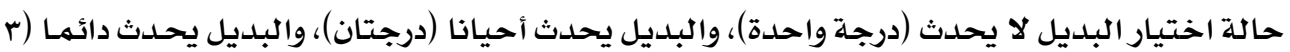
درجات) يخ حالة المفردات التي يخ اتجاه العنف، ويتم عكس التقدير يِ حالة المفردات عكس الاتجاه.

r- الاتساق الداخلي:

قـام البـاحـث بحسـاب معـامـلات الارتبـاط بـين مفـردات كـل بعـد والدرجـة الكليـة على البعـد كمؤشر عن صدق مفردات المقياس، والجدول التالي يوضـح هذه النتائج.

" أ.د. أحمد عبد الرحمن عثمان أ.د. محمد مصطفى الديب د. حمدان محمود فضة د. ــ محمد محمود سعودي د مدحت

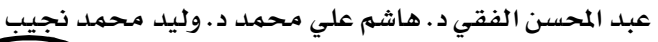




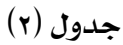

توزيـع مفردات مقياس العنف الأسـري ومعامـلات ارتبـاط المفردات بالدرجة الكلية للأبعاد

\begin{tabular}{|c|c|c|c|c|c|c|c|c|c|c|}
\hline معامل الارتباط & المفردات & معامل الارتباط & المفردات & معامل الارتباط & المفردات & معامل الارتباط & المفردات & معامل الارتباط & |المفردات & الأبعاد \\
\hline , OrI & $1 \varepsilon$ & $\cdot, 70$. & 11 & $\cdot, 7.1$ & $\wedge$ & וTוT & 0 & $\cdot, 094$ & $r$ & \multirow{3}{*}{ الجسمية الإساءة } \\
\hline •, 7rq & ra & •, 798 & rq & $\cdot, 017$ & rr & $\cdot, 001$ & r. & $\cdot, 094$ & iv & \\
\hline & & •, VYT & $\$ 1$ & - ora & rA & $\cdot, 7 \vee 7$ & ro & r & rr & \\
\hline •, YAl & ir & •, orq & 1. & •, 711 & $v$ & $\cdot, v+7$ & $\varepsilon$ & rוT, & 1 & \multirow{9}{*}{ الإساءة } \\
\hline •, Vrr & $r A$ & $\cdot, 7.1$ & ro & $\cdot, 7 \leqslant 0$ & rr & , OrI & 19 & $\cdot, 7.9$ & 17 & \\
\hline •, 7 & \&r & - , $1 \leqslant 7$ & $\xi$. & •, $7 \leqslant V$ & rv & •, 794 & $r \varepsilon$ & $\cdot, 0 \leqslant \wedge$ & r & \\
\hline •, YA & $\varepsilon \wedge$ & • & sv & $\cdot, 0 \wedge \varepsilon$ & $\Sigma 7$ & $\cdot, 099$ & \$o & •, orr & $\llbracket \varepsilon$ & \\
\hline$\cdot, 019$ & or & - oro & or & , Ory & 01 & - , 798 & 0. & שr Tr T & $\leqslant 9$ & \\
\hline$\cdot, 7 \cdot 7$ & $\Delta A$ & $\cdot, 007$ & or & $\cdot, 0 \leqslant \wedge$ & 07 & •,07r & $\Delta 0$ & $\cdot, 0.0$ & $\Delta \varepsilon$ & \\
\hline$\cdot, r \cdot q$ & 10 & •, 717 & ir & •, 7.4 & 9 & •, 707 & 7 & •, riv & $r$ & \\
\hline$\cdot, 010$ & $r$. & •, OVA & rr & -, OVy & rE & •, orq & M & $\cdot, 0 \leqslant 7$ & in & \\
\hline & & $\cdot, 70$ & sr & , 77. & rq & ודו, & rq & $\cdot, 018$ & rr & \\
\hline
\end{tabular}

وجميـع معامـلات الارتباط السـابقة موجبـة، ودالة عند مستوى 1 .,.

ثبات المقياس :

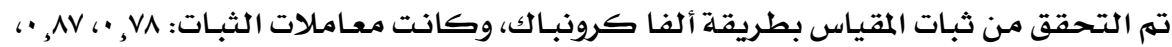

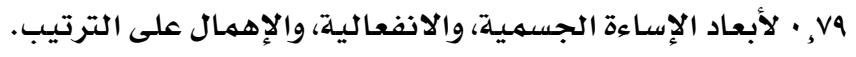

ثانيا: مقياس العدوان

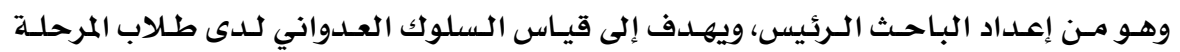

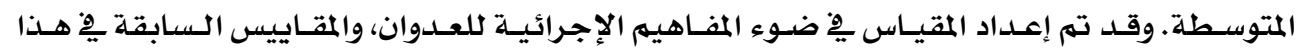

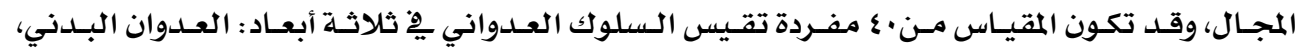

والعدوان اللفظي، ومهيئات العدوان.

صدق المقياس:

تحقق الباحث من صدق المقياس بالطرق التالية:

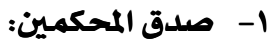

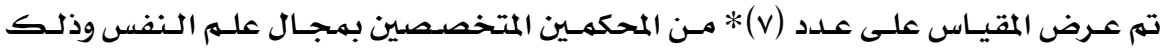

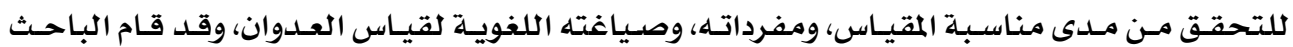

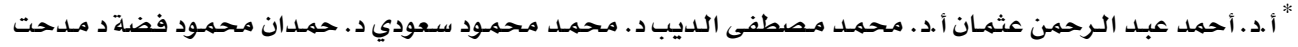

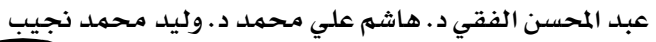




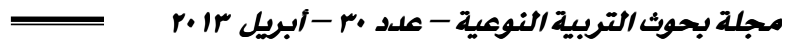

بتعديل صياغة بعض المفردات بناء على توجيهاتهم. وقد قبل الباحث بنسبـة اتفـاق لا تقل عن (10٪).

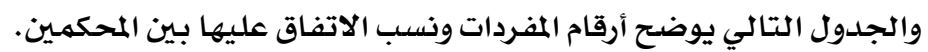

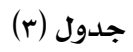

نسب الاتفاق بين المحكمـين على مفردات مقياس العدوان

\begin{tabular}{|c|c|c|c|c|c|c|c|c|c|}
\hline نسبة الاتفاق & |المفردة & نسبة الاتفاق & المفردة & نسبة الاتفاق & المفردة & نسبة الاتفاق & المفردة & نسبة الاتفاق & |المفردة \\
\hline$\% 1 . \cdot$ & 0 & $\% 1 .$. & $\varepsilon$ & $\% 1 .$. & $r$ & $\% 1 .$. & $r$ & $\% 1$. & 1 \\
\hline$\% \wedge 9$ & 1. & $\% 1 \cdots$ & 9 & $\% 1 \cdots$ & $\wedge$ & $\% \wedge 7$ & $\checkmark$ & $\% 1$. & 7 \\
\hline$\% 1 \cdots$ & 10 & $\%$ & $1 \varepsilon$ & $\%$ & ir & $\%$ & ir & $\%$ & 11 \\
\hline$\%$ & r. & $\%$ & 19 & $\%$ & IN & $\% \wedge 7$ & iv & $\%$ & 17 \\
\hline$\% 1 \cdots$ & ro & $\%$ & $r \xi$ & $\% 1 \cdots$ & rr & $\% 1 \cdots$ & rr & $\% 1 .$. & rI \\
\hline$\% \wedge 7$ & $r \cdot$ & $\%$ & rq & $\%$ & $r \wedge$ & $\% \wedge 7$ & $r V$ & $\%$ & rq \\
\hline$\% 1 \cdots$ & ro & $\%$ 1.19 & $r \varepsilon$ & $\%$ & rr & $\%$ & rr & $\%$ & rI \\
\hline$\% 1 \cdots$ & ६. & $\%$ & rq & $\% 1 \cdots$ & rA & $\% 1 \cdots$ & rv & $\% 1 \cdots$ & rq \\
\hline
\end{tabular}

الاتساق الداخلي:

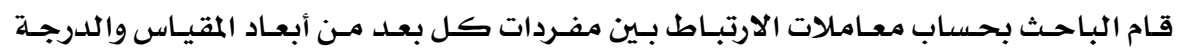

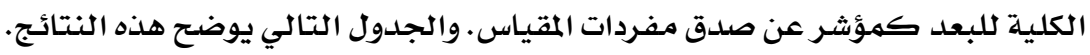

$$
\text { جدول (ء) }
$$

\begin{tabular}{|c|c|c|c|c|c|c|c|c|c|c|}
\hline الارتباط & $A$ & الارتباط & p & الارتباط & a & الارتباط & A & الارتباط & ? & البعد \\
\hline$\cdot, 09$ & ir & $\cdot, \leqslant 9$ & 1. & •, & $r$ & $\cdot, \leqslant 9$ & $\varepsilon$ & $\cdot, 09$ & 1 & \multirow{3}{*}{ البلدني } \\
\hline$\cdot, 00$ & rA & $\cdot, r \varepsilon$ & ro & $\cdot, 07$ & rr & •, हr & 19 & •, हr & 17 & \\
\hline & & •, rA & $r q$ & •, हr & $r v$ & $\cdot, 00$ & rz & $\cdot, 09$ & ו & \\
\hline •, ro & $1 \varepsilon$ & •, & 11 & $\cdot, \$ 0$ & $\wedge$ & • & 0 & •, Or & $r$ & \multirow{3}{*}{ اللفظي } \\
\hline •, Zr & rq & $\cdot, 00$ & $r q$ & •, \$1 & $r r$ & • & $r$. & $\cdot, \sum \wedge$ & iv & \\
\hline & & & & & & •, $₹ 9$ & ro & $\cdot, \mathrm{rA}$ & rr & \\
\hline$\cdot, 09$ & 10 & $\cdot, 09$ & ir & • & 9 & •, ه & 9 & •, हr & $r$ & \multirow{3}{*}{ العديئات } \\
\hline •, rv & $r$. & $\cdot, 07$ & $r v$ & •, हr & rE & •, हr & $M$ & $\cdot, \mathrm{rq}$ & IA & \\
\hline & & •, rA & \&. & $\cdot, \$ 9$ & ra & • & rq & |हा & $r r$ & \\
\hline
\end{tabular}

توزيـع مفردات مقياس العددوان ومعامـلات ارتباط المفردات بـالدرجة الكلية لكلأبعاد

وجميع معاملات الارتباط السابقة موجبة ودالة 
ثبات المقياس :

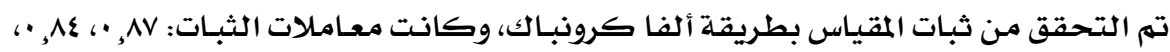

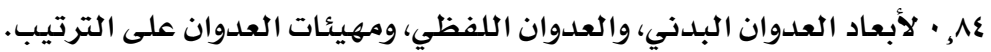

ثالثا: مقياس توكيد الذات

وهو مـن إعـداد الباحـث الـرئيس، ويهـدف إلى قيـاس درجـة توكيد الـذات لدى طلاب المرحلـة

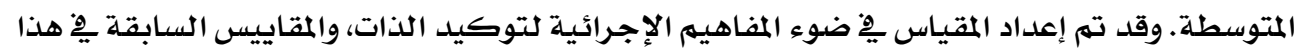

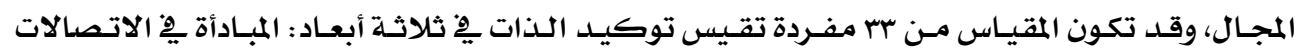

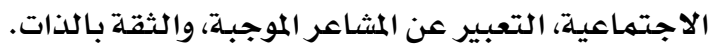

صدق المقياس:

تحقق الباحث من صدق المقياس بالطرق التالية:

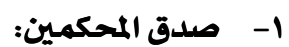

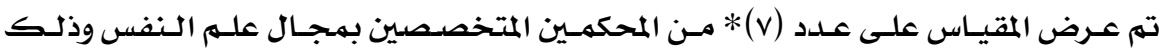

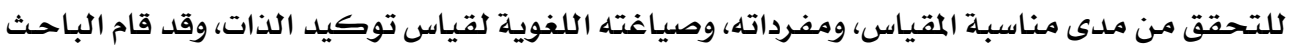

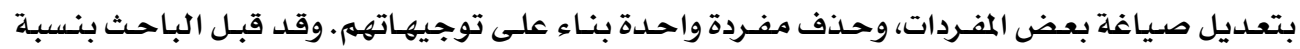

اتفاق لا تقل عن (10٪) . والجدول التالي يوضـح أرقام المفردات ونسب الاتفاق عليها بين المحكمين.

جدول (0) (0)

نسب الاتفاق بـين المحكمـين على مفردات مقيـاس توكيد الذات

\begin{tabular}{|c|c|c|c|c|c|c|c|c|c|}
\hline نسبة الاتثاق & المثردة & نسبة الاتفاق & المثردة & نسبة الاتفاق & المثردة & نسبة الاتفاق & المفردة & نسبة الاتثاق & المفردة \\
\hline$\% 10$ & 0 & $\% 1 \cdots$ & $\varepsilon$ & $\%$.А & $r$ & $\% 10$ & $r$ & $\% 1 \cdots$ & 1 \\
\hline$\% 1$. & 1. & $\% 1 \cdots$ & 9 & $\% 1+$. & $\wedge$ & $\% 1 \cdots$ & v & $\% 1+$. & 7 \\
\hline$\% 1 \cdots$ & 10 & $\% 1 \cdots$ & 18 & $\% 1+$ & ir & $\% 1+$ & ir & $\% 1+$ & 11 \\
\hline$\% 1.0$ & r. & $\% 1 \cdots$ & 19 & $\% 1 \cdots$ & 11 & $\% \wedge 7$ & iv & $\% 1 \cdots$ & 17 \\
\hline$\% 1$ & ro & $\% 1$. & rz & $\% \wedge 7$ & rr & $\% 1 \cdots$ & rr & $\% 1 \cdots$ & M \\
\hline \multirow[t]{2}{*}{$\% 1$} & r. & $\% \wedge 7$ & rq & $\% 1+$. & $r \Lambda$ & $\% 1+$ & rv & $\% 1 \cdots$ & ry \\
\hline & & & & $\% 1+$. & rr & $\% 1+$. & rr & $\% 1+$ & M \\
\hline
\end{tabular}

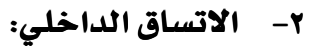

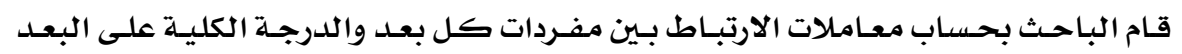

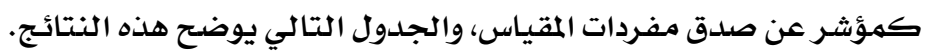

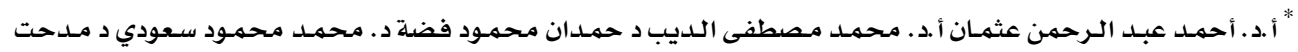

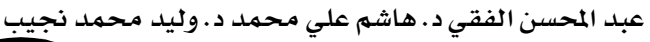




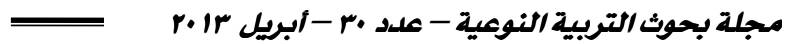

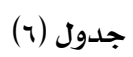

توزيـع مفردات مقياس توكيد الذات ومعاملات ارتبـاط المفردات بالدرجـة الكلية للأبعاد

\begin{tabular}{|c|c|c|c|c|c|c|c|c|c|c|}
\hline معامل & المفردات & معامل & المفردات & معامل & المفردات & معامل & المفردات & معامل & |المفردات & الأبعاد \\
\hline$\cdot$, , 991 & ir & $\cdot 01 \varepsilon$ & 1. & •, orr & $v$ & •, ¿VY & $\varepsilon$ & $\cdot, 011$ & 1 & \multirow{3}{*}{ المبادأة في الاتصالات } \\
\hline •, OYY & rA & - ovo & ro & $\cdot, 00$. & $r r$ & •, OOr & 19 & $\cdot$, • ¿q४ & 17 & \\
\hline & & & & & & & & $\cdot, 00 \xi$ & rI & \\
\hline$\cdot, \Sigma 9$. & $1 \xi$ & •, OAV & 11 & •, 800 & $\wedge$ & •, Orr & 0 & , OrA & $r$ & \multirow{3}{*}{ التعبير عن المشاعر } \\
\hline , ovy & rq & •, 074 & rq & - ora & rr & •, $\{\leqslant \wedge$ & r. & •, \$0. & iv & \\
\hline & & & & & & & & •, Оहा & rr & \\
\hline$\cdot, 071$ & 10 & $\cdot, \$ 90$ & ir & $\cdot, 071$ & 9 & •, Ora & 7 & $\cdot, 0 \leqslant V$ & $r$ & \multirow[t]{2}{*}{ الثقة بالذات } \\
\hline •, "r. & r. & - ov. & $r v$ & & Y & •, OYE & r & $\cdot, 0 \leqslant 1$ & 11 & \\
\hline
\end{tabular}

ثبات المقياس :

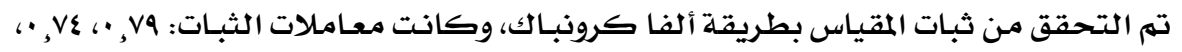

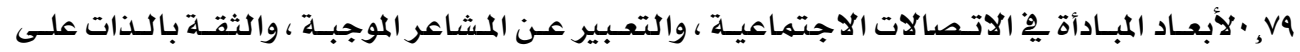
الترتيب.

\section{نتائج فروض البحث:}

تتائج الفرض الأول:

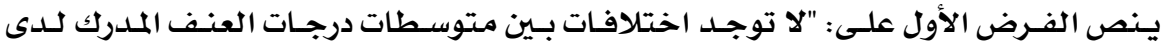

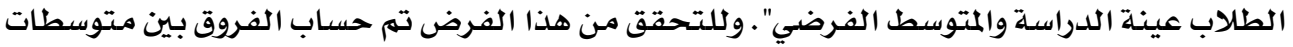

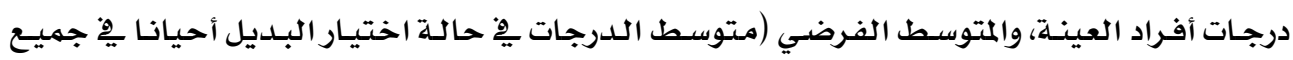

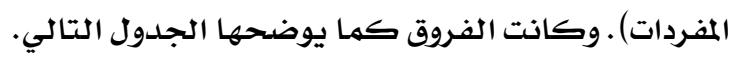

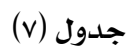

\begin{tabular}{|c|c|c|c|c|c|}
\hline \multirow{2}{*}{ مستوى } & \multirow[t]{2}{*}{ قيمة ت } & \multirow{2}{*}{ الانحرافات المعيارية } & \multicolumn{2}{|c|}{ المتوسطات } & \multirow[t]{2}{*}{ البيان } \\
\hline & & & العينة & الفرضي & \\
\hline$\because \cdot 1$ & $\varepsilon r, \cdot \eta$ & $r, r$ & 11,0 & rA & الإساءة الجسمية \\
\hline$\because+1$ & gr, rr & $v, \Lambda$ & $\mathrm{ra}, \mathrm{or}$ & 7. & الإساءة الانفعالية \\
\hline$\because \cdot 1$ & $r \xi, r$ & $\xi, r \xi$ & $19, \cdot r$ & rA & الإهمال \\
\hline
\end{tabular}

الفروق بين متوسطات درجات العنف المدررك لدى الطلاب عينـة الدراسـة والمتوسط الفرضي 


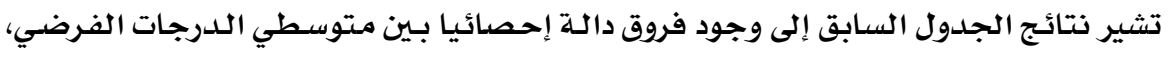

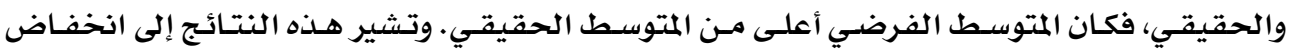

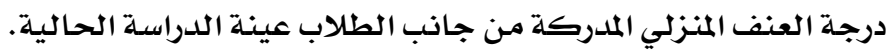

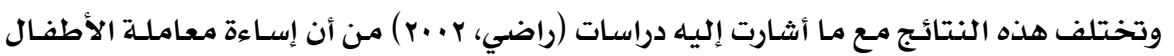

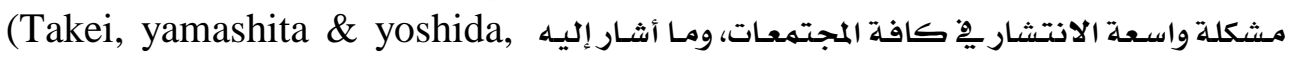

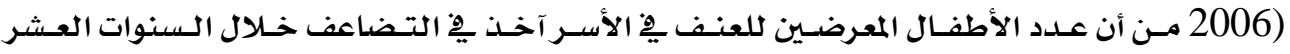
الأخيرة.

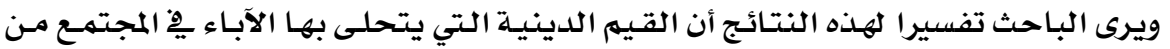

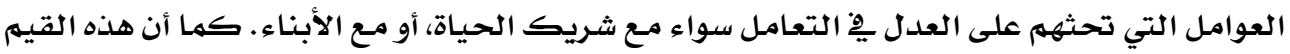

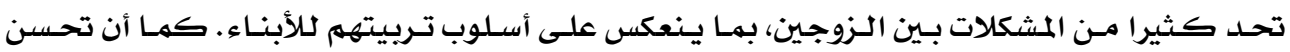

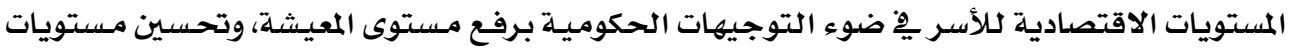

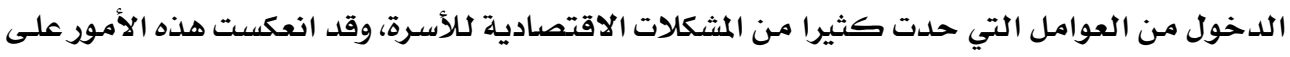
استمـرار الأسرة وتماسكها. ويعد ارتفاع المستوى التعليمي للآباء ِِّ الوقت الحاضر، وتعدد مصدادر المعلومات حول الأسرة

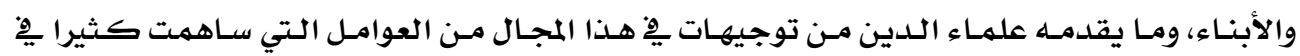

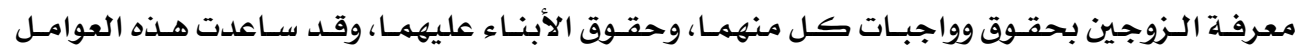
مجتمعة يِّ الحد من مشكلة العنف يِّ الأسرة.

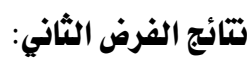

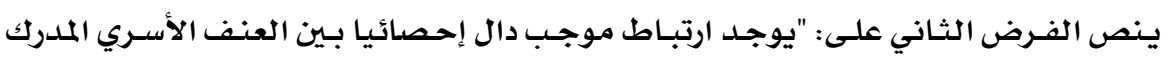

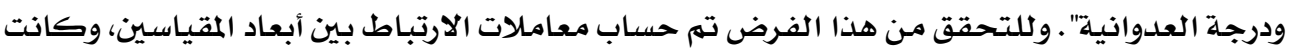

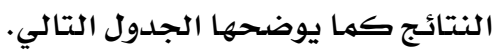

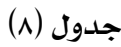

معاملات الارتبـاط بين العنف المدرك من الأبناء ودرجة العدوانية

\begin{tabular}{|c|c|c|c|c|}
\hline \multicolumn{3}{|c|}{ مقياس العدوان } & \multirow{2}{*}{\multicolumn{2}{|c|}{ البيان }} \\
\hline مهيئات العدوان & العدوان اللفظي & العدوان البلدي & & \\
\hline$\cdot, 11$ & $\dot{x} \cdot, 1 r$ & $\cdot, 0$ & الإساءة الجسمية & \multirow{3}{*}{ مقياس العنف الأسري } \\
\hline$\cdot, \cdot \xi$ & $\bullet, \cdot r$ & $\cdot, \cdot 1$ & الإساءة الانفعالية & \\
\hline$\cdot, 11$ & $\cdot, \cdot 9$ & 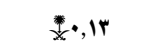 & الإهمال & \\
\hline
\end{tabular}

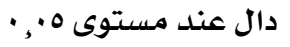

وتشير نتائج هـذا الفـرض إلى عدم وجـود علاقـات دالـة بـين العنف الأسـري بأبعـاده، والعـدوان

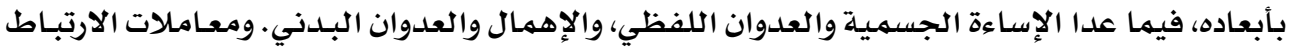




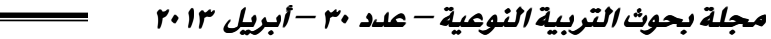

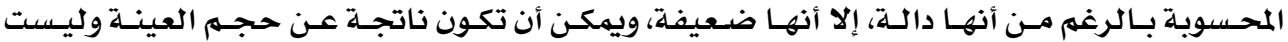
جوهريـة.

وتختلف النتائج السـابقة مـع توصلت إليـه الدراسـات العربيـة مـن أن إدراك العنف يِّ المنـزل

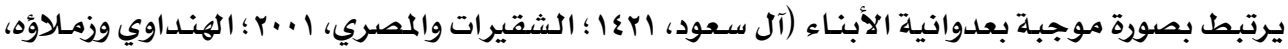

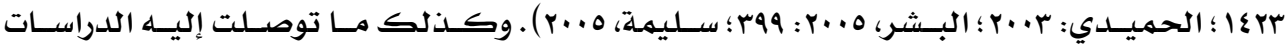

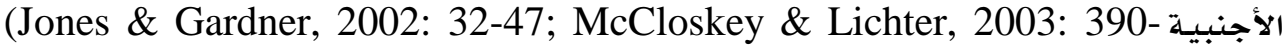
412; Norman \& Ryan, 2008: 561-566; Shorey et al., 2010; Kaufman et al., 2011: 2042-2072).

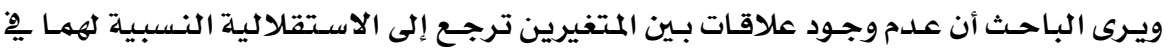

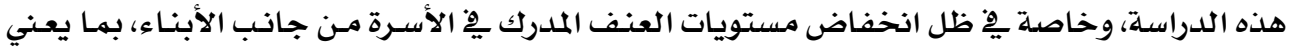

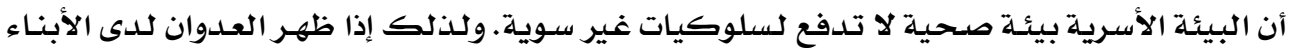

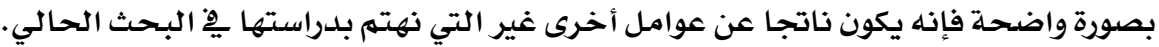

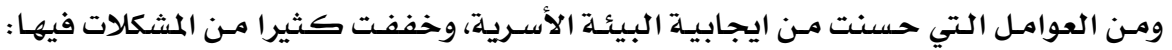

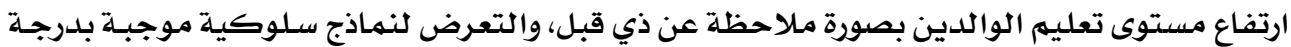

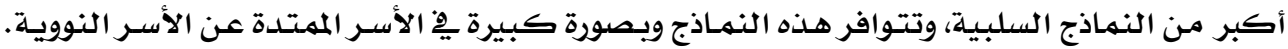

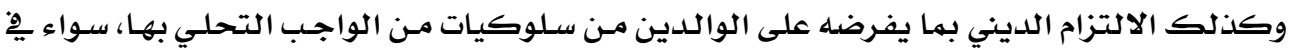

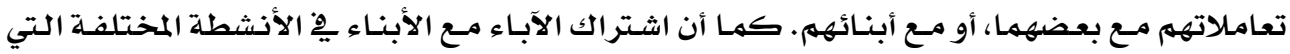

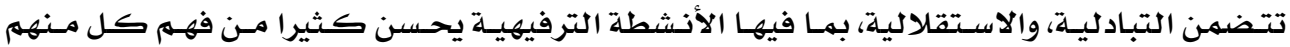

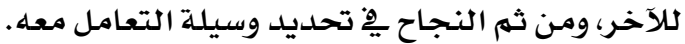

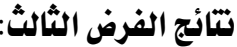

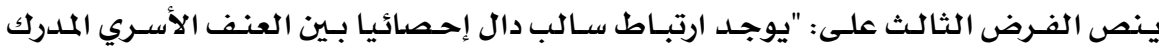

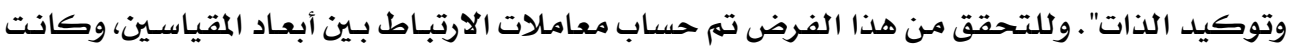

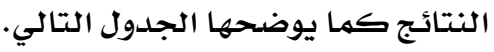

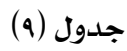

معاملات الارتباط بين العنف المدرك مـن الأبناء ودرجة توكيد الذات

\begin{tabular}{|c|c|c|c|c|}
\hline \multicolumn{3}{|c|}{ مقياس توكيد الذات } & \multirow{2}{*}{\multicolumn{2}{|c|}{ البييان }} \\
\hline الثقة بالذات & التعبير عن المشاعر الموجبة & المبادأة في الاتصالات الاجتماعية & & \\
\hline$\cdot, \cdot 0$ & $\bullet,+1$ & $\bullet, \bullet \xi$ & الإساءة الجسمية & مقياس العنف \\
\hline$\bullet, \bullet r$ & $\pm \cdot, 14$ & $\bullet, \bullet$ & الإساءة الاثفعالية & الأسري \\
\hline$\cdot,+1$ & $\bullet,+1$ & $\cdot, \cdot 1$ & الإهمال & \\
\hline
\end{tabular}

دال عند مستوى 0 •., 


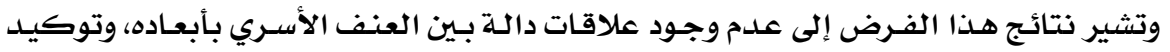

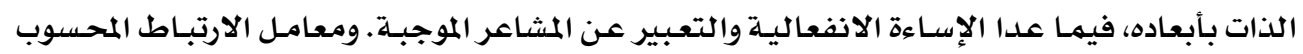

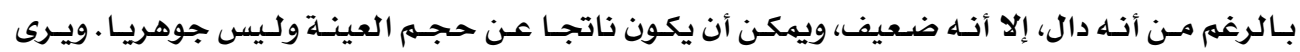

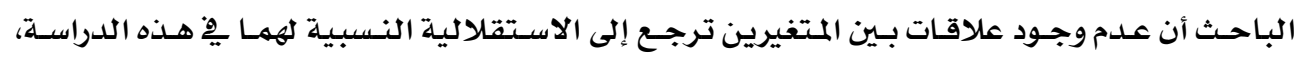

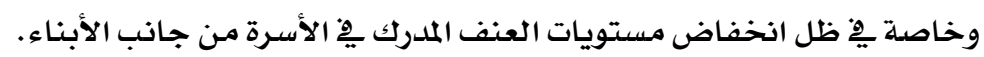

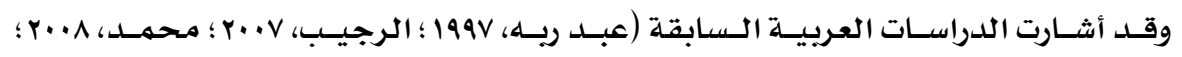

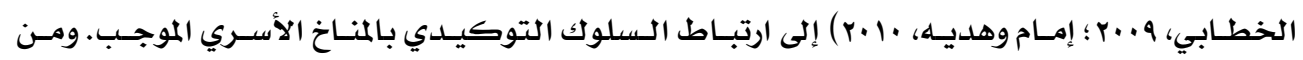

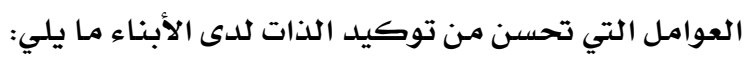

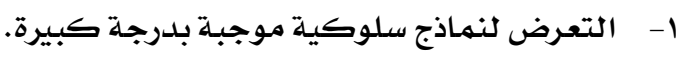

$$
\text { r - r التقدير المرتفع للذات. }
$$

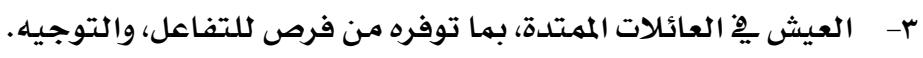

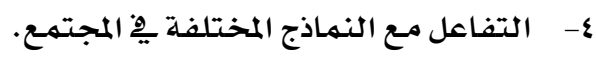

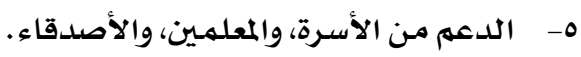

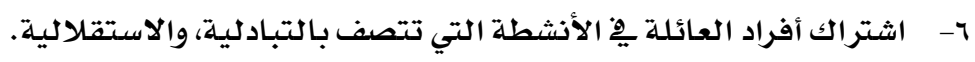

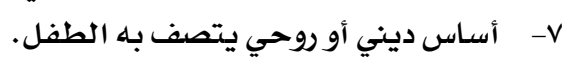

\section{تقائج الفرض الرابع:}

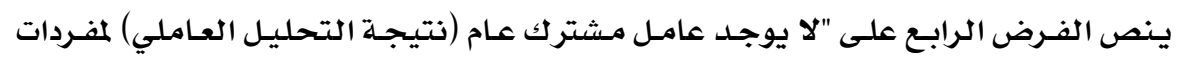

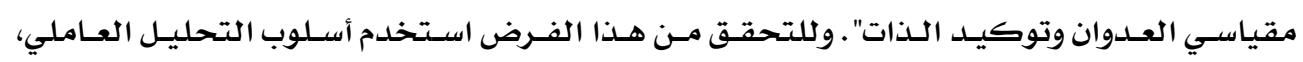

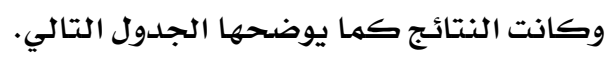

\begin{tabular}{|c|c|c|c|}
\hline العامل الثاني & العامل الأول & 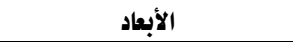 & ค \\
\hline & $\bullet, 9$. & العدوان البدني & 1 \\
\hline & $\cdot, 94$ & العدوان البدني & $r$ \\
\hline & $\cdot, \wedge \wedge$ & العلدوان البلدي & $r$ \\
\hline •,94 & & المبادأة في الاتصالات الاجتماعية & $\varepsilon$ \\
\hline$\cdot, 9 \xi$ & & التعبير عن المشاعر الموجبة & 0 \\
\hline$\cdot, 19$ & & الثقة بالذات & 1 \\
\hline$r, r \wedge$ & $r, 79$ & الجزر الكامن & \\
\hline$r v, q r$ & $\llbracket \xi, \wedge r$ & التباين & \\
\hline
\end{tabular}

$$
\text { جدول (1.) (1) }
$$

قيم تشبعات الأبعاد على عواملها 


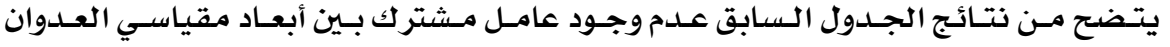

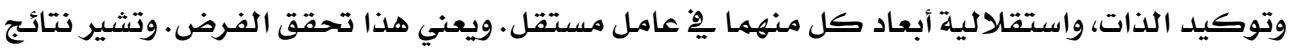

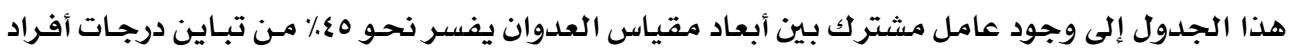

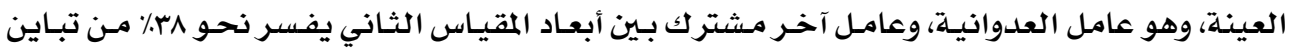

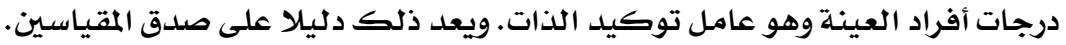

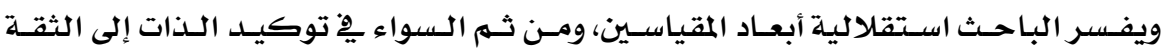

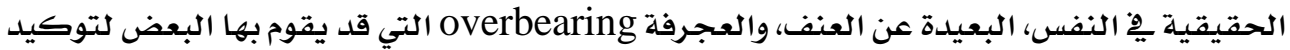

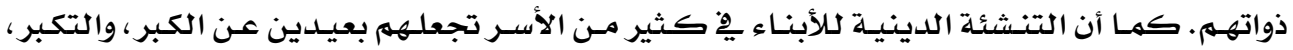

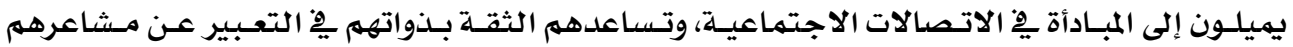

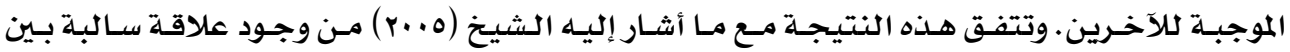

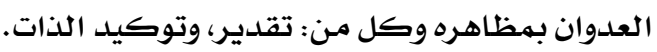

\section{التوصيات والتطبيقات تربوية:}

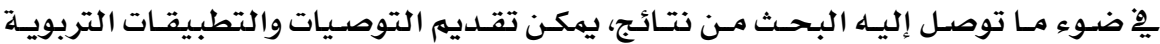

ا. استمرار الاهتمام بما يقدم يِّ المدارس من معلومات دينية واجتهاعية عن الأسرة.

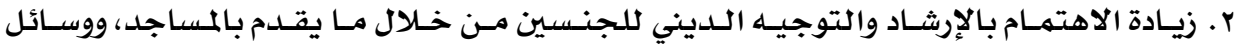

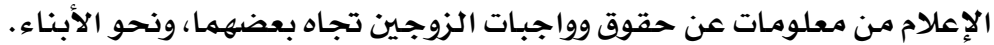

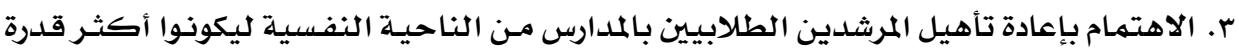

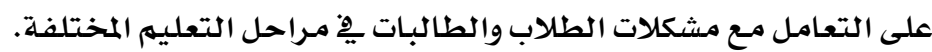

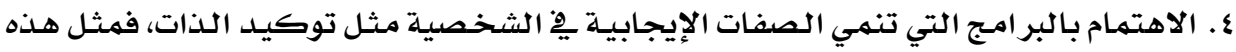

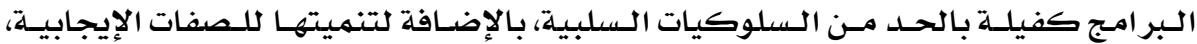
فالشخصية كل متكامل.

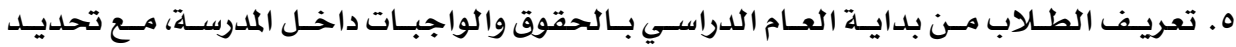

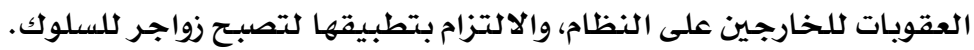
1. الاهتمام بالطلاب ذوي المشكلات الخاصدة ومساعدتهم نفسيا واجتماعيا العيا على مواجهتها. 


\section{قائمة المراجع:}

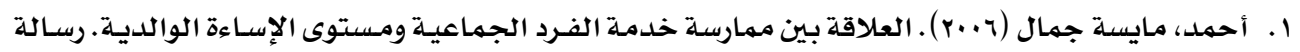

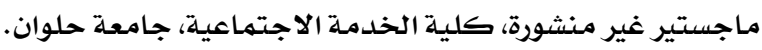

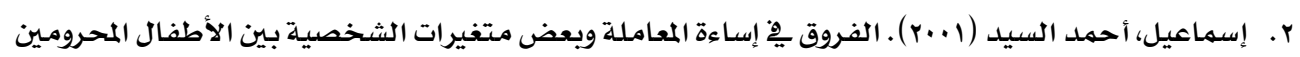

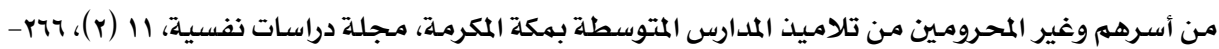
. rVa

r. آل سعود، منيرة بنت عبد الرحمن (1) اهـ). إيذاء الأطفال أنواعه وأسبابه وخصائص المتعرضـين لهـ: دراسـة

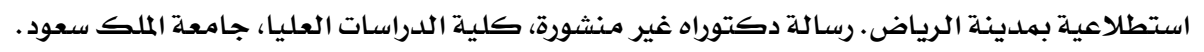

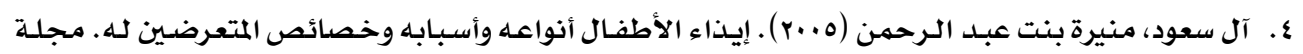

$$
\text { مركز الدراسات والبحوث التربوية، الرياض. }
$$

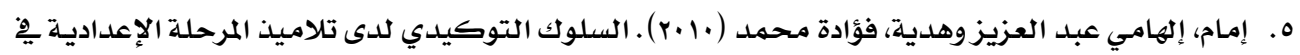

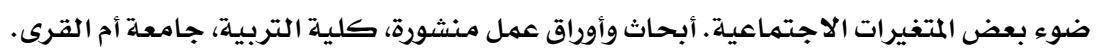

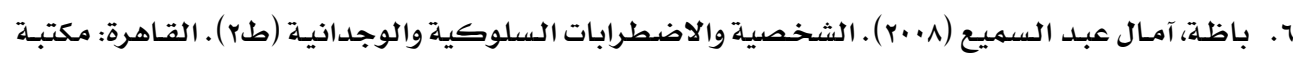
الأنجلو المصرية.

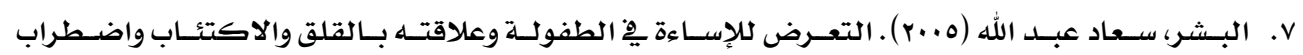

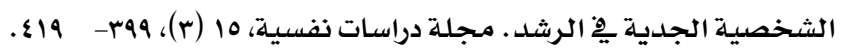

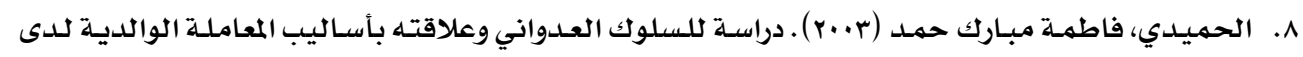

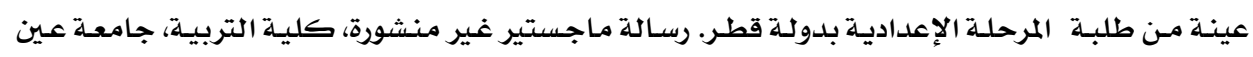
شمس.

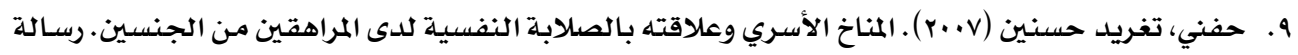

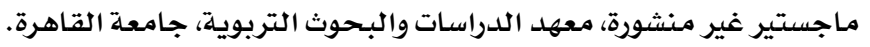

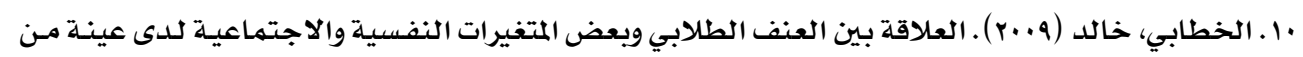

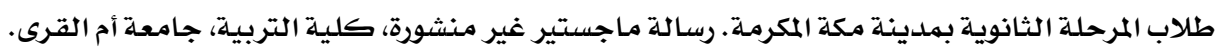

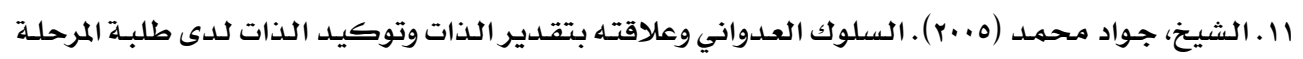

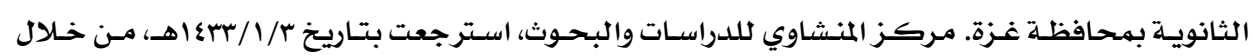

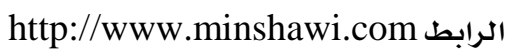

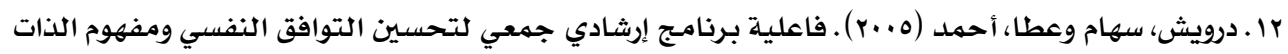

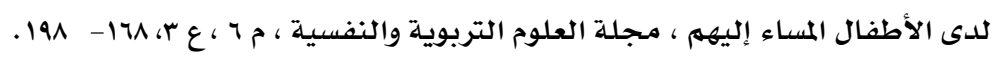

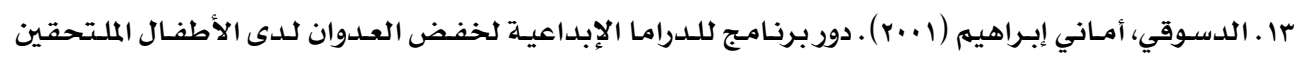

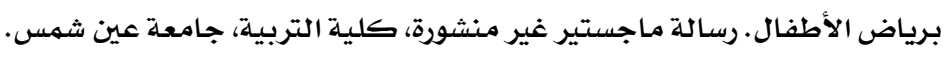

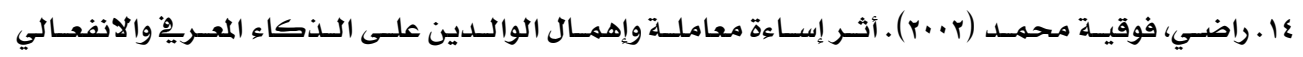

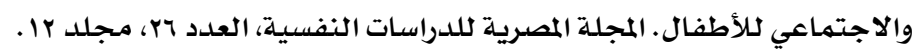




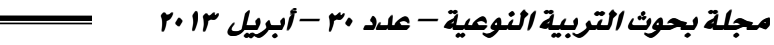

1 ـ الرجيب، يوسف على فهد (r. . . . . مهارات توكيد الذات وعلاقتها بأساليب التنشئسة الوالدية. مجلة دراسـات الطفولة، عدد يناير.

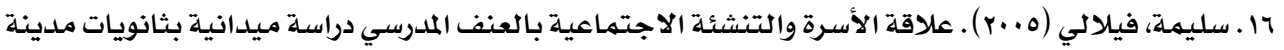
باتنة. رسالة ماجستير غير منشورة، جامعة الحاج لخضر، الجزائر.

Vا ـ السيـ، فؤاد البهـي وعبــ الـرحمن، سـعد (1999) . علهم الـنفس الاجتهـاعي رؤيـة معاصـرة. القـاهرة: دار الفكر

العربي.

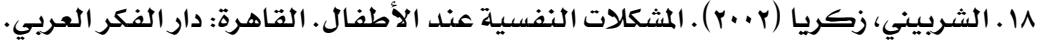

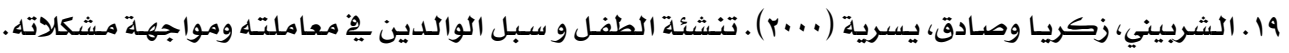
القاهرة: دار الفكر العربي.

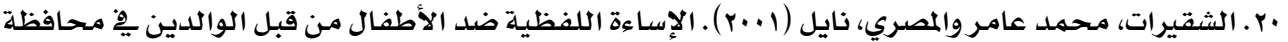

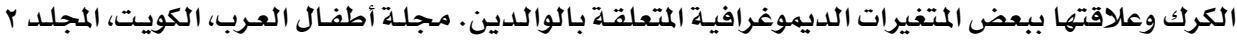

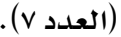

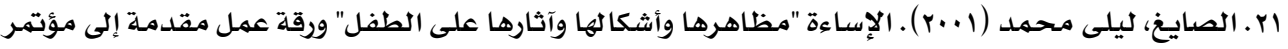
نحو بيئكة خالية مـن العنف لكلأطفال العرب. مـركز حماية الطفل، الأردن، عمان، ا - با. r. . الصبـان، عبير بنت محمد (11 +r). خبر ات العنف الأسـري لدى عينـة من طالبـات المرحلـة المتوسطة والثانويـة هِ مدارس التعليهم العام بـالعاصمة المقدسة. مجلـة بحـوث التربيـة النوعيـة، جامعة المنصورة، العـدد الحـادي والعشرون، ا-

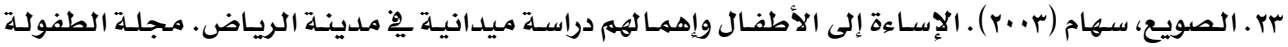

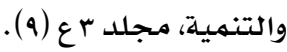

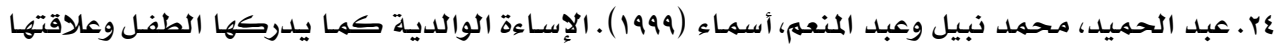
ببعض المتغيرات النفسية والاجتماعية. مـجلد بحث المؤتمر الدولي للإحصاء والحسابات العلمية والبحوث

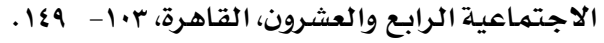

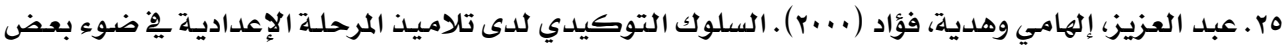

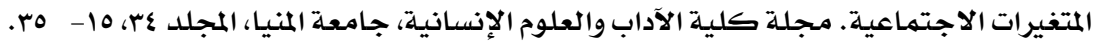
جr . عبد الغفار، عبد السـلام (199V) ). مظاهر إسـاءة معاملة الطفل يِّا المجتمـع المصري. القـاهرة: مـركز الإرثـاد النفسي، جامعة عين شمس.

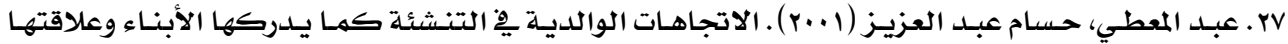

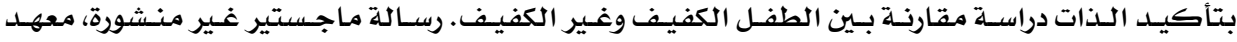
الدراسـات العليا للطفولة، جامعة عين شمس.

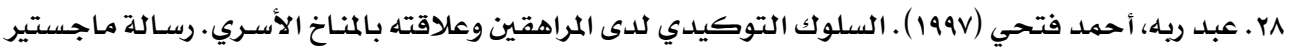
غير منشورة، كلية البنات، جامعة عين شمس.

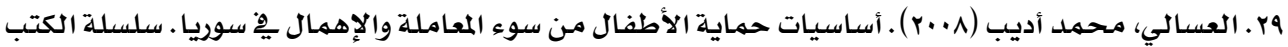
الالكترونية، إصدارات شبكة العلوم النفسية العربية. 
•r. العقاد، عصام عبد اللطيف (1 +.r). سيكولوجية العدوانية وترويضها ـ القاهرة: دار غريب للطباعة والنشر.

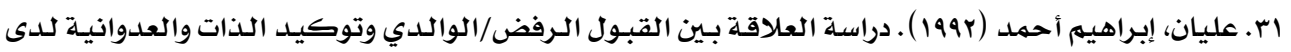
المراهقين. رسالة ماجستير غير منشورة، كلية الآداب، جامعة الزقازيق.

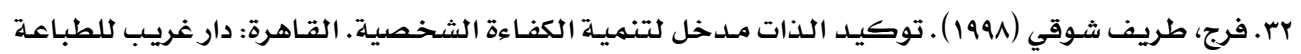
والنشر.

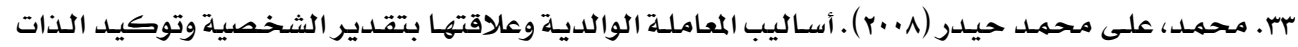
لدى الأطفال المصابين باضطراب القراءة. رسالة ماجستير غير منشورة، كلية الآداب، جامعة الزقازيق.

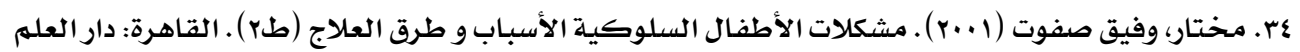
و الثقافة.

هب. مخيمـر، عمـاد محمد (199V) ـ الصلابة النفسية والمساندة الاجتهماعية متغيرات وسيطة للعلاقة بين ضـغوط

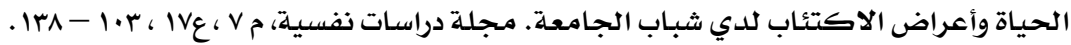

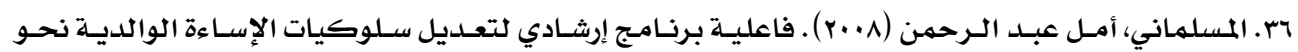

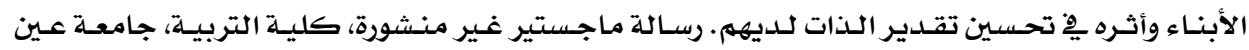
شمس.

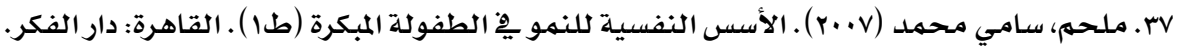

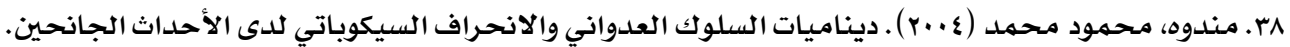
مجلة كلية التربية، جامعة المنصورة ،ع (به)، اع-

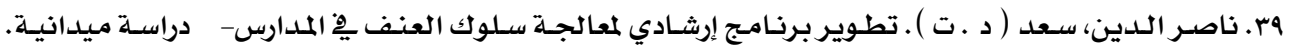
موقع أطفال الخليـج ذوى الاحتياجات الخاصدة. • ع. الهجين، عادل عبد الفتاح (1991) ـ أثر التفاعل بين البيئة الأسرية والبيئة المدرسية على مستوى التوكيدية لدى تلاميذ المرحلة الإعدادية. رسالة ماجستير غير منشورة، كلية التربية جامعة عين شمس. اءـ الهنداوي، علي فالح ؛والزغول، رافع عقيل والبكور، نائل محمـود (سبع اهـ) ـ الفـروق بـين الطلاب العـدوانيين

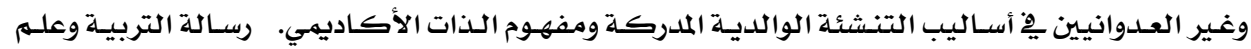
النفس، العدد (14).

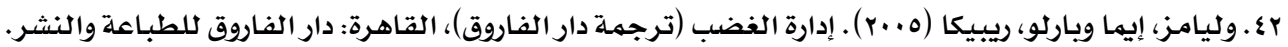
43. Alberti, R. E. \& Emmons , M. L. ( 2001 ) : Your Perfect Right: Assertiveness and Equality in Your Life and Relationships (8th ed). Sanluis Obispo(CA): Im Publishers.

44. Aneshensel, C. S. (1992). "Social stress: theory and research". Annual Review of Sociology, 18: 15-38.

45. Bonem, M.; Stanely- Kime, K. L. \& Corbin, M. (2008). A behavioral approach to domestic violence. Journal of Behavior Analysis of Offender and Victim: Treatment and Prevention, 1(4), 210-213. 
46. Bragg, H. L. (2003). Child Protection in Families Experiencing Domestic Violence. Washington, D.C.: U.S. Dept. of Health and Human Services, Administration for Children and Families, Administration on Children, Youth, and Families, Children's Bureau, Office on Child Abuse and Neglect. Retrieved online on August 5, 2011 from:

http://nccanch.acf.hhs.gov/pubs/usermanuals/domesticviolence/domesticviolen ce.pdf

47. Carlson, B. E. (2000). Children exposed to intimate partner violence: research findings and implications for intervention. Trauma, Violence, and Abuse, 1(4), pp. $321-340$.

48. Child Welfare Information Gateway (2009). Domestic violence and the child welfare system. U.S. department of health and human services, Retrieved online on August 5, 2011 from: www.hhs.gov

49. Doorways for Women and Families (2004). Striving to end domestic violence and family homelessness in Northern Virginia .Retrieved online on August 5, 2011 from: www.doorwaysva.org/children.../impact-of-domestic-violence.

50. Dutton, D. G. (1994). "Patriarchy and wife assault: The ecological fallacy". Violence and Victims, 9 (2): 125-140.

51. Follingstad, D. \& DeHart, S. (2000). "Defining psychological abuse of husbands towards wives: contexts, behaviors, and typologies". Journal of Interpersonal Violence, 15, 720-745.

52. Goode, W. (1971). "Force and violence in the family". Journal of Marriage and the Family (National Council on Family Relations), 33 (4): 624-36.

53. Hamberger, L. K. \& Hastings, J. E. (1986). "Personality correlates of men who abuse their partners: A cross-validation study". Journal of Family Violence, 1 (4), 232-346.

54. Hamberger, L. K. \& Hastings, J. E. (1991). "Personality correlates of men who batter and non-violent men: some continuities and discontinuities". Journal of Family Violence, 6 (2), 131-47.

55. Hart, S. D.; Dutton, D. G. \& Newloves, T. (1993). "The prevalence of personality disorder among wife assaulters". Journal of Personality Disorders, 7, 328-340.

56. Järvinen,L. K. \& Keinonen, M. (1988). Aggression, self-confidence, and cardiovascular reactions in competitive performance in adolescent boys. Journal Home, Vol. 14, Issue 4, 245-254. 
57. Jones, R. \& Horan, S. (1997). "The American college of obstetricians and gynecologists: A decade of responding to violence against women". International Journal of Gynecology and Obstetrics, 58 (1), 43-50.

58. Jones, S. R. \& Gardner, S. P. (2002). Variables related to attitudes toward domestic violence and use of reasoning, verbal aggression, and violent conflict tactics in high school students. Education, v20 n1, 32-47.

59. Kaufman, J.; Ortega, S.; Schewe, P.; Kracke, K. \& Safe Start Demonstration Project Communities (2011). Characteristics of young children exposed to violence: The safe start demonstration project. J Interpers Violence, vol. 26, (10), 2042-2072.

60. Kirch, J. S. (2006). Children Adolescents and Media Violence : A critical Look at the Research . London: sage Publications.

61. Markowitz, S. (2000). "The Price of alcohol, wife abuse, and husband abuse". Southern Economic Journal (Southern Economic Association), 67 (2), 279303.

62. McCloskey, L. A. \& Lichter, E. L. (2003). The Contribution of marital violence to adolescent aggression across different relationships. J Interpers Violence, vol. 18, 4, 390-412.

63. National Coalition Against Domestic Violence (2010). Retrieved April 24, 2011 from: http://www.ncadv.org/.

64. Norman, M. \& Ryan, L. J. (2008). The Rosenzweig picture-frustration study "extra-aggression" score as an indicator in cognitive restructuring therapy for male perpetrators of domestic violence. J Interpers Violence, vol. 23, 4, 561566.

65. Sexual assault survivor services (SASS) (1996). Facts about domestic violence. SASS home page at: http://www.portup.com/

66. Shorey, R.; Brasfield, H.; Febres, J. \& Stuart, L., (2010). The association between impulsivity, trait anger, and the perpetration of intimate partner and general violence among women arrested for domestic violence. J Interpers Violence, 30.

67. Shorey, R. C., Cornelius, T. L. \& Bell, K.M. (2008). Behavioral theory and dating violence: A framework for prevention programming. Journal of Behavior Analysis of Offender and Victim: Treatment and Prevention, 1(4), 113. 


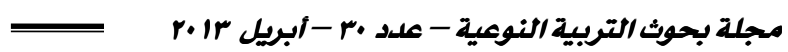

68. Sorensen , P . D .\& Commedore , C. (1998), ADHD Children and social skills training a handout for teacher. National Association of school psychologists, 4340, East west Highway.

69. Stanley, N.; Miller, P.; Foster, H. \& Thomson, G. (2010). Children's experiences of domestic violence: developing an integrated response from police and child protection services. J Interpers Violence, vol. 26 (12) 23722391.

70. SunnyKids annual report (2010). Available at: www.sunnykids.org.au

71. Takei, T.; Yamashita, H. \& Yoshida, K. (2006). The mental health of mothers of physically abused children: the relationship with children's behavioral problems report from Japan. Journal Of Child Abuse Review, Vol., 5, 204 218.

72. Terr, L. (1991). Childhood trauma: An outline and overview. American Journal of Psychiatry, 148, 10-20.

73. Thombs, B.; Bennett, W.; Roy C. Ziegelstein, R. C.; Bernstein, D.; Scher, C. \& Forde, D. (2007). Cultural sensitivity in screening adults for a history of childhood abuse: evidence from a community sample. Society of General Internal Medicine, v. 22 (3), 1-9.

74. Twohey, M. (2009). "How can domestic abuse be stopped?". Chicago Tribune. Retrieved at 16 April 2011 from:

http://www.chicagotribune.com/news/local/chi-abusers-02jan02,0,1147422. story?page $=1$.

75. U.S Department of Justice (2007). "About domestic violence". Retrieved August 2, 2011 from: http://www.usdoj.gov/ovw/domviolence.htm.

76. Vitanza, S. \& Vogel, R. (1995). "Distress and symptoms of posttraumatic stress disorder in abused women". Violence and Victims, 10 (1): 23-34.

77. Walton, S. (2005). Domestic Violence and Children. In B. Jacobs (Ed.), Family violence and children: Perspectives for policy (pp. 25-34) (New Mexico Family Impact Seminar Briefing Report \#1). Las Cruces, NM: New Mexico State University. 